\title{
Chiral and Racemic Fields Concept for Understanding of the Homochirality Origin, Asymmetric Catalysis, Chiral Superstructure Formation from Achiral Molecules, and B-Z DNA Conformational Transition
}

\author{
Valerii A. Pavlov ${ }^{1, *}$, Yaroslav V. Shushenachev ${ }^{2}\left(\mathbb{C}\right.$ and Sergey G. Zlotin ${ }^{1}(\mathbb{C}$ \\ 1 N. D. Zelinsky Institute of Organic Chemistry, Russian Academy of Sciences, 47 Leninsky prosp., \\ Moscow 119991, Russia; zlotin@ioc.ac.ru \\ 2 N. S. Kurnakov Institute of General and Inorganic Chemistry, Russian Academy of Sciences, 31 Leninsky \\ prosp., Moscow 119991, Russia; slavash@mail.com \\ * Correspondence: pvlv69@mail.ru; Tel.: +(07)-495-750-2545
}

Received: 6 March 2019; Accepted: 23 April 2019; Published: 8 May 2019

\begin{abstract}
The four most important and well-studied phenomena of mirror symmetry breaking of molecules were analyzed for the first time in terms of available common features and regularities. Mirror symmetry breaking of the primary origin of biological homochirality requires the involvement of an external chiral inductor (environmental chirality). All reviewed mirror symmetry breaking phenomena were considered from that standpoint. A concept of chiral and racemic fields was highly helpful in this analysis. A chiral gravitational field in combination with a static magnetic field (Earth's environmental conditions) may be regarded as a hypothetical long-term chiral inductor. Experimental evidences suggest a possible effect of the environmental chiral inductor as a chiral trigger on the mirror symmetry breaking effect. Also, this effect explains a conformational transition of the right-handed double DNA helix to the left-handed double DNA helix (B-Z DNA transition) as possible DNA damage.
\end{abstract}

Keywords: environmental chirality; $C_{1}$ - and $C_{2}$-symmetric catalysts; chiral field (memory); racemic field; Viedma ripening effect; Wallach's rule

\section{Introduction}

Curie [1] was convinced that "without asymmetric physical impact no asymmetric chemical effect arises". Modern experimental data support this criterion: asymmetric induction in asymmetric catalysis is only implemented through the asymmetric ( $C_{1}$ symmetry axis) key intermediate [2].

If a substrate has two or three functional groups which can be coordinated in that intermediate, chiral $C_{2}$-symmetric catalyst loses $C_{2}$ symmetry in the substrate coordination stage. Nature has chosen such substrates (amino acids and sugars) as components of important macromolecules. However, the only variant of configuration ratios ( $\mathrm{L}-\mathrm{D})$ of amino acids and sugars has been selected from the four possible: D-D, L-L, D-L, and L-D (Figure 1). 


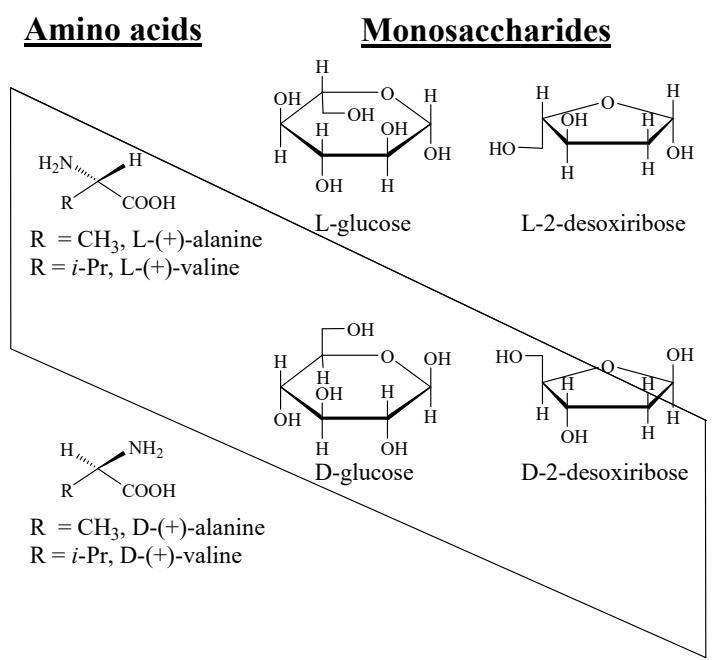

Figure 1. Schematic corridor of amino acid and sugar configurations of life support processes.

A reason for this choice has not received a generally recognized explanation up to now [3-17]. These references indicate a variety of scenarios for the emergence of homochirality and therefore origin of life [16]. Various scenarios are explained by external and internal reasons existing on the primary Earth. Possible scenarios of homochirality origin include Earth and exoterrestrial origins, mirror-symmetrical and non-mirror symmetrical forces, different ampllification mechanisms leading to L- or D-amino acids and sugars, and L-amino acids excess during meteorite impact.

We believe [3,4] that a possible basis for such a ratio of configurations is the right-handed helix $(P)$ conformation of important biomacromolecules formed from amino acids and monosaccharides. (Scheme 1).

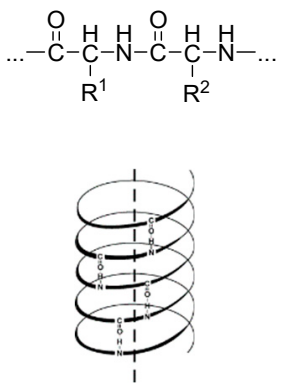

right-handed
helix $(P$ - helix or
-helix) of
polypeptides
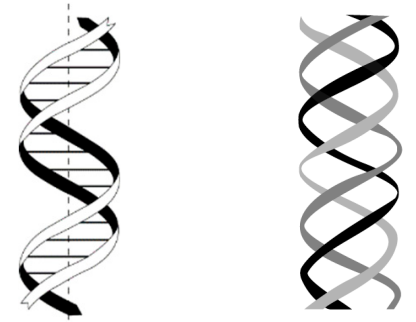

righthanded double $(P)$ helix of DNA

Scheme 1. The triad of right-handed important biomacromolicules.

The L-D ratio of amino acid and sugar monomer configurations may merely occur where there is a right-handed helix conformation. Mutual relations of single, double and triple right-handed $(P)$ helixes are also not accidental. The single helix ( $\alpha$-polypeptide) protects amino acids from racemization by hydrogen bonds between helical turns.

Contradictory situation arises during the single helix formation from monocaccharide hexose. Indeed, $\alpha$ - $(1 \rightarrow 2)$-D-mannan and $\beta$-( $1 \rightarrow 3)$-D-glucan generate $M$ - and $P$-helices, corresponddingly, in the same conditions [18]. A helical configuration of amylose relies on the crystallization conditions 
(Table 1). A possible stabilizing factor of the P-helix formation is the double helix (Table 1, items 1 and 2).

Table 1. Structures of linear polysaccharide amylose as function of the solvent used for crystallization.

\begin{tabular}{ccccc}
\hline No & Amylose & Solvent & Helix & Reference \\
\hline 1 & Amylose A ${ }^{1}$ & water & $P$ & {$[19]$} \\
2 & Amylose B & water & $P$ & {$[20]$} \\
3 & Amylose V & - & $M$ & {$[21]$} \\
4 & KOH-Amylose & water, KOH & $M$ & {$[22]$} \\
5 & Amylose V Vropan-2-ol & propan-2-ol, water & $M$ & {$[23]$} \\
6 & Amylose & water & $M$ & {$[24]$} \\
\hline
\end{tabular}

${ }^{1}$ Double helix.

Indeed, linear polysaccharides, viz. i-carrageenan [25] and xanthan [26], form double helices with the $P$-structure as well. Schisofillan, a nonlinear polysaccharide, also gives a double $P$-helix [27-29].

Thus, it is not by chance that nature has chosen the double helix structure to stabilize the right-handed conformation of DNA. In this case, the configuration error reducing factor is also important [27]. There is directionality to a right-handed helix in triple helical structures such as in fungi, mushrooms, and so on. For example, the simplest $\beta$-(1 $\rightarrow 3)$-D-glucans, namely curdlan [27], lentinan [30], scleroglucan [31], xylan [32], etc., with side chains [33-38] form triple $P$-helices with the right-handed helical conformation. Hence, there is a triad pronounced in Scheme 1. That is why right-handed helix structures of important biomacromolecules are representatives of the regular trend in nature.

Since all natural processes occur in the open system, in previous work [39], we attemted to assess the external chiral effect on the homochirality origin on the early Earth. A possible influence of an external asymmetric inductor was analyzed for metastable (stochastic and spontaneous) reactions [39]. In this review, we continue the search for traces of the external chiral inductor, such as the chiral gravitational field, in the most studied reactions with mirror symmetry breaking.

\section{Gravity as a Chirality Inductor}

Davankov [40] suggested chirality to be an indispensable feature of different levels of matter. While evolving this idea, we [39] considered a possibility of chiral effects of various physical phenomena on chemical reactions (electric field [41], electric field (propeller effect) [42], a combination of electric and magnetic fields [4,43], magnetic field [4,39,44], circularly polarized light [45], plasma torch of meteorite impact [46,47], solar irradiation [48,49], parity violation energy difference [29], and similar effects [39]). Gravity is among such physical phenomena as asymmetric factors [39]. Basing on Barron's concept [50] of true and false chirality, we can assume that the mutual gravitational influence of a space object and its satellites is a chiral factor. In the schematic diagram (Figure 2), we tried to summarize information on mutual gravitational impact (moving in space) of Sun, Earth, Moon, and Venus. Their mutual movements create a combination of trajectories in the form of virtual chiral helices. The image below gives a view of the chiral gravitational environment that is probably strictly individual for Earth (The Earth-Moon (ratio of masses 81/1) is a double planet system unlike other planets and satellites of the Solar system, for example, Jupiter-Europe $\left(4 \cdot 10^{4} / 1\right)$, Mars-Phobos $\left(6 \cdot 10^{7} / 1\right)$, and so on). A hypothesis about the formal similarity and possible effect of the Earth's right-handed (spin) rotation near the Moon, alongside with the right-handed Earth's orbital motion around moving Sun and right-handed helix symmetry of biomacromolecules, was published earlier [3,29,39,51]. 

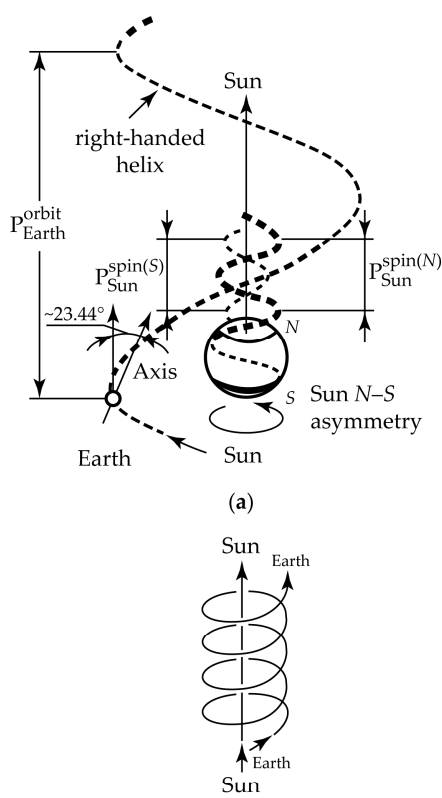

right-handed heli

(c)
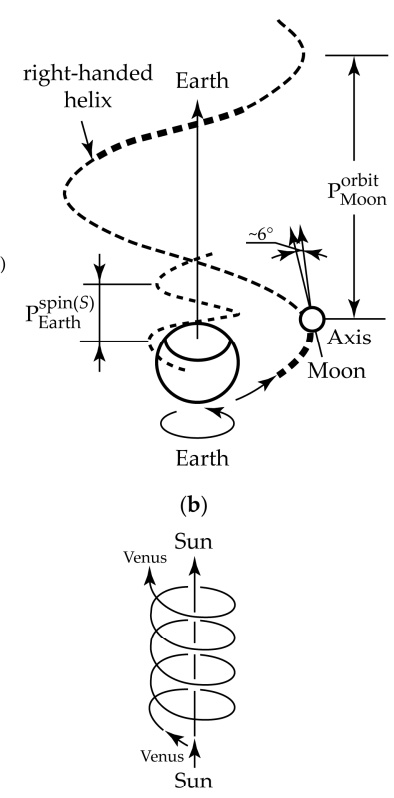

left-handed

(d)

Figure 2. Schematic image of right-handed helices created by the orbital and spin rotation of moving Sun - Earth (a, c), Earth - Moon (b), and the left-handed helix as a result of the orbital rotation of Venus around Sun $(\mathrm{d})$. Pitches $(\mathrm{P})$ of the helices: $\mathrm{P}_{\mathrm{E}}{ }^{\text {spin }}=1$ day, $\mathrm{P}_{\mathrm{E}}{ }^{\text {orbit }}=1$ year, $\mathrm{P}_{\mathrm{M}}{ }^{\text {spin }}=\mathrm{P}_{\mathrm{M}}{ }^{\text {orbit }}=1$ lunar (sunderic) month, $\mathrm{P}_{\mathrm{S}}$ spin $(\mathrm{N})=\mathrm{P}_{\mathrm{S}} \operatorname{spin}(\mathrm{S})=\sim 38$ Earth's days (near polar caps). The rotation of Sun around the axis tilted $82^{\circ} 45^{\prime}$ to the plane of the Earth's orbit occurs in the same direction as the spin rotation of Earth (counterclockwise).

Perhaps, all spiral movments shown in Figure 2 should be considered as a manifestation of the unified structure of the gravitational field of our Galaxy. The Milky Way Galaxy is a double snail of flat structure (Figure 3a,b) [52-55]. A symmetry plane virtually divides the Galaxy into a mirror symmetric left-handed snail - "bottom" (Figure 4c), and a right-handed snail - "top" (Figure 3d). Hence, the Milky Way may be presented as a mesostructure (an inner racemate).

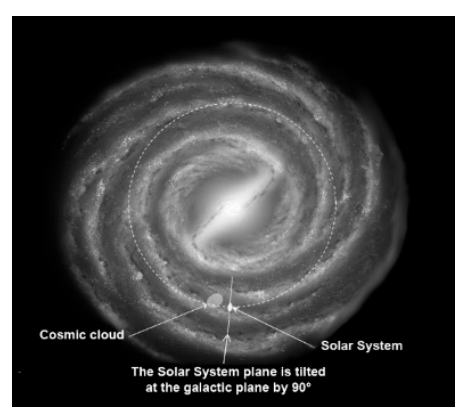

(a)

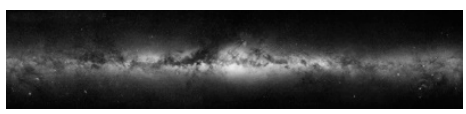

(b)

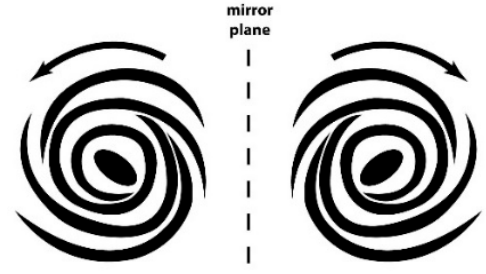

View of the galactic "bottom" from south (Msnail)

(c)
View of the galactic "top" from north $(P$ snail)

(d)

Figure 3. The Milky Way Galaxy (a) top (view from the galactic north) and (b) sideways. Schematic structure of the Galaxy: (c) "bottom" snail and (d) "top" snail. 


\section{MOTIONS OF THE SOLAR SYSTEM IN THE GALAXY}

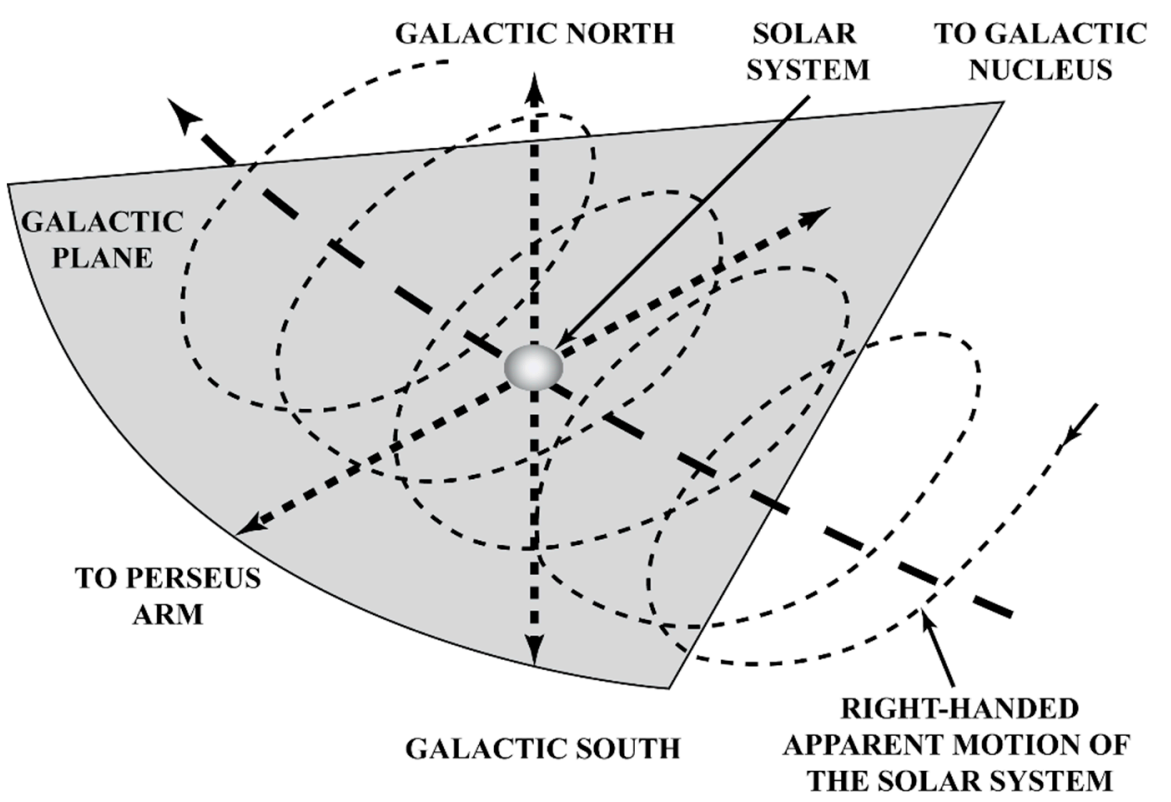

Figure 4. Motions of the the solar system in the Milky Way [51].

In terms of symmetry, the Galaxy bears a similarity to inner racemate (for example, meso-tartaric acid. It is conceivable that this mesostructure is confirmed by the anomalous rotation (counterclockwise) of Venus in the Solar system. This movement does not contradict with the complexity of the Galaxy structure. Indeed, the mirror symmetry plane divides "clockwise" and "counterclockwise" fields (Mirror reflection effect or a positive-negative photoeffect.) of the galactic space ( $P$ - and $M$-snails). Because the Solar system spins and moves along the right-handed trajectory [52-55] (Figure 4) in the $P$-snail field, Earth and other planets move identically (clockwise) with the exception of Venus.

An example of the chiral environment's (chiral gravitational field?) influence is found in configurational stability (mirror symmetry breaking) of sea snail shells [56,57] (Figure 5). All collectors of sea shells (conchiologists) evidence that the opposite left-handed structure is an extreme rarity [58].

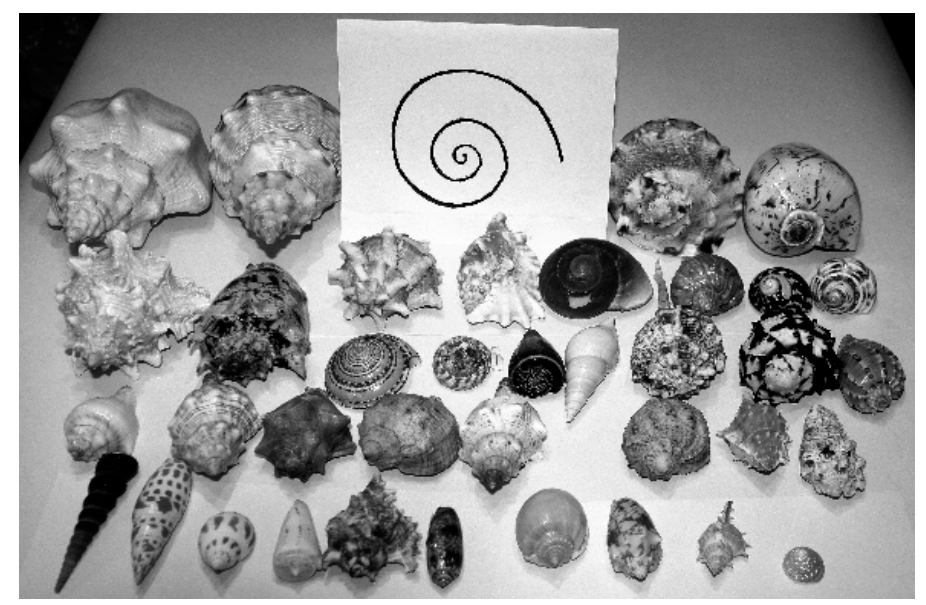

Figure 5. The right-handed helix shape of arbitrary sampled shells of sea mollusks (about 70,000 species in total [54]).

How does gravity affect symmetry of molecules? In contrast to the influence of the electromagnetic field [59], the effect of gravity on chemical reactions is difficult to verify experimentally. It was previously 
believed that this effect was absent or very insignificant. Another point of view appeared possible with the beginning of the space flight era.

\section{Gravitational Field Impact on Chemical Reactions}

Analyzing an open system, we have to evaluate all possible physical inductors which may affect the system. Among the non-obvious physical factors that may affect chemical reactions is gravity. After the discovery of gravitational waves (Gravitational waves discovery (Abbott B.P. et. al. Observation of Gravitational Waves from a Binary Black Hole Merger. Phys. Rev. Lett., 2016. 116. 061102) suggests the complex structure of the gravitational field.) the influence of this factor, especially in unstable asymmetric reactions, became more obvious. A nuclear decay has a reputation of a stable process that does not depend on external physical inductors. If an external inductor such as a gravitational field can alter the radioactive decay rate it is bound to affect the nucleus mass. Therefore, if such effect occurs, this phenomenon may be called a "mass resonator" or "mass resonance". Fischbach et al. [60-62] analyzed a ${ }^{137}$ Cs decay sample onboard the Messenger spacecraft during its mission to Mercury and ${ }^{54} \mathrm{Mn}$ decay data during the solar flare on December 13 2006. The goal was to show the limits of a possible correlation between nuclear decay rates and solar activity. Such correlation was suggested not only on the basis of the ${ }^{54} \mathrm{Mn}$ decay during the solar flare but also by indications of annual and other periodic variations in the decay rates of ${ }^{32} \mathrm{Si},{ }^{36} \mathrm{Cl}$ and ${ }^{226} \mathrm{Ra}$. Data from five measurements of the ${ }^{137} \mathrm{Cs}$ count rate over a period of approximately 5.4 years was fit to a formula which accounts for a typical exponential decrease in the count rate over time, alongside with the addition of a theoretical solar contribution varying with the Messinger-Sun distance [61]. These controversial data on nonexponential periodic decay rates drew attention and gave rise to discussion [63-65].

Ivanova et al. [48] observed North-South solar asymmetry and anisotropy of cosmic rays over solar polar caps. The measurements were taken onboard the Kosmos-480 satellite on 18 April 1972 over a 10-h period. In particular, the flow above the south pole was an order of magnitude higher than that above the north pole. Svirzhevsky et al. [49] examined N-S solar poles asymmetry relative to the solar wind speed, plasma density, and some other solar parameters. Asymmetry between the north and south solar fields was observed in the plasma density, solar radio flux, and geomagnetic indices [66]. Consequently, N-S solar asymmetry (Figure 3a) is an additional chirality trigger alongside with chirality of the right-handed helix orbital trajectory of Earth revolving around Sun (Figure 3c). Indeed, N-S solar asymmetric poles during the Sun's movement form a virtual double right-handed helix (Figure 3a). Gravitation field asymmetry throughout the entire life time of the Solar system can culminate in the chiral biomacromolecules origin as well as in biological objects (Figure 6). Nevertheless, the question of the noticeable effect of asymmetric gravity on symmetry of molecules remains unanswered. However, asymmetric gravity could affect metastable chiral reactions if assume the gravitational field affects the radioactive decay. 


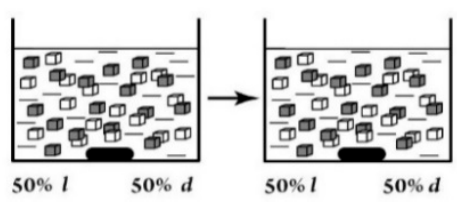

(a)

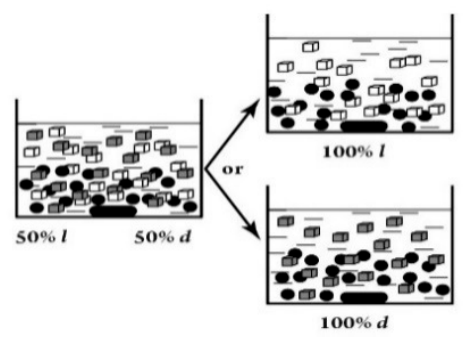

(c)

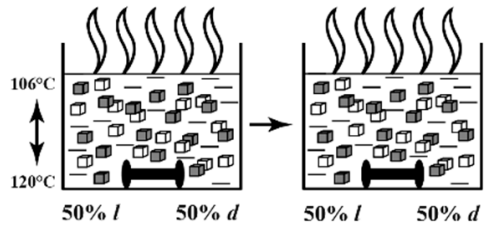

(b)

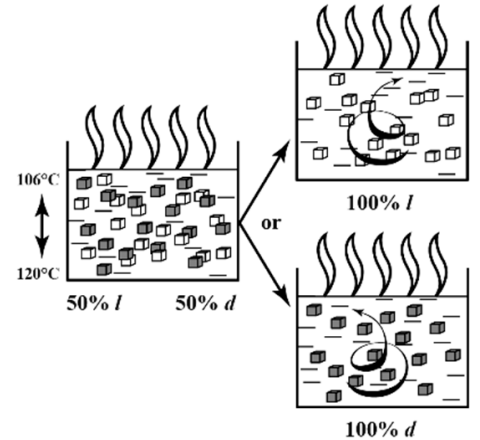

(d)

Figure 6. (a) Stirring of $l$ - and $d$-crustals (50/50\%) of $\mathrm{NaClO}_{3}$ without glass beads and (b) boiling of the mixture with stirring. (c) Stirring of the mixture with glass beads and (d) deracemization of the mixture under possible convection fluxes by the temperature gradient during boiling.

\section{Stirring (Helical Flux) of the Reaction Mass as a Chirality Trigger}

The formation of a conglomerate $\left(50 / 50 \% l\right.$ - and $d$-crystals) during crystallization of $\mathrm{NaClO}_{3}$ from a saturated aqueous solution proceeds over a short time interval. However, stirring of the $\mathrm{NaClO}_{3}$ solution (for appreciable time) leads to mirror symmetry breaking (Scheme 2). The enantiomeric direction of crystallization during stirring was ascribed to the primary crystal as a crystallization germ ('secondary' crystal nuclei) $[67,68]$.

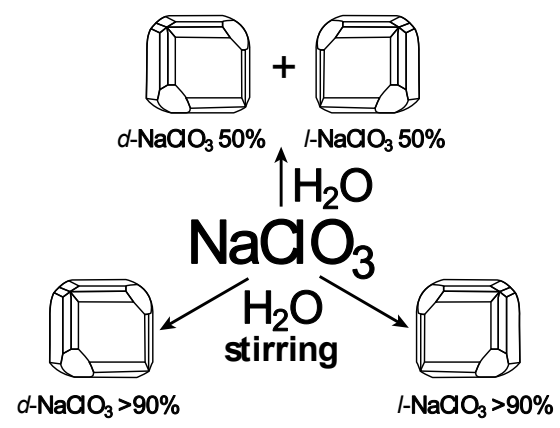

Scheme 2. Influence of solution helical flux.

Similar enantiomeric and racemic conglomerate crystallization was observed in stirred and unstirred 1,1'-binaphthyl melts [69,70]. The enantiomeric excess (ee up to $80 \%$ ) in each stirred crystallization test varied randomly as well.

Stirring of $l$ - and $d$-crystals mixture of $\mathrm{NaClO}_{3}(50 / 50 \%)$ with glass beads led to $100 \% l$ - or $d$-crystals, randomly, whereas stirring without glass beads left the mixture unchanged [71] (Figure 7a,c). It is interesting to note that the "stirring time to achieve $100 \%$ ee depends on the number of glass beads and the stirring rate" [72]. In attempt to explain $\mathrm{NaClO}_{3}$ crystallization data, Kondepudi et al. [66-70,73,74] and other researchers [75-78] attached importance to the experimental fact of stirring. To explain enantioselectivity of $\mathrm{NaClO}_{3} l$ - and $d$-crystals stirring with and without glass beads (Figure 6a,c) many researchers [71,79-87] argued that attrition/grinding was the key factor. 


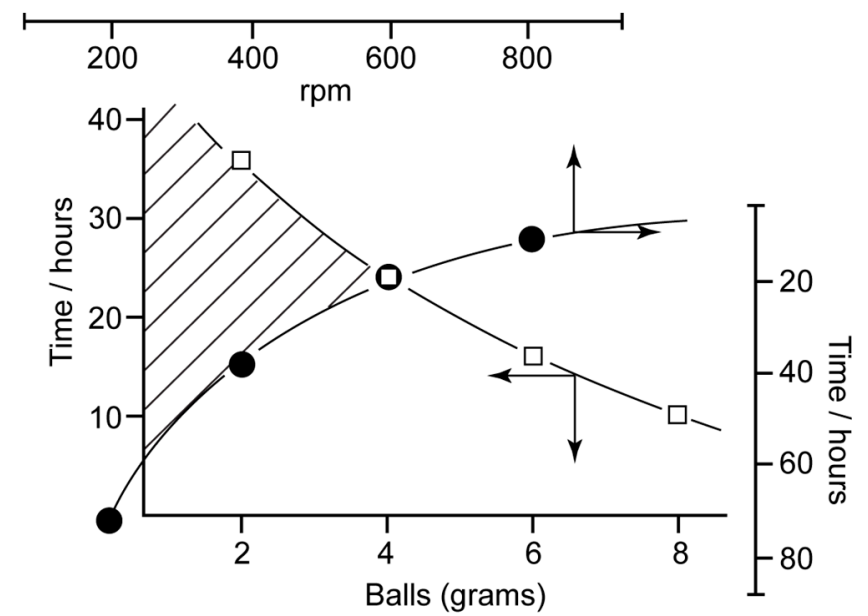

Figure 7. Stirring of the mixture of $l-/ d-\mathrm{NaClO}_{3}$ crystals and glass balls. Time necessary for achievement of chiral purity is plotted for the constant speed of its agitation $(600 \mathrm{rpm})-\square$ and for the agitation speed, with the constant number of balls ( $4 \mathrm{~g}$ of balls)

There are data that argue against the role of stirring. In boiling solutions of the racemic mixture of $\mathrm{NaClO}_{3}$ crystals, stirring (without abrasion) did not bring mirror symmetry breaking [88] (Figure 6b). However, the temperature gradient $\left(120^{\circ} \mathrm{C}\right.$ lower layer-106 $\mathrm{C}$ upper layer of colution in the reaction vessel) [88] led to the formation of spiral flows inb the oiling solution (Figure 6d) (shown by the snail-shaped arrows). These flows could appear destroyed while stirring, which is why the enantioenrichment did not occur (Figure 6b).

Even more obvious evidence of the effect of temperature flows of the reaction mixture on enantioselectivity is sublimation. For example, valine, racemic amino acid, was converted via sublimation into a conglomerate [89]. During continued heating, the crystals underwent substantial chirality amplification (increase of initial ee). This phenomenon occurred both in the closed and in the open system [89]. The authors observed the appearance of three sublimation regions depending on their location in the form of rings on the conical flask walls. The most enantioselective region corresponded to the enantioenrichment of the valine sublimate with $e e 80 \%$ (the closed system) and ee $70 \%$ (the open system). In our opinion, the intervention of the external chiral inductor in this experiment is reasonably evident.

We believe that the rotation of the flow energy (stirring) or temperature convectional flow of the helical structure can be a reason for the emergence of enantioselectivity. This scenario can also be triggered by an external chiral field.

The possible existence of this field is evidenced by statistical experiments while studying the Viedma ripening procedure (VRP). Viedma [90] discarded any explanation of VRP by the parity violation energy difference (PVED) effect (Table 2). 
Table 2. The number of VRP experiments for $\mathrm{NaClO}_{3}$ or $\mathrm{NaBrO}_{3}$ with the initial racemic population of $l$ - and $d$-crysals and their final chiral purity [90].

\begin{tabular}{ccccc}
\hline \multirow{2}{*}{$\begin{array}{c}\text { Starting Racemate } \\
\text { in VPR }\end{array}$} & $\begin{array}{c}\text { Number of VPR } \\
\text { Experiments }\end{array}$ & \multicolumn{3}{c}{ Final Chirality Purity } \\
\cline { 3 - 5 } & 200 & $\boldsymbol{l}$-Crystals & $\boldsymbol{d}$-Crystals & \% of $\boldsymbol{l}$-Crystals \\
\hline & 240 & 160 & 40 & 79.5 \\
$\mathrm{NaClO}_{3}$ & 200 & 236 & 4 & 98.3 \\
& 100 & 102 & 98 & 51.0 \\
& 100 & 83 & 17 & 83.0 \\
& 100 & 79 & 51 & 49.0 \\
& 260 & 258 & 27 & 73.0 \\
\hline & 280 & 274 & 6 & 99.2 \\
& 200 & 89 & 111 & 97.8 \\
& 100 & 80 & 20 & 44.5 \\
& 100 & 52 & 48 & 80.0 \\
& 100 & 68 & 32 & 52.0 \\
\hline
\end{tabular}

"The experiments were performed with racemic mixtures obtained spontaneously from the same solutions and in the same competing conditions between $l$ - and $d$-crystals" ("natural" or true population) [90]. Those data support Viedma's opinion that the handedness of chiral crystals remaining in the solution (Table 2) is not random. As seen from Table 2, there is a predominance of $l$-crystals (in some cases up to $99.5 \%$ ), alongside with a few exceptions (l-crystals $49 \%$ and $44.5 \%$ ). Thus, there is quite a definite trend expressed in the predominant formation of $l$-crystals. According to Viedma [90] these experimental results may be explained by the "cryptochiral environment in control".

To our knowledge, a thorough statistical analysis of changes in left-handed or right-handed chirality of reaction products, depending on the direction of reaction mixture stirring (clockwise or counterclockwise), has not been undertaken (there is an opinion that the stirring direction is not important in VRP expirements [76]). In addition, the nature and origin of this cryptochiral environment's effect have not been discussed [81-89,91]. About the same statistical likelihood of random (stochastic) signs of chirality is observed even with the same rotation direction (also, stochastic distribution of the enantiomer outcome was observed in crystallization under cooling [92]).

$\mathrm{NaClO}_{3}$ crystallization and similar dissolution-crystallizations are metastable processes [93,94]. Therefore, even a small energy of the spiral flow during mixing can affect chirality as an inductor or trigger. It explains well the influence of product enantiopurity on the number of glass beads and the stirring rate [72]. It resembles a search of resonance such as the action of the ultrasonic radiation field $(20 \mathrm{KHz})$ on enantiopurity of the product during threonine crystallization (5(D) $\rightarrow 70-87(\mathrm{D}) \% e e)$ [95].

Indeed, Figure 7 shows that the maximal enantioenrichment of $\mathrm{NaClO}_{3}$ crystallization occurs in the time corridor of 20-24 h of stirring at a speed of $600 \mathrm{rpm}$ (rotation per minute) and with $4 \mathrm{~g}$ of glass balls (data from Reference [72]). This result is likely to be a reflection of a search of resonance with some external chiral inductor. The shaded area in this figure is the possible resonance region.

Moreover, chiral enrichment vectors are the same in time but are manifested as stochastically (random) reactions, while enantioselectivity vectors are not the same for different enantiomers (Figure 8). 


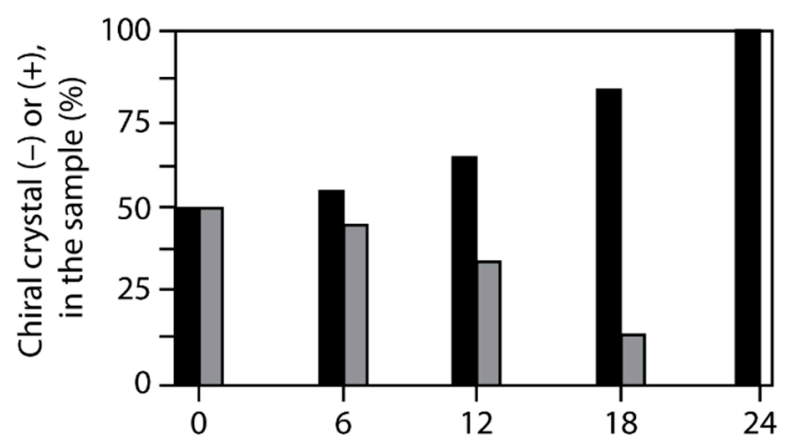

Figure 8. Stirring of $50 / 50 \% \mathrm{l}$ - and $d$-crystals mixture of $\mathrm{NaClO} 3$ and $4 \mathrm{~g}$ of balls lead to $100 \%$ chiral purity after $24 \mathrm{~h}(600 \mathrm{rpm})$ randomly.

The results given in Table 2 also testify to the vector of predominant "natural" enantioselectivity. A striking case of a literally "mechanistic" embodiment of stirring in the chiral effect can be demonstrated by the example of antracene polymerization into a chiral nanofiber structure (Figure 9) [96].

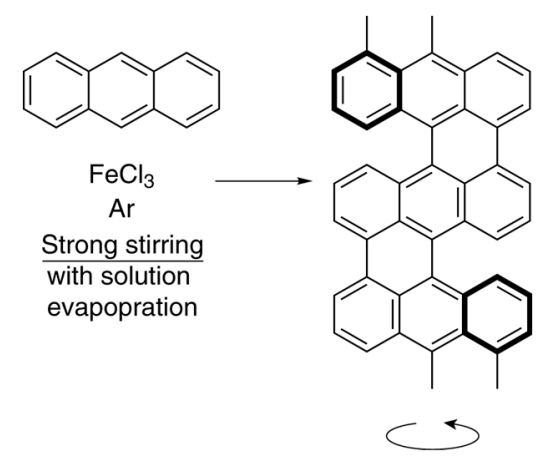

Figure 9. Schematic illustration of the formation of supermolecular polyantracene with left-handed helical nanoarchitectures.

An average diameter of the rotational helix flux of the reaction solution as a result of stirring and the supermolecular polyantracene helix cannot be directrly interdependent because of the incompatibility of helix sizes (the ratio of the diameter of the helices is $\sim 5 \cdot 10^{9}-1 \mathrm{~nm}$ ). Therefore, chirality of the reaction product could appear apparently only due to an external chiral inductor as a resonator or the rotation flux of the reaction mixture as a trigger.

Low temperature can also be a stabilization factor of chirality. Mirror symmetry breaking occurred upon low temperature spontaneous crystallization of achiral macrocyclic imines [97]. An absolute asymmetric synthesis was also carried out with a chiral reagent from chiral crystals with axial chirality [98]. Crystalline $\mathbf{1}$ was melted at $120^{\circ} \mathrm{C}$ and then gradually solidified by lowering the temperature to $110^{\circ} \mathrm{C}$ with vigorous stirring. Reactions (1) and (2) proceeded as 'frozen chirality' [98] at a low temperature ("frozen chirality") [92]. Low temperature monitoring data for the reaction (2) are given in Table 3.

Table 3. Cyclopropanation of $\mathbf{1}$ using sulfur ylide.

\begin{tabular}{ccccc}
\hline Entry & Temp. $/{ }^{\circ} \mathbf{C}$ & Conv. of $\mathbf{1 / \%}$ & Yield of $\mathbf{2} / \%$ & ee of $\mathbf{2} / \boldsymbol{\%}$ \\
\hline $\mathbf{1}$ & 20 & 69 & 37 & 0 \\
$\mathbf{2}$ & 0 & 38 & 53 & 50 \\
$\mathbf{3}$ & -20 & 27 & 65 & 67 \\
$\mathbf{4}$ & -40 & 16 & 93 & 97 \\
\hline
\end{tabular}


<smiles>CCc1c(C(=O)N(CC)CC)c(=O)oc2ccccc12</smiles>

(R)-1<smiles></smiles>

$99 \%$ yield

$99 \%$ ee

$P 2_{1} 2_{1} 2_{1}$ crystal system

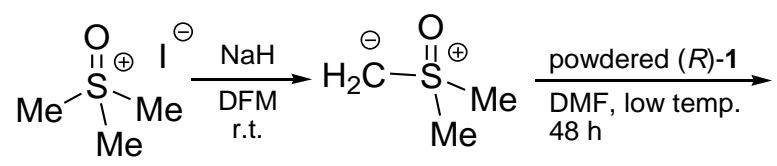<smiles></smiles>

$(R, R)-2$

There are other examples of axially chiral reagents with "frozen chirality" at a low temperature [99].

Crystallization of racemic axially chiral pyrimidinethione led to the chiral product with up to $91 \%$ ee at a high temperature only [100].

Strong temperature stabilization of axial chirality suggests the existence of a chirality resonator. A similar assumption can be made in analyzing a dependence of the helicity sign from temperature. The helicity dependence from temperature was vividly exemplified by experimenting with poly \{(S)-3,7-dimethyloctyl-3-methylbutulsilylene\} 3 [101] (Scheme 3). Also, a similar $P \leftrightarrow M$ transition was observed for other polysilylenes and analogous polymers at different temperatures, with various solvents and varying other reaction conditions [102-107].

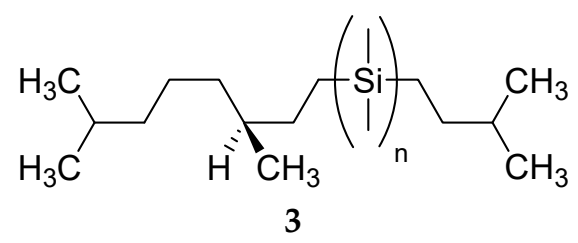

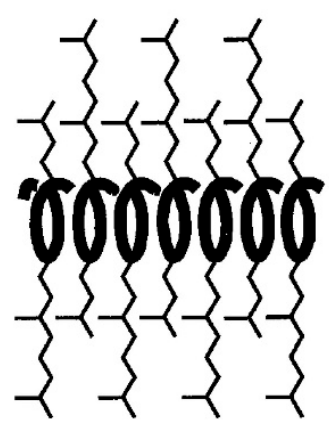

$M$-helix at $-40^{\circ} \mathrm{C}$

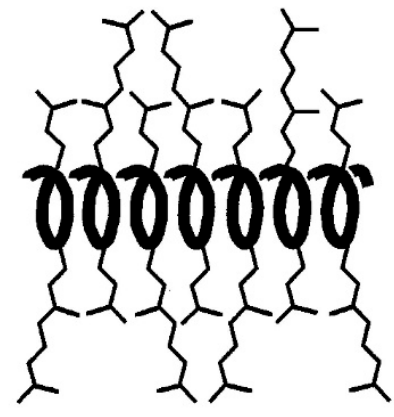

$P$-helix at $-5^{\circ} \mathrm{C}$

Scheme 3. Schemtic helicity dependence of 3 from temperature.

Reactions (3) and (4) resulted in helical products with different signs. When analyzing the differences in the energy of these product conformations, it was shown that small amount of energy ( $1 / 600$ of the ambient energy) is only distinguished $P$ - and $M$-helices in these deuterated polyisocyanates [108-111]. Therefore, it is quite possible that even a weak external inductor may be capable of affecting the chiral conformation of helical nanostructures. This assumption should be verified with special care, for example, in the case of the $P \leftrightarrow M$ conversion of DNA (see Section 8). 

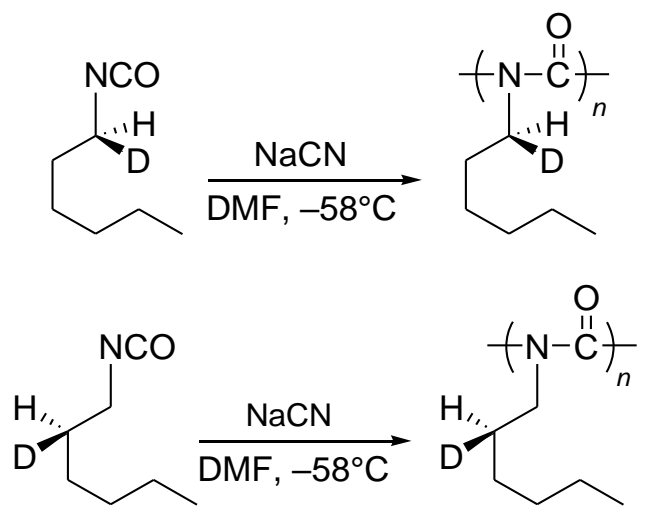

A possible existence of the chiral environmental inductor is also evidenced by asymmetric reactions of achiral molecules adsorbed on the surface of metals [112-115]. Ernst rightly noted that product's chirality depends not only on the surface structure but also on the molecules orientation (Figure 10) [116]. Chirality in this case can occur, apart from under the action of the chiral surface structure, under the impact of the adsorbing molecule orientation. The environmental chiral inductor in turn can contribute to this chiral orientation. Problematical chirality of metal surfaces suggests that the chiral orientation is the main factor that provides enantioselectivity of the reaction of adsorbed achiral molecules.

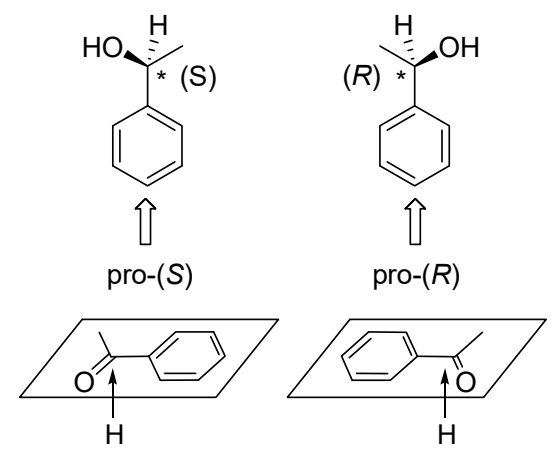

Figure 10. Mirror symmetry in planar molecules on a surface.

\section{Chiral and Racemic Field in Asymmetric Catalysis and Nonlinear Effects}

Racemic compounds can also exist in solution, e.g., in ongoing reactions. The formation of racemic intermediates of a reaction is observed in catalytic asymmetric reactions. The use of non-enantiopure chiral auxiliaries as asymmetric catalysts sometimes causes a deviation from the proportional linearity to $e e$ of a catalytic reaction product (nonlinear effect NLE) in asymmetric catalysis [117] (Figure 11). Scheme 4 shows two models for explaining nonlinear effects: Kagan's and Noyori's models [118]. According to both models racemates and homochiral dimers function as real actors of the reaction mechanism. However, both schemes do not take into account the specifics of the reaction and substrate to predict the NLE occurance. 


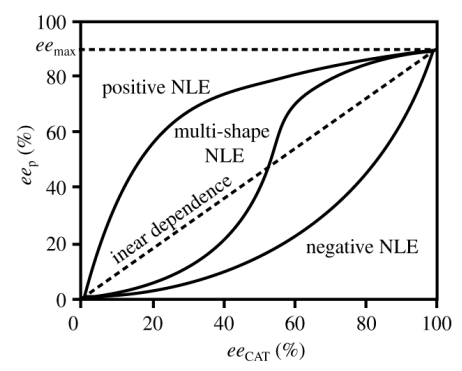

Figure 11. Examples of nonlinear effects in asymmetric catalysis $e e$ max $=e e$ provided by an enantiopure catalyst.

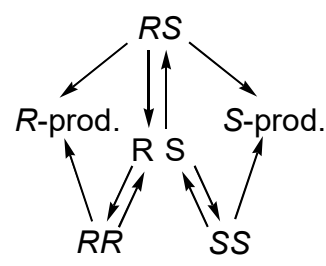

Kagan model<smiles>[R20][PH]([R20])([R6])S(=S)(=S)SO</smiles>

Noyori model

Scheme 4. Kagan and Noyori NLE models.

Steigelmann et al. [119] observed remarkable (-)-NLE in diethylzinc addition to benzaldehyde in the presence of $(S)$ - and (R)-fenchols (5). Methylzinc dimeric C2-symmetrical complexes $(R, R-4)$ and $(S, S-4)$ were formed in this reaction (Scheme 5).
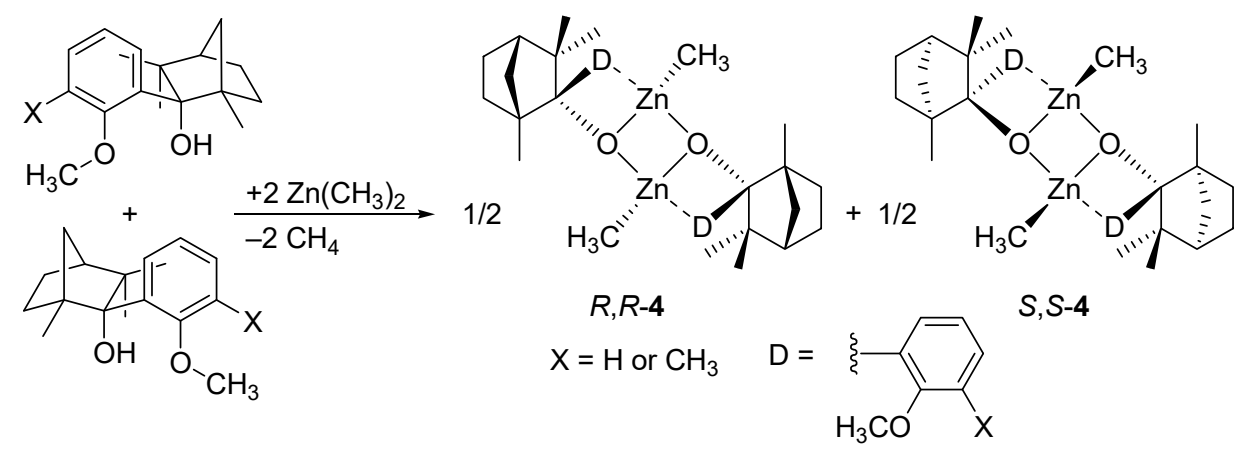

Scheme 5. Racemic complex formation with (-)-NLE at $\mathrm{X}=\mathrm{H}$ or $\mathrm{CH}_{3}$.

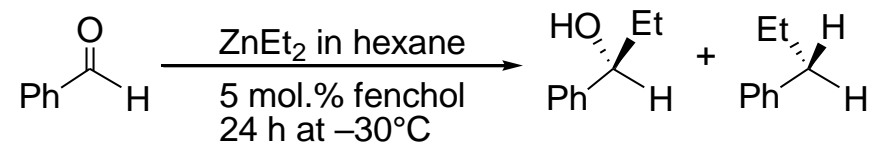

A racemic (heterochiral) complex was formffed where $\mathrm{X}=\mathrm{SMe}_{3}$ or $t$-Bu (Scheme 6). 


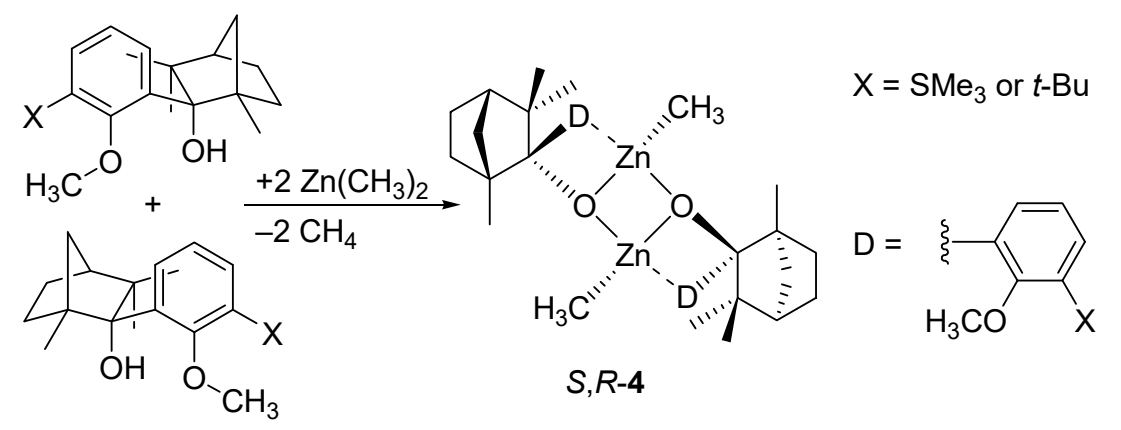

Scheme 6. Racemic complex formation with linear relationship at $\mathrm{X}=\mathrm{SMe}_{3}$ or $t$-Bu.

The use of fenchols with $\mathrm{X}=\mathrm{H}$ and $\mathrm{X}=\mathrm{CH}_{3}$ in the reaction (5) resulted in (-)-NLE while fenchols with $\mathrm{X}=\mathrm{SMe}_{3}$ and $\mathrm{X}-t$-Bu catalyzed this reaction with a linear relationship. Thus, the emergence or absence of (-)-NLE in the reaction (5) depends only on the structure of ligands. Therefore, in this case, the (-)-NLE emergence is formally defined by Kagan-Noyori models.

Chen et al. [120] discovered a substrate dependence of the nonlinear effect in diethylzinc addition to aromatic aldehydes over chiral auxiliary 5 .<smiles>CC12CCC(C)(C1)C(N1CCOCC1)C2O</smiles>

5

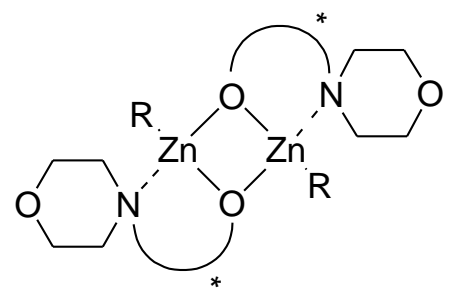

$R, R-6, S, S-6, R, S-6$

Reactions with electron-donating substituents on the aromatic ring of aldehyde exhibited a greater (+)-NLE than those with electron-withdrawing substituents. These data contradict with the Noyori-Kagan models. The observed substrate dependence can be explained by a reaction of aldehydes with diastereomeric homo- and hetero-chiral dimers of $\mathbf{6}$ via different pathways.

Dimethylzinc addition to aromatic aldehydes (6) using BINOLate-titanium complexes 7 as catalysts produced weak (-)-NLE [121].

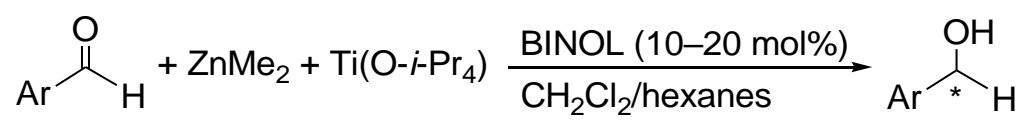

Several BINOLate-titanium complexes (e.g., 7—reaction (7)) were synthesized at a low temperature and characterized by crystallography X-ray crystallography. It was shown that (-)-NLE was only observed in stoichiometric experiments (Figure 12). Catalytic experiments replicated the proportional linearity of the ee product and the ee catalyst [122]. 


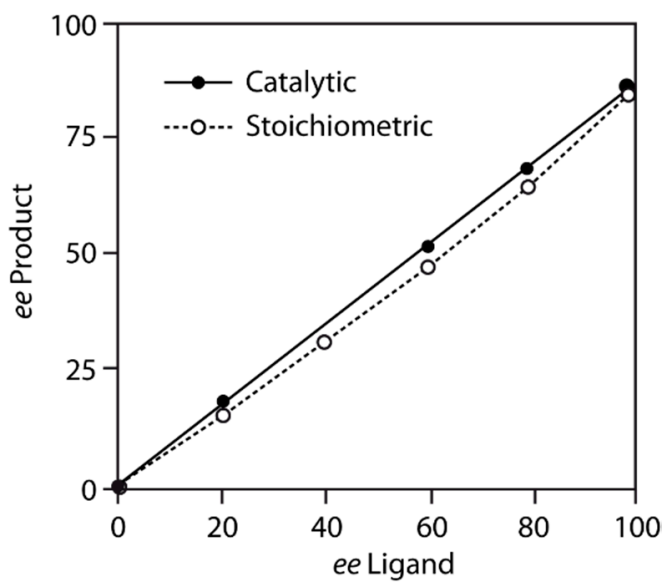

Figure 12. And stoichiometric experimental data (Ti/ non-enantiopure BINOL ligand).<smiles>[R]c1ccc2ccccc2c1-c1c(O)ccc2ccccc12</smiles>

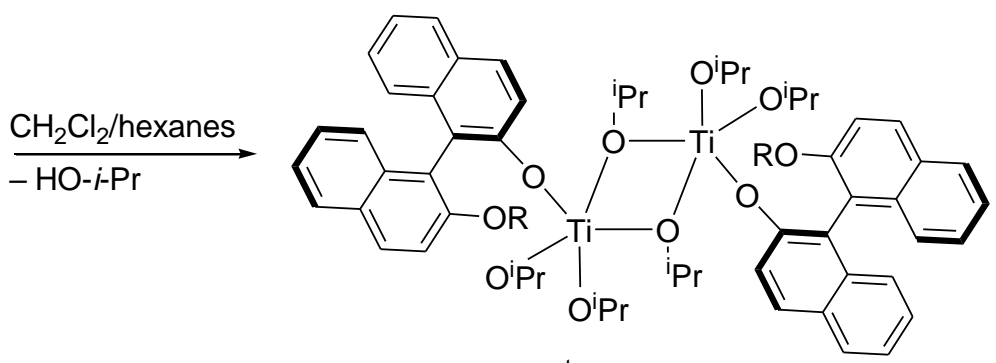

$\mathrm{R}=\mathrm{Me},{ }^{\mathrm{t}}-\mathrm{Bu}(R, R-7)$

Catalytic reactions were run with $20 \mathrm{~mol} \%$ of (BINOLate)Ti(O-i-Pr) $)_{2}$ and $80 \mathrm{~mol} \%$ of titanium tetraisopropoxide. The stoichiometric reaction were performed using $100 \mathrm{~mol} \%$ of (BINOLate)Ti(O-i-Pr $)_{2}$.

Such a difference between the stoichiometric and catalytic experiments is true if homochiral dimers catalyze the reaction path to enantiomerically pure products (no NLE). The stoichiometric reaction results in non-enantiomerically pure products. Given the observed difference the NLE formation mechanism remains unclear. The heterochiral dimer was shown to be significantly more stable than homochiral dimers [123]. It is safe to assume that the concentration of homochiral dimers is higher in the stochiometric experiments than in the catalytic ones. On the basis of this ratio, we may hypothesize a more pronounced role of homochiral dimers $\left(\mathrm{C}_{2}\right.$-symmetrical) in the occurance of $(-)$-NLE during the stochiometric experiments.

The assumption about the leading role of $C_{2}$-symmetric homochiral dimers in the appearance of (-)-NLE gained experimental justification in other reactions. For example, pronounced (-)-NLE was observed in Friedel-Crafts alkylation of pyrrole with chalcones (8) catalyzed by $\mathrm{C}_{2}$-symmetric chiral dinuclear zinc catalyst 8 [124] and in the hetero-Diels-Alder reaction of Danishefsky's diene and aromatic aldehydes (9) over BINOLate-Zn complex 9 [125].<smiles>[R]C(=O)/C=C(/[R])c1ccc[nH]1</smiles> 
<smiles>C=C(/C=C/OC)O[R5](=O)O[Na]</smiles><smiles>Cc1cc(CN2CCC(c3ccccc3)C2(O)c2ccccc2)c(O)c(C23CCC(c4ccccc4)(C2)C3(O)c2ccccc2)c1</smiles>

$(S, S)-8$<smiles>Oc1c(Br)cc2ccccc2c1-c1c(O)c(Br)cc2ccccc12</smiles>

$(S, S)-9$

Thus, the deviation from the linearity in favor of the racemic product ((-)-NLE) occurs in case aromatic substrates in reactions catalyzed by homochiral $C_{2}$-symmetric dimeres in situ formed from dialkylzinc. This observation resembles catalytic reactions of aromatic substrates under the action of $C_{2}$-symmetric chiral catalysts that occur with anomalous low ee, i.e., an almost racemic product. Addition of diethylzinc to trifluoromethyl ketones (aromatic) over $C_{2}$-symmetric chiral auxiliaries (10) pertains to such reactions (Table 4) [126].

Table 4. Results of chiral ligand 10-15 screening in the reaction (10).

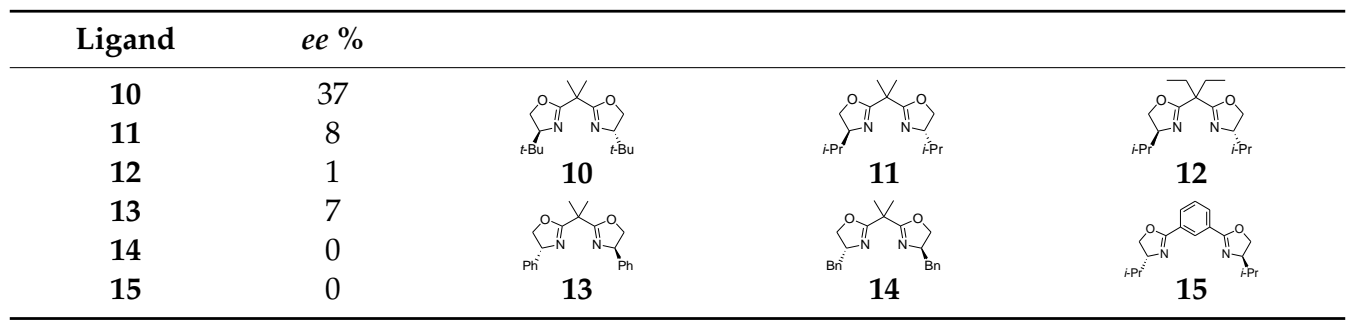

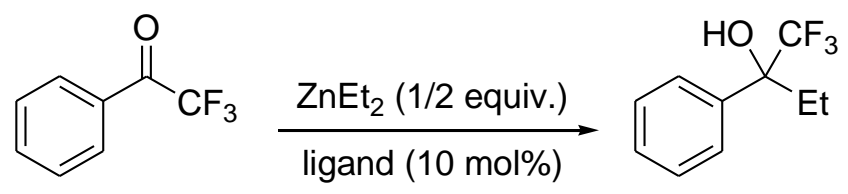

It can be seen that all complexes with $C_{2}$-symmetric ligands in the reaction (10) lead to racemate-like products.

Addition of diethylzinc to aromatic aldehydes (11) in the presence of chiral auxiliaries manifests other interesting features: differences in enantioselectivity of $C_{2}-$ and $C_{1}$-symmetric chiral auxiliaries of similar structures are sometimes greater than an order of magnitude (Table 5 ). 
Table 5. Results of chiral ligand 16-23 screening in the reaction (11).

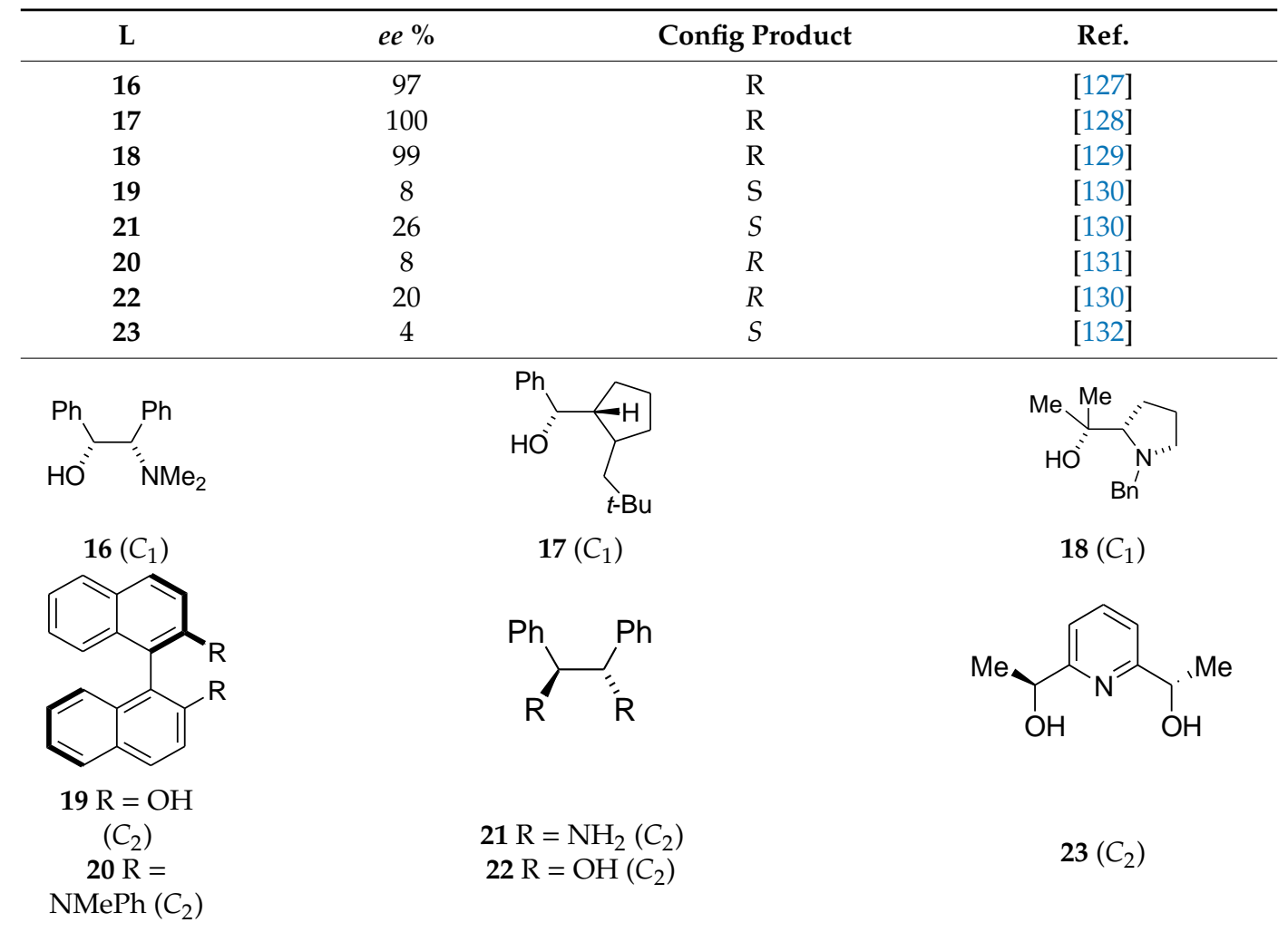

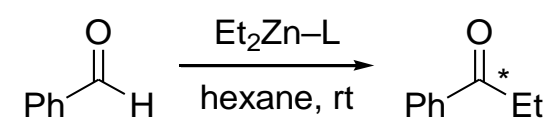

The catalytic cycle of this reaction in the presence of asymmetric $\left(C_{1}\right)$ ligands 16-18 was suggested on the basis of a calorimetric study of kinetics [133]. The decrease in enantioselectivity in the reaction (11) over $C_{2}$-symmetric chiral auxiliaries can be explained on the grounds of a similar catalytic cycle (Scheme 7) [134].

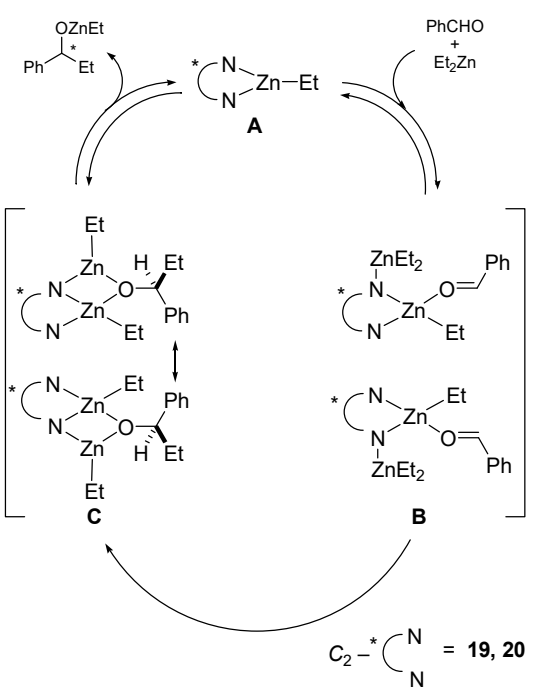

Scheme 7. Possible catalytic cycle of the reaction (11) in the presence of $C_{2}$-symmetric ligands 19, 20. 
Key intermediate $\mathrm{A}$ in this scheme is also $\mathrm{C}_{2}$-symmetric. Both intermediate $\mathrm{C}$ and $\mathrm{B}$ are racemic dimers. A possible $\pi \rightarrow \pi^{*}$ conjugation (shown by the arrow in intermediate $C$ ) reduces the energy barrier and facilitates this reaction path. Therefore, the reaction (11), in accordance with the mechanism, can proceed with the formation of a product of low optical purity, in accordance to the experiment.

The deviation from the linearity to a racemic product ((-)-NLE) was observed not only in the reactions of dialkylzinc addition to aromatic substrates catalyzed by homochiral dimers on the basis of zinc. Remarkable (-)-NLEs were observed in reactions (12) and (13) $[135,136]$ and similar reactions [137] of aromatic substrates over $C_{2}$-symmetric chiral catalysts:
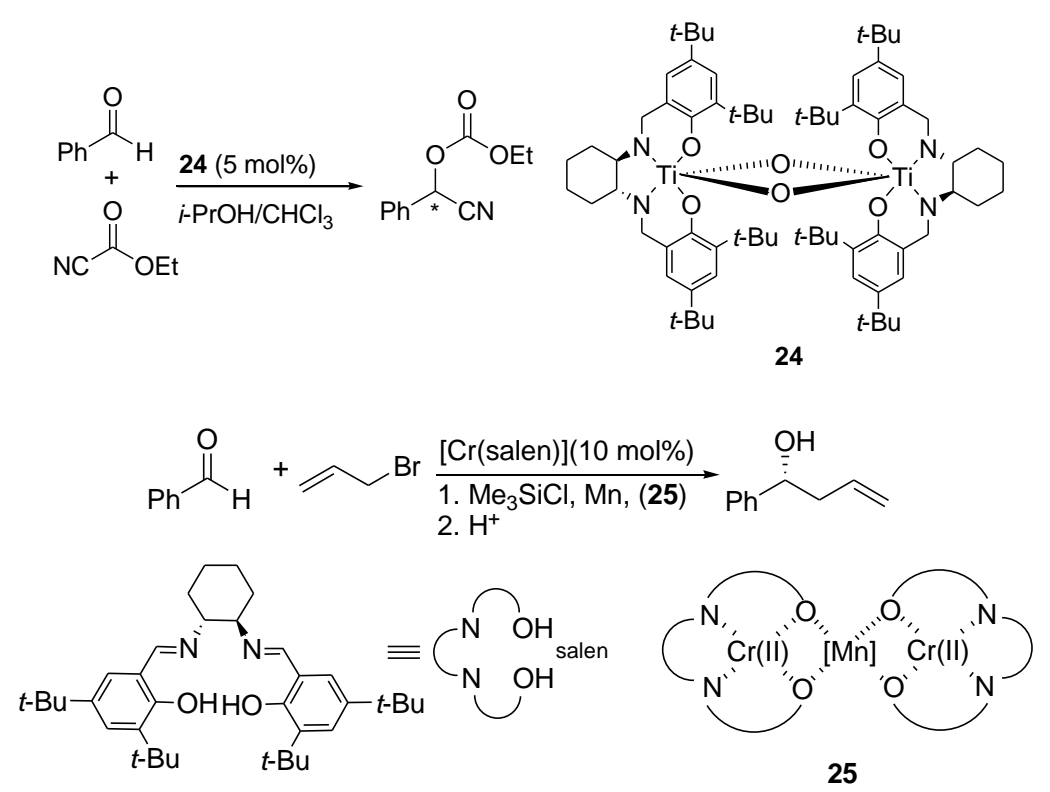

Thus, all reactions with (-)-NLE occur on the basis of aromatic substrates under the action of $\mathrm{C}_{2}$-symmetric chiral complexes. A similar effect was mentioned above for the reactions over in situ formed catalysts with the dialkylzinc participation. The deviation from the linearity with the formation of the low ee product in asymmetric catalytic reactions occurs where there is an abnormally low $e e$ product in the presence of $C_{2}$-symmetric chiral complexes as compared to $C_{1}$ complexes of similar structure [2].

Noticeable distinctions between enantioselectivities of identical catalysts with ligands having a similar structure but different symmetry $\left(C_{2}-\mathbf{2 1}, 26,27\right.$ and $\left.C_{1}-28\right)$ were observed in reactions (14) and (15) [138-141] (Scheme 8) where aromatic prochiral compounds were used as substrates. 


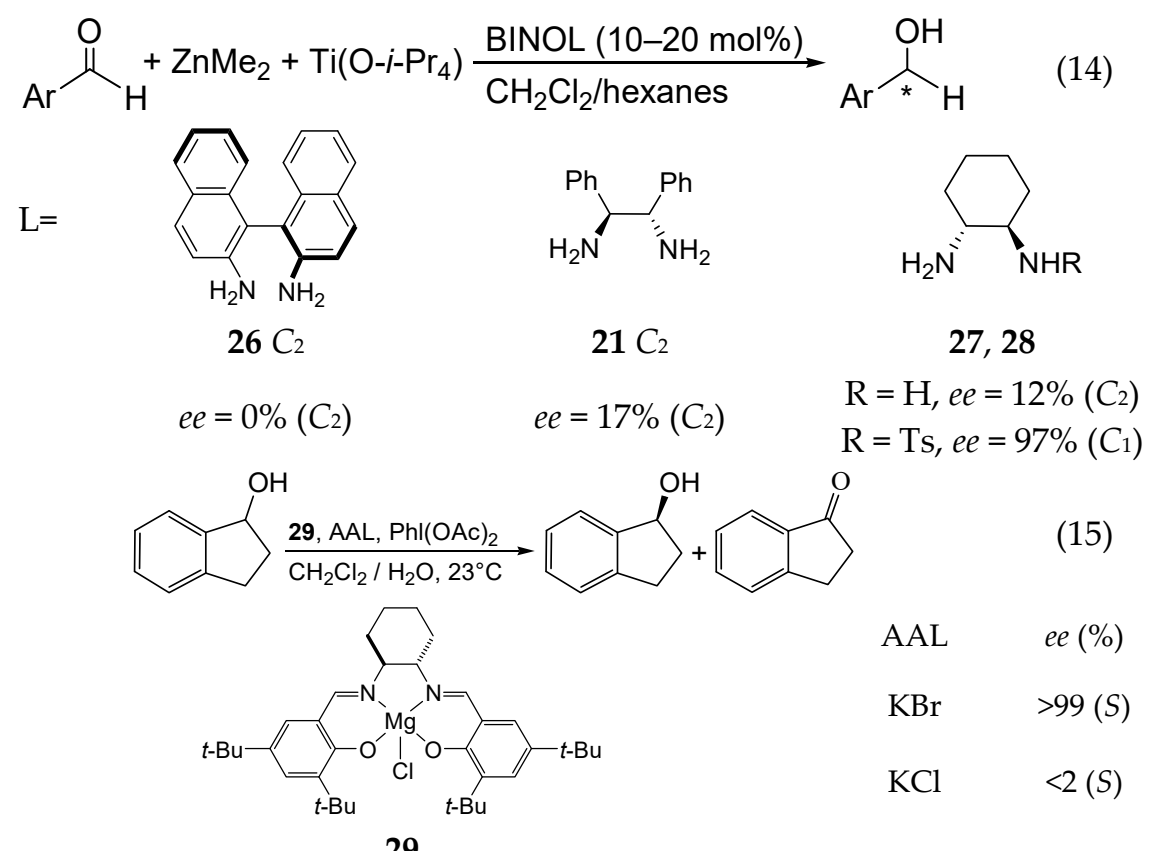

29

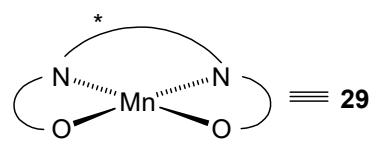

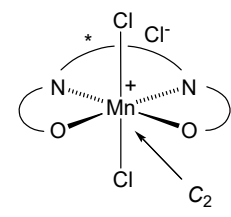

30

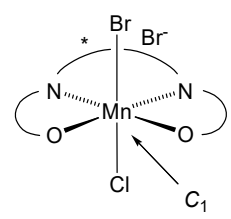

31

Scheme 8. Dependence of the reaction (14) and (15) enantioselectivity upon $C_{1}$ and $C_{2}$ symmetry of the ligand 21, 26-29.

Thus, simple aromatic substrates (acetophenone, etc.) exhibit similar behavior with respect to $C_{2}$ or $C_{2}$ inductor (catalysts). These monofunctional substrates which coordinate with a catalyst by the reacting group (single-point coordination) only receive stereospecific information directly from the asymmetric catalyst. A racemic field formed by the $\pi \rightarrow \pi^{*}$ coordination of aromatic substrates (Scheme 7) can induce a decrease in enantioselectivity. A stage of intermediate complexing with $\mathrm{C}_{2}$-symmetric ligand may be responsible for the product ee reduction. This mechanism, perhaps, is similar to the mechanism of the (-)-NLE occurrence established for aromatic substrates.

Since asymmetric induction occurs at the catalyst-substrate stage, symmetry of this intermediate determines enantioselectivity. If the substrate has two or three functional groups, the chiral $C_{2}$-symmetric catalyst loses $C_{2}$ symmetry at the stage of coordination with such substrate. Indeed, hydrogenation of amino acid precursors on $C_{2}$-symmetric chiral complexes (three-point coordination) involves the formation of the $C_{1}$ (asymmetric) intermediate [2].

All asymmetric reactions on chiral metal complexes as catalysts support this concept [2]. The experimental data are entirely consistent with Curie-Pasteur's doctrine: only asymmetric factors are responsible for products with asymmetric carbon atoms [1].

A similar situation is observed in asymmetric reactions over chiral organocatalysts. A typical example of such reactions is two-component reactions such as aldol reactions of acetone with $\alpha$-ketoesters, reactions of cyclohexanone derivatives and $\beta$-nitrostyrenes (Michael reactions), nitroaldol (Henry) reactions [39,142-148], etc. Two plausible transition states TS- $R$ and TS-S (Figure 13) reflect the structure and bonds of the key intermediate of the reaction (16) over $C_{2}$ organocatalyst 32 [149]. As seen from the figure, each of the possible transition states (key intermediates) do already not have $C_{2}$ symmetry like the basicorganocatalyst. These key intermediates are asymmetric structures in the reaction (16). 


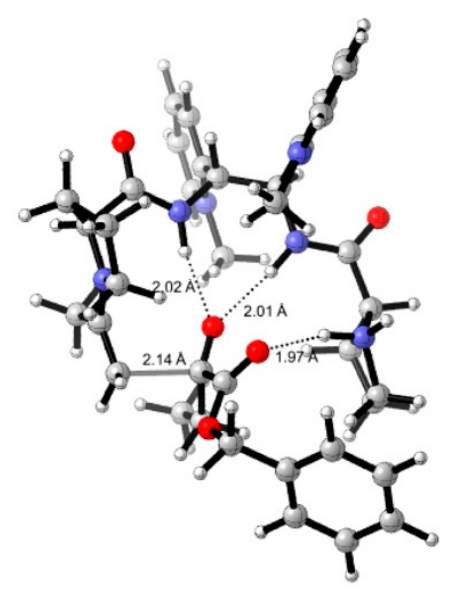

TS-32-R

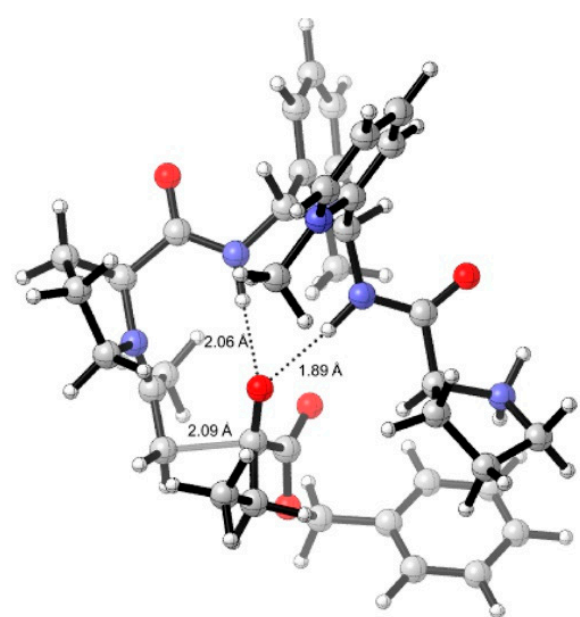

TS-32-S

Figure 13. Transition states of the reaction (16) on $C_{2}$ organocatalyst 32 .
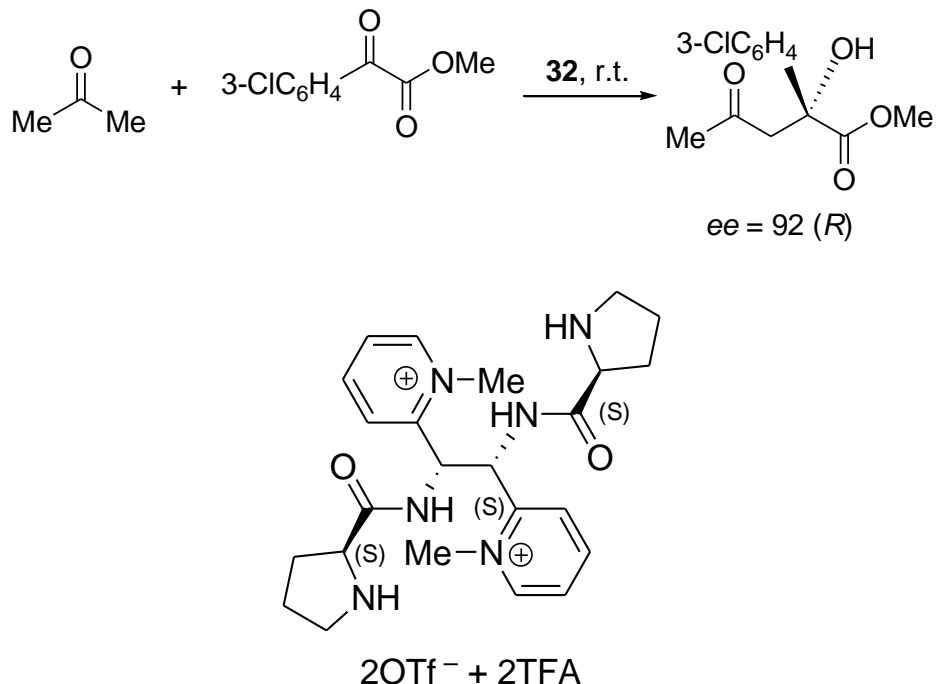

Therefore, asymmetric induction proceeds through the $C_{1}$-symmetric (asymmetric) key intermediate in two-component reactions catalyzed by $C_{2}$ organocatalysts. Another example in support of this conclusion is Michael's reaction (17) on novel $C_{2}$-symmetric $N, N^{\prime}$-bis-[(pyrrolidin-2-yl)methyl-squaramide] TFA $((R, R)-33$ or $(S, S)-33)$ salts [150].

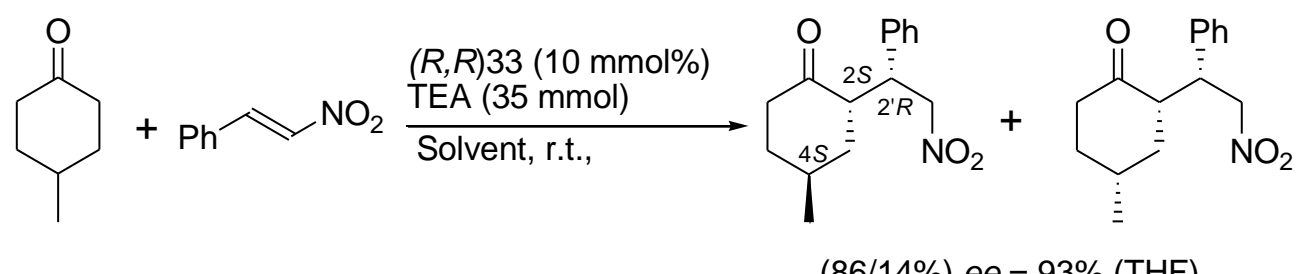

$(86 / 14 \%) e e=93 \%(\mathrm{THF})$

Figure 14 shows two possible favoured and two disfavoured intermediates which are different from the viewpoint of an approach of the reagents to $C_{2} 33$ (a front or rear approach). Both favoured-1 and favoured-2 intermediates, alongside with those disfavoured- 1 and disfavoured-2, are formed as a result of the reactants coordination with different side nitrogen atoms of $C_{2}$ - symmetrical 33. Therefore, 
they are similar in terms of the structure and symmetry of both $\mathbf{1}$ and $\mathbf{2}$ favoured or disfavoured $\mathbf{1}$ and 2 key intermediates ( $C_{2}$ symmetry of 33 and $C_{1}$ symmetry of key intermediates).

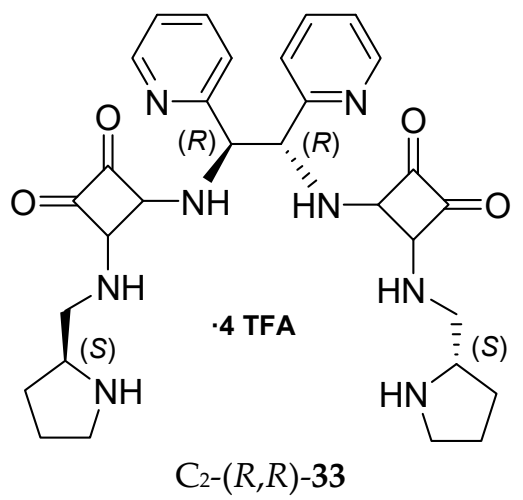

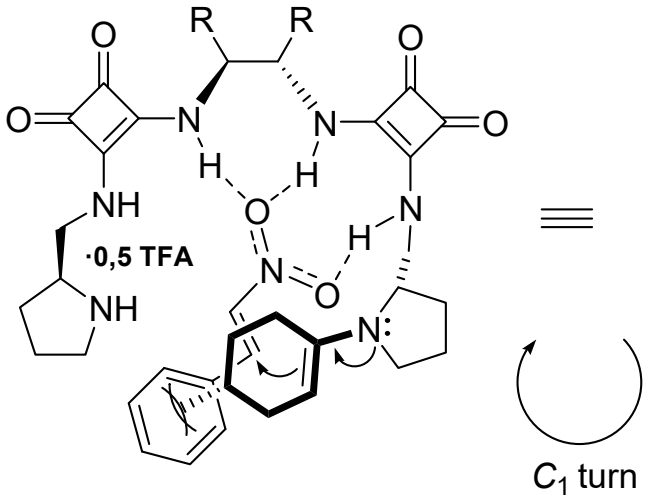

Disfavored-1

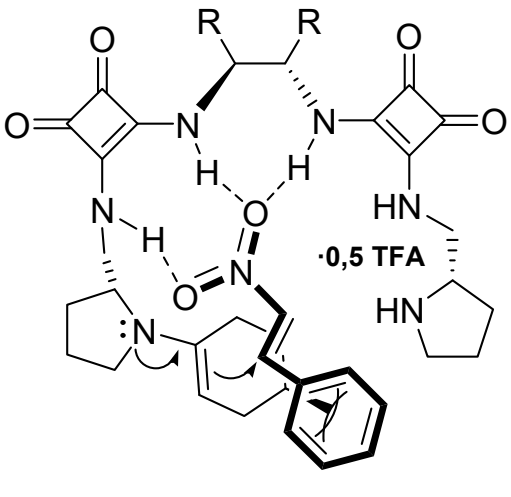

Disfavored-2

C 1 symmetry

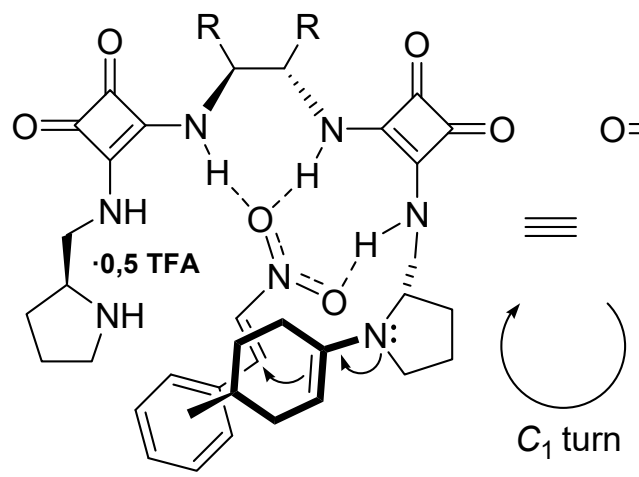

Favored-1

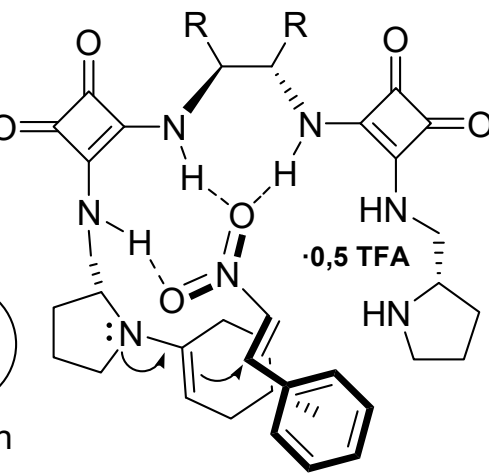

Favored-2

$C_{1}$ symmetry

Figure 14. Proposed transition states for the asymmetric Michael reaction (17) over $(R, R)-33$.

A similar loss of $C_{2}$ symmetry of an organocatalyst was observed at the key intermediate stage in the aldol reaction (18) of $\beta$-carbonyl acids with trifluoroacetalaldehyde over the $C_{2}$-symmetric bisoxazoline catalyst [151] and analogou reactions [151-156].

Nonetheless, the $C_{2}$ symmetry loss by the key intermediate does not guarantee high enantioselectivity. An example is a Henry two-component reaction catalyzed by $\mathrm{Cu}(\mathrm{OAc})_{2}$ complexes with $C_{2}$ ligands 34-36 and 37-39 (Table 6) [157]. Supposedly, the proposed structure of key intermediate disfavoured and favoured mechanisms of the reaction $(19)$ on complexes with $35(34,36)$ only corresponds to high enantioselectivity (Scheme 9). 
Table 6. Henry reaction of $p$-nitrobenzaldehyde with nitromethane in the presence of different ligands.

\begin{tabular}{cccc}
\hline Ligand & Product $e e^{\%}$ & \\
34 & 69 & $34 \mathrm{R}^{1}=\mathrm{Et}, \mathrm{R}=\mathrm{Bn}$ & $37 \mathrm{X}=\mathrm{N}, \mathrm{R}=\mathrm{H}$ \\
35 & 71 & $35 \mathrm{R}^{1}=\mathrm{Et}, \mathrm{R}=\mathrm{Ph}$ & $\mathbf{3 8 X}=\mathrm{N}, \mathrm{R}=\mathrm{Ph}$ \\
36 & 67 & $36 \mathrm{R}^{1}=\mathrm{Me}, \mathrm{R}={ }^{\mathrm{i} P r}$ & $\mathbf{3 9} \mathrm{X}=\mathrm{C}={ }_{\mathrm{Pr}}^{\mathrm{Pr}}$ \\
38 & 0 &
\end{tabular}<smiles>[R]C(O)C[N+](=O)[O-]</smiles>

Disfavoured<smiles>[R]C(O)C[N+](=O)[O-]</smiles>

"Disfavoured"<smiles>[R]C(O)C[N+](=O)[O-]</smiles>

Favoured<smiles>[R]C(O)C[N+](=O)[O-]</smiles>

"Favoured"

Scheme 9. Key intermediate strctures of reaction (19).

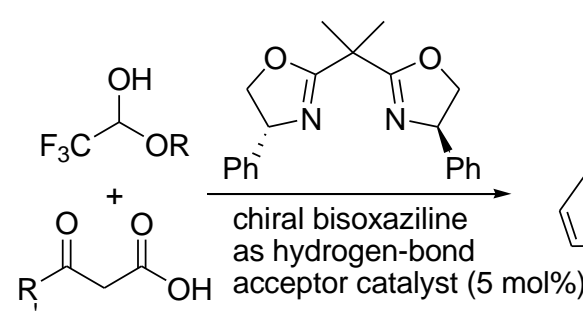

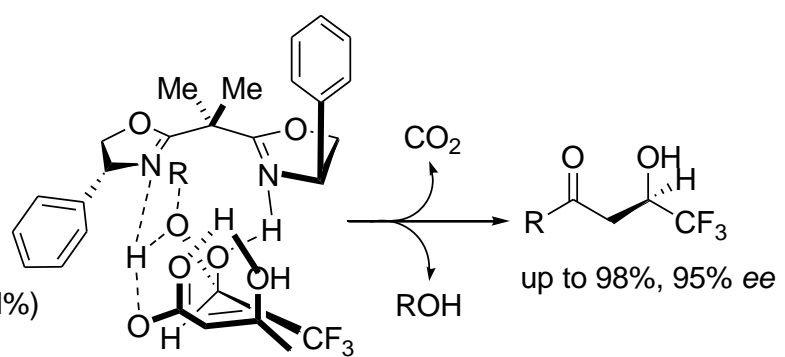




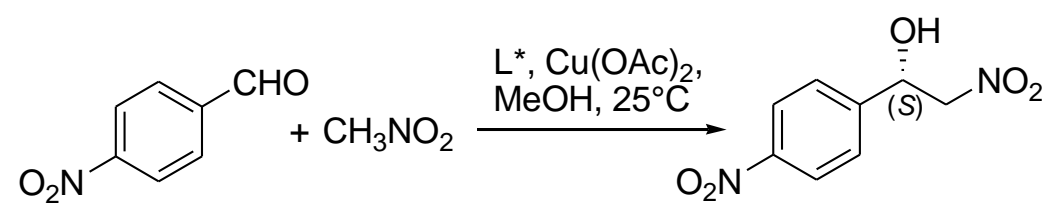

Favoured and disfavoured routes of the reaction pathway are equally likely (low enantioselectivity) in the caseof the reaction $(19)$ on $\mathrm{Cu}(\mathrm{OAc})_{2} / \mathbf{3 7}(\mathbf{3 8 , 3 9 )}$. Therefore, this mechanism is in agreement with the experiment.

Thus, all the above-mentioned reactions of asymmetric catalysis proceed by the standard scheme: asymmetric catalyst (an asymmetry inductor) - asymmetric product. $C_{2}$ chiral catalysts (a $C_{2}$ chiral metallocomplex and a $C_{2}$ chiral organocatalyst) lose $C_{2}$ symmetry of the key intermediate that determines asymmetric induction. Therefore, asymmetric catalytic reactions run in the asymmetric field and do not occur in the chiral field (asymmetry- $\left(C_{1}\right)$, chirality- $\left(C_{1}, C_{2}, C_{n}, D_{2}\right)$.

\section{Spontaneous Chiral Ordering of Achiral Molecules in Liquid Crystals}

A common feature of achiral molecules involved in chiral ordering is the ability to bind to each other due to $\pi-\pi^{*}$ staking, hydrogen bonds or hydrophobic interactions. Linked by those bonds, they shift relative to each other around the central axis on the right or left screw. This synchronization of achiral molecules in chiral superstructures occurs in smectic (lamellar) or nematic liquid crystal (LC) phases. Numerous studies [158-165] of these nanostructures with a "banana", "hat" or crown-like shape show that a ratio of layers with chiral superstructures of different signs in the LC phase is $50: 50 \%$ or so. It is viewed in photomicrographs as chiral domains (dark/bright spots of equal areas) between slightly uncrossed polarizers. Therefore, the definition of such spontaneous crystallization of achiral molecules as "mirror symmetry breaking" [158-165] can only refer to one individual domain or monolayer with superstructures of similar chirality. Since the ratio of domains of different signs is close to racemic, this definition is not correct for crystallization of the entire mass of molecules.

Thus, the formation of chiral superstructures from achiral molecules in LC and distribution of these chiral structures of different signs in the LC matrix is strikingly similar to the formation of chiral crystals from achiral inorganic compounds/salt molecules (Section 4). For example, a similar pattern of the equal ratio $(l / d=1: 1)$ of chiral inorganic crystals is observed in deposits of quartz [166-169] (Figure 15) as well as in the formation of a conglomerate (a mixture of $l$ - and $d$-crystals) during $\mathrm{NaClO}_{3}$ crystallization (Scheme 2).

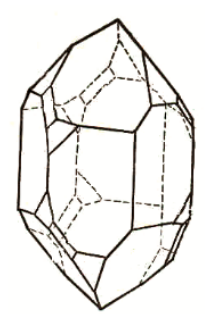

(a)

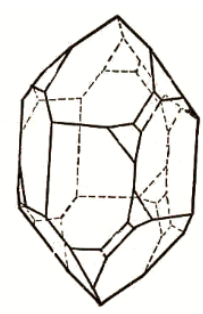

(b)

Figure 15. Natural quartz (a) left-handed crystals versus (b) right-handed ones [167].

Powdering of natural chiral quartz crystals blends left- and right-handed domains [166-169]. Chiral surfaces of centric calcite $\left(\mathrm{CaCO}_{3}\right.$,) were observed as well [170-172]. Asymmetric crystals of gypsum $\left(\mathrm{CaSO}_{4} \cdot 2 \mathrm{H}_{2} \mathrm{O}\right)$ were also found [173] and used for asymmetric adsorption [174]. It is believed that natural processes of nucleation and growth of these crystals last for a very long time under the influence of the chiral environment. 
Crystallization of achiral molecules in LC and crystallization of quartz and other minerals and salts (see Scheme 8) in nature are likely to proceed according to the laws same as of chirality occurrence. This regularity was also confirmed in the conditions of a standard organic reaction (20) [175].

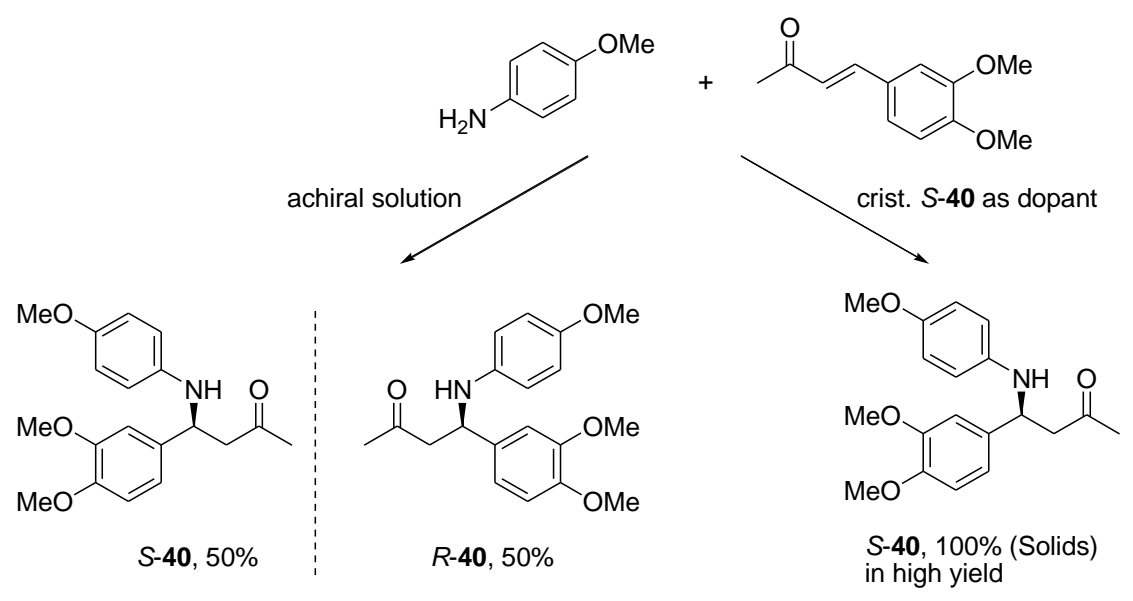

Achiral molecules crystallize in the LC matrix with an approximately equal area of domains of chiral superstructures with different chirality signs. It is difficult to measure the exact ratio of superstructures with different signs of chirality using a polarizing microscope technique (domains) or scanning electron microscopy (twisted ribbons). Therefore, the (1:1) ratio (a racemic mixture) can be assumed valid on the grounds of many publications [158-165].

Spontaneous formation of chiral nanostructures from achiral molecules in the LC matrix has a high inertia depending on heating or cooling to reach a certain temperature. For example, a paradoxal situation may arise when chiral domains of different chirality signs can be formed at the same temperature depending on its achievement by heating or cooling (Figures 16 and 17) $[57,176]$.

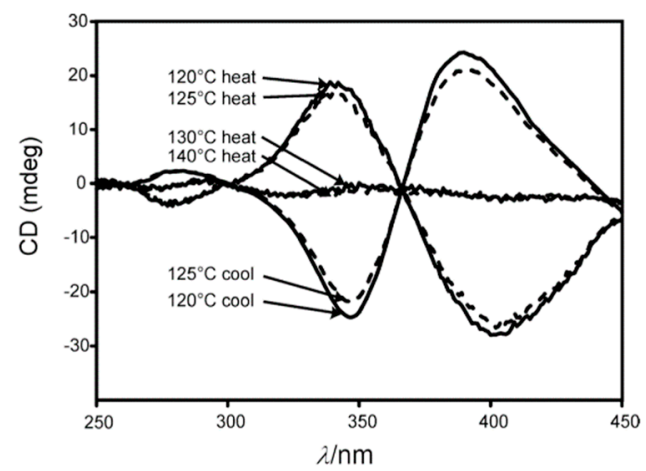

Figure 16. Temperature dependence of circular dichroism (CD) spectra (ellipticity) of 41 [176]. 


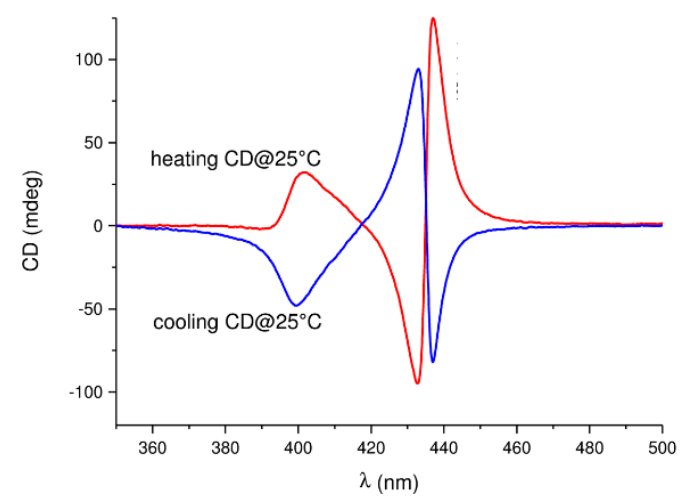

Figure 17. Temperature dependence of CD spectra of 42 [57].

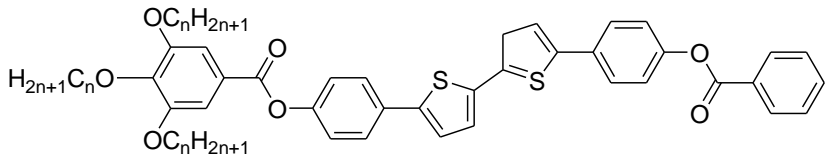

41

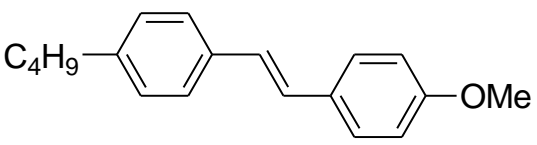

43

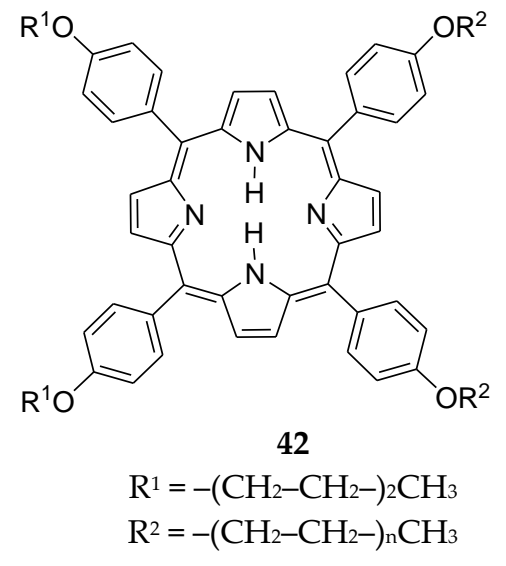

Similar effects were observed in the ongoing formation of other chiral superstructures from achiral molecules $[57,177-180]$. The dependence of chiral nanostructures from various mesophase temperatures of LC (maximal order) suggests that this regularity is of general nature. The temperature inertia of the formation of chiral superstructures is comparable with the time inertia of crystallization of calcite, gypsum or quartz in nature.

Mineo et al. [57] suggested that chiral superstructures on the basis of "achiral porphyrin-based molecules 42 can be induced and controlled by means of a weak asymmetric thermal gradient" or "asymmetric heat flow." It can be considered as evidence of "very weak forces having an important role in natural chiral selective processes" [57]. May it be regarded as a manifestation of resonance with the external chiral field?

Another feature of the reaction of the chiral superstructure formation from achiral molecules is a dependence of the conformation of $P$ or $M$ helical structures from irradiation of different energy. The ratio of $P \uplus_{M}$ enantiomeres was found to be reproducible depending on irradiation [158,162] (Figure 18). 


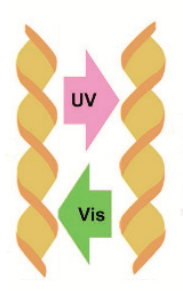

(a)

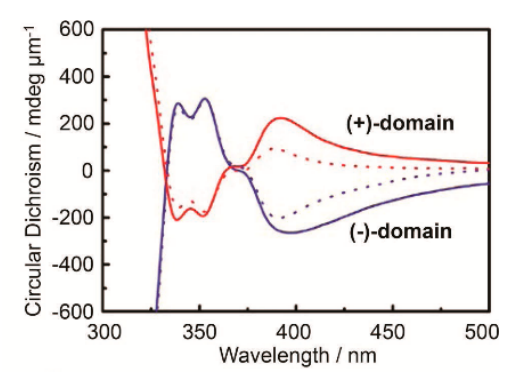

(b)

Figure 18. (a) Photoresponsive azobenzene 43. (b) CD spectra for (+) and (-) domains of sample 43 [162].

If enantiomers are an energy equivalent, the ratio of enantiomers should be random and non-reproducible. The reproducibility of $M \rightarrow P$ ratio UV and the opposite $P \rightarrow M$ sequence after Vis irradiation (Figure 18) could result from the action of the external chiral inductor as a chiral trigger.

Another strange feature of crystallization of achiral molecules in the LC phase was found during crystallization of pyridinum-tailored antracene 44 [181] in the presence of iodine and other pseudo-halogen anions with a similar anionic radius.

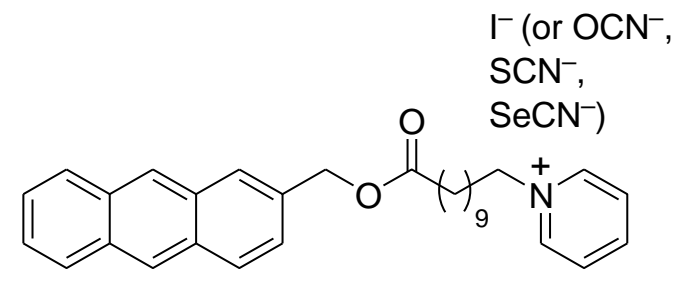

44

A specific role of the anionic radius to form chiral supromolecular assemblies from achiral molecule 44 testifies to the influence of the helix pitch size in the ongoing formation of a helix structure. An external chiral inductor may also be responsible for this experimental data. It is difficult to explain a similar sensitivity of the organic helical framework to the metallic core radius by internal reasons [182].

An extremely interesting effect was observed in a supamolecular self-assembly of achiral tetraphenylethylene 45 (Figures 19 and 20) [183] due to solvent evaporation. (A) $R=C_{7}$, (B) $R$ $=\mathrm{C}_{8},(\mathrm{C}) \mathrm{R}=\mathrm{C}_{9},(\mathrm{D}) \mathrm{R}=\mathrm{C}_{10}, M, P, M, P$, correspondingly. 


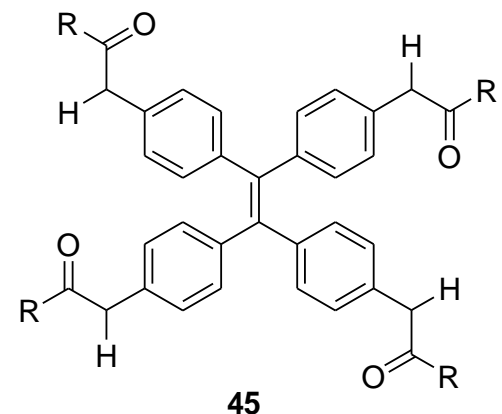

$\mathrm{R}=\mathrm{n}-$ Heptyl $\mathrm{C}_{7}, \mathrm{n}$-Octyl $\mathrm{C}_{8}, \mathrm{n}-$ Nonyl $\mathrm{C}_{9}, \mathrm{n}-$ Decyl $\mathrm{C}_{10}$

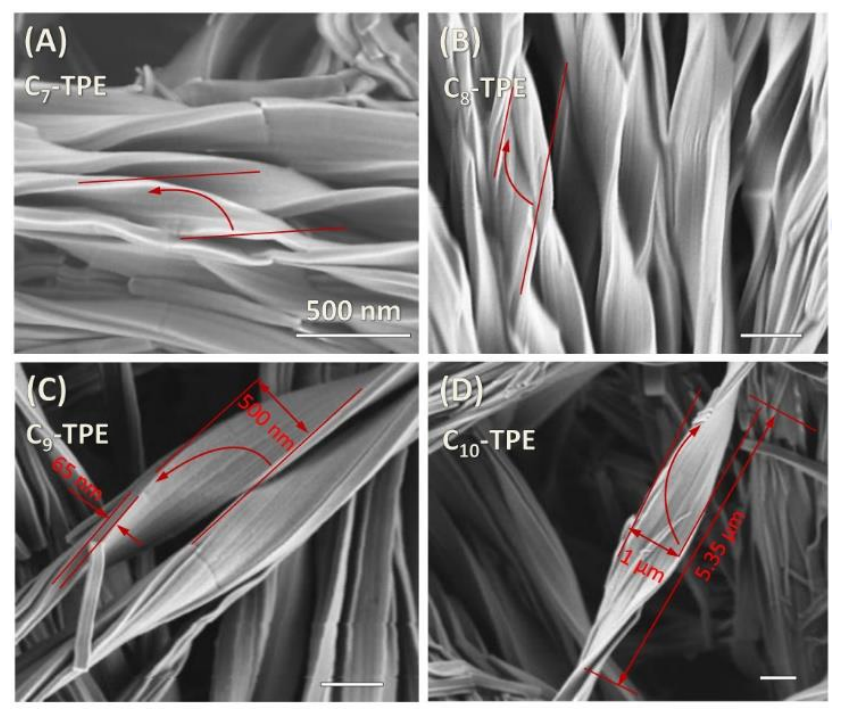

Figure 19. Twisted ribbons of 45 on silicon wafers from MeCN/THF (9:1 v/v). (A) $R=C_{7}$. (B) $R=C_{8}$. (C) $\mathrm{R}=\mathrm{C}_{9}$. (D) $\mathrm{R}=\mathrm{C}_{10}$ [183].

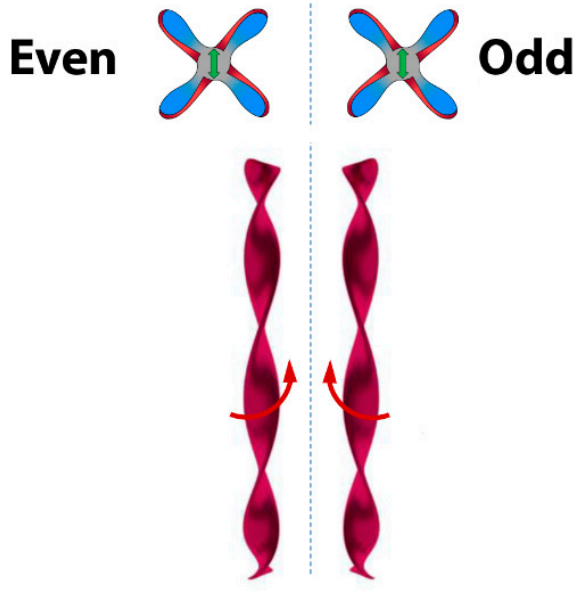

Figure 20. Graphical illustration of the 45 self-assembly effect [183].

Hence, 45 with the even number of carbon atoms in alkyl chains was produced by right-handed superstructures, whereas the odd number led to the left-handed supramolecular structure (Figure 20). 
No physical rationale for this phenomenon has been discussed. We believe that a possible explanation for this effect may be the influence of an external chiral inductor as a resonator.

The sensitivity of this resonator to the structure of achiral molecules could be illustrated by the following examples (Figures 21-24).

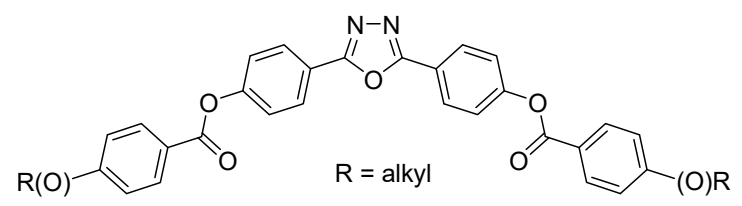

46

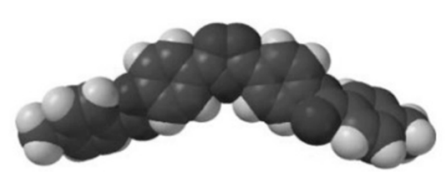

$\mathrm{R}=$ methyl

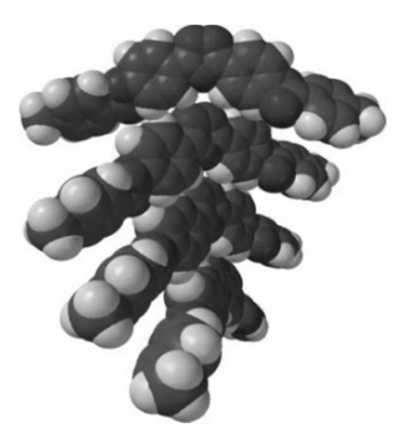

Figure 21. Schematic illustration of the chiral superstructure on the basis of $46[148,164]$. 


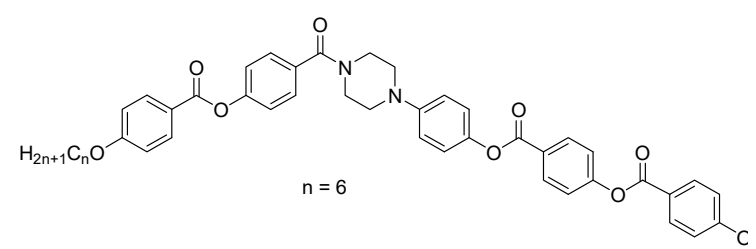

47

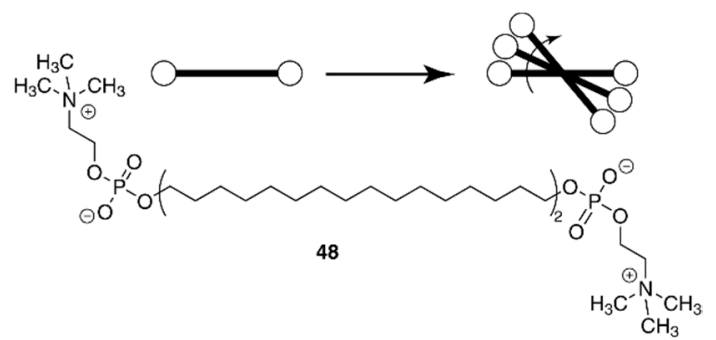

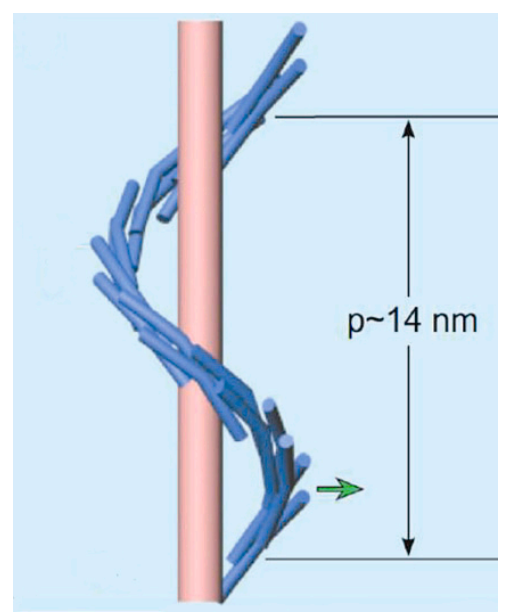

Figure 22. Schematic representation of the chiral superstructure on the basis of 47 [183].

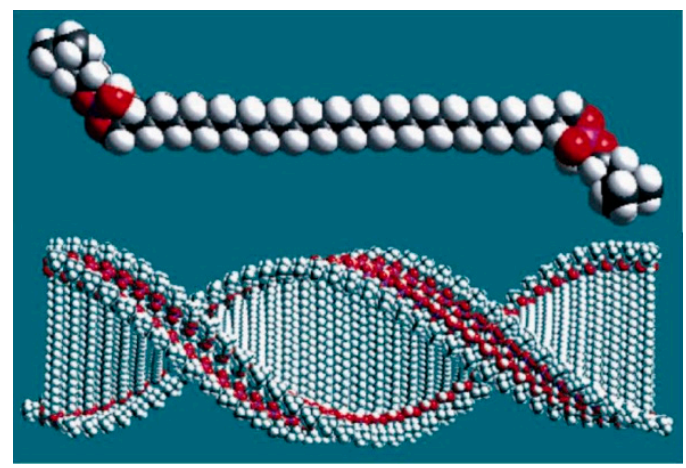

Figure 23. Schematic model of the chiral superstructure based on propeller-shaped molecule $48[184,185]$. 


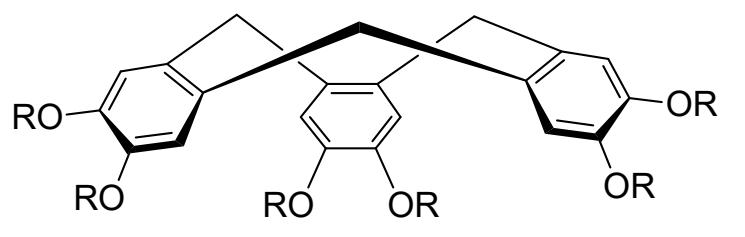<smiles>[R]Cc1ccc(OC)c(OC)c1</smiles>

49

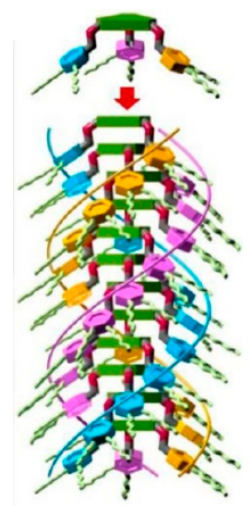

Figure 24. Schematic illustration of the chiral superstructure on the basis of crown-shaped molecule $49[186,187]$.

As can be seen, symmetry $\left(C_{2}, C_{4}\right)$ of corresponding chiral superstructures coincides with symmetry of the underlying achiral molecules $(46,45,48)$. Crown-shaped molecule 49 with 12 peripheral alkyl chains $\left(C_{3}\right)$ form single columns with 12-fold triple helices $\left(C_{3}\right)$ (Figure 24) $[186,187]$. Asymmetric molecule 47 ( $C_{1}$ symmetry axis) with the center of gravity in the side chain forms a helix from the linear sequence of these molecules (tail to head) with $C_{1}$ symmetry (Figure 22).

Thus, the centers of gravity (symmetry) of achiral molecules and relevant chiral superstructures are similar. This coincidence could be possible evidence of the gravitational influence in the construction of chiral ensembles from achiral molecules.

Not necessarily organic compounds or salts solely participate in the formation of chiral superstructures. Singh et al. [188] observed that cubic nanocrystals ( 13.4 nm) of magnetite $\mathrm{Fe}_{3} \mathrm{O}_{4}$ as dipoles self-assembled into arrays of helical superstructures. $\mathrm{Fe}_{3} \mathrm{O}_{4}$ dipoles are oriented along the applied magnetic field $(\mathrm{H}=700 \mathrm{~g})$. The chains of single magnetite particles aggregated as the solvent evaporated (Figure 25). Examples of self-assembly of one-dimensional $\mathrm{Fe}_{3} \mathrm{O}_{4}$ nanocube belts can be seen in Figure 26.
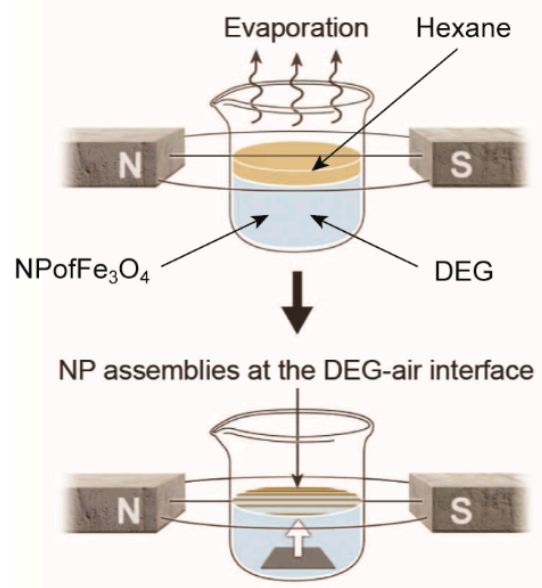

Figure 25. Assemblies of the formation of $\mathrm{Fe}_{3} \mathrm{O}_{4}$ nanoparticles (NP) in diethylene glycol (DEG)-air interface in the magnetic field [188]. 


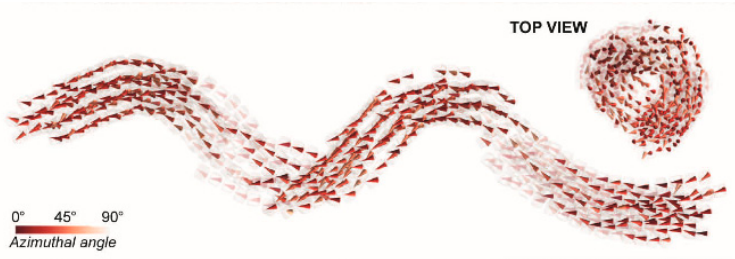

(a)

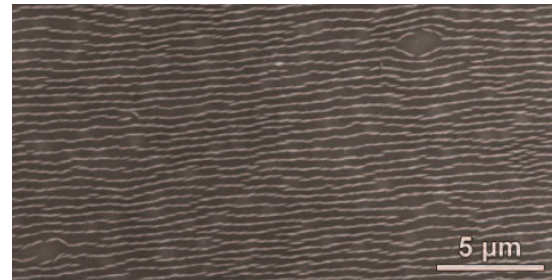

(c)

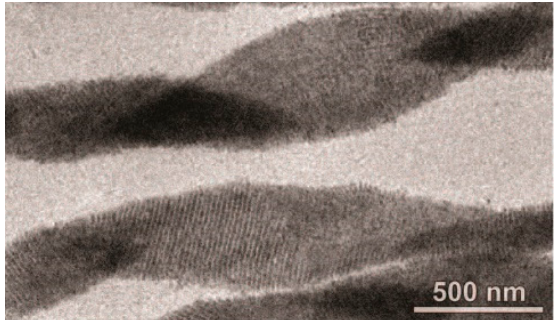

(b)

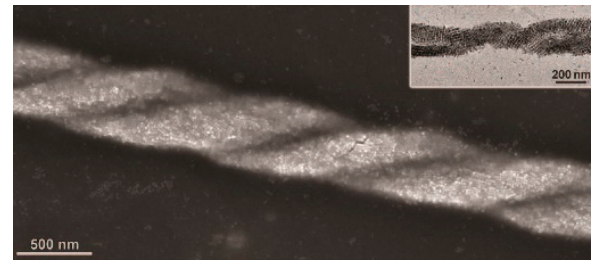

(d)

Figure 26. Of $\mathrm{Fe}_{3} \mathrm{O}_{4}$ nanoparticle chiral arrays. (a) One-dimensional belt folding into a left-handed helix. (b) Transmission electron microscopy (TEM) image of an individual left-handed helix. (c) Scanning electron microscopy (SEM) of single-stranded helices. (d) SEM image of (left-handed) double helix [188].

The authors concluded that "there was no intrinsic preference for helices of either handedness; each experiment began with the nucleation of either right- or left-handed helices with equal probability". At the same time, chiral arrays during a single experiment retained the identical handedness. Double or triple helices were observed during some experiments (Figure 27a,b). Figure 27c,d also shows chirality inversion cases in some single experiments (denoted by arrows). Consequently, chirality was preserved during the experiments, except for some cases of partial inversion which reduced enantioselectivity. Whereas crystallization of chiral superstructures from achiral molecules in LC can be compared with $\mathrm{NaClO}_{3}$ crystallization without stirring (Scheme 2 top), chiral arrays of $\mathrm{Fe}_{3} \mathrm{O}_{4}$ nanoparticles in the magnetic field can be compared with $\mathrm{NaClO}_{3}$ crystallization with stirring (Scheme 2, bottom). Indeed, the images (Figures 26 and 27a) show domains with homochiral superstructures (single handedness).

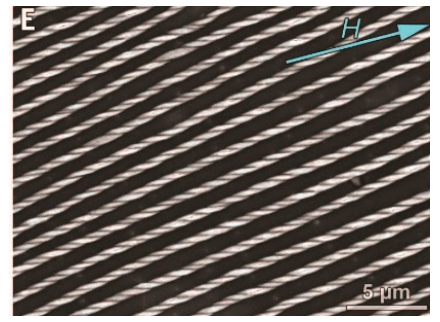

(a)

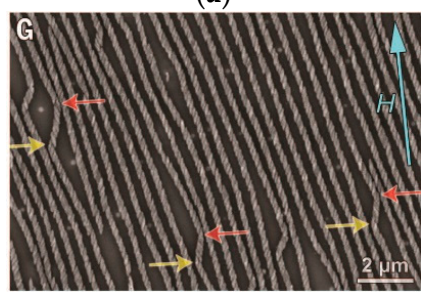

(c)

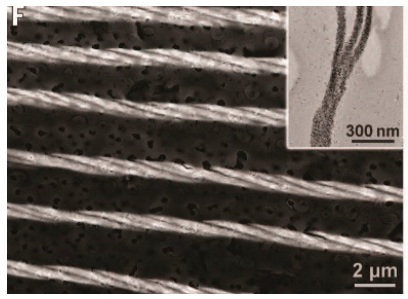

(b)

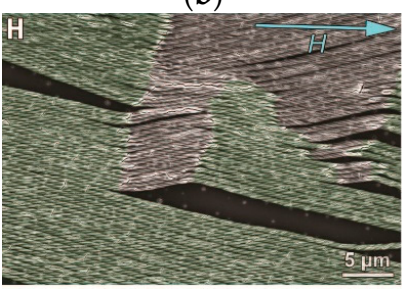

(d)

Figure 27. (a) Self-assembly of helical $\mathrm{Fe}_{3} \mathrm{O}_{4}$ nanocrystal superstructures. (b) SEM image of the right-handed array of double helices. (B) Array of right-handed triple helices and the end of a triple helix (inset). (c) SEM image of self-healing (handedness inversion or damage). The arrows indicate chirality inversion sites. (d) SEM Image of left-handed double or triple helices $\left(\mathrm{Fe}_{3} \mathrm{O}_{4} \mathrm{Ag}\right)$ with sites of helices with the sign reversal [188]. 
A comparison to $\mathrm{NaClO}_{3}$ crystallization with stirring implies a presence of a hypothetical chiral inductor. Hence, the magnetic field alone cannot be a chiral inductor in the formation of the chiral order of magnetite crystals. It is believed that a combination of the magnetic field only with another field [189] (electrical or gravitational) can be an asymmetric inductor.

A number of nanotubes were synthesized $\left(\mathrm{BN}, \mathrm{WS}_{2}, \mathrm{MoS}_{2}, \mathrm{NbSe}_{2}, \mathrm{NiCl}_{2}, \mathrm{SiO}_{2}, \mathrm{TiO}_{2}, \mathrm{MoO}_{3}\right.$, and $\mathrm{V}_{2} \mathrm{O}_{5}$ ) [189]. Celik-Aktas et al. [190] studing boron nitride nanotubes by transmission electron microscopy (TEM), observed "regular, zigzag, dark and bright spots on the side walls of the nanotubes."

These spots moved in a regular fashion around the tube. Basing on this evidence, the authors [191,192] suggested a double-helix structural model (Figure 28) "as a result of a stronger wall-wall interaction associated with the ionic bonding in boron nitride". However, stabilization of the right-handed helix structure (Figure 28) is opposite to that of the left-handed. It is possible that the preference of right-handed helix symmetry can be explained as the result of an external chiral inductor (chiral environment).

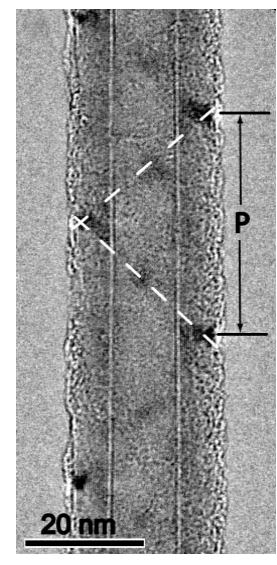

(a)

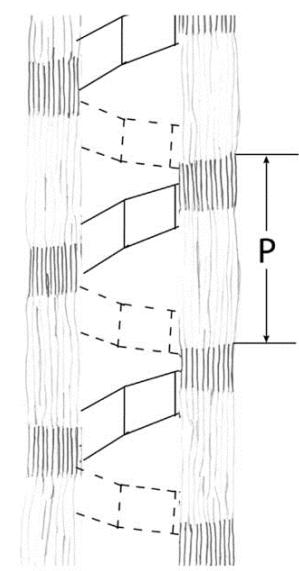

(b)

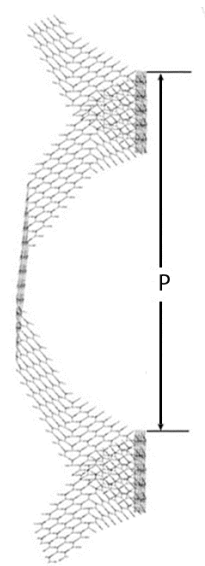

(c)

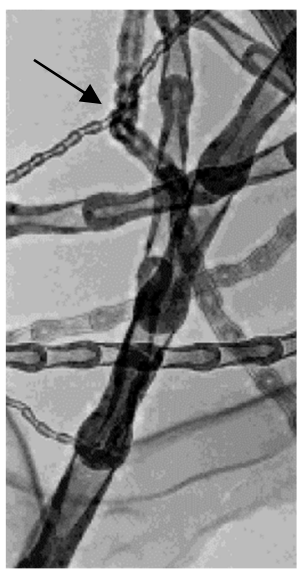

(d)

Figure 28. TEM image of BN nanotubes. (a) "Dark contrast regions in the middle of the tube and on the side walls are visible." (b) Schematic helix structure of BN nanotubes. (c) Atomic structure of BN hexagonal helices. (d) BN nanotubes (the change point is indicated by an arrow) [191-193].

The sharp turning point of the BN nanotube at an angle of about 30-40 (Figure 28) [190-193] is extremely similar to the inversion point of the chirality sign of the magnetite nanocrystals self-assembly (Figure 27c,d). Therefore, it can be assumed that this BN point is the turning point of the transition of the right-handed helix to the left-handed one (or the contrary).

\section{Chiral Field (Chiral Memory) and Racemic Field}

An example of the chiral field existence can be an enantioselective reaction (21) of prochiral substrate hydrogenation on an achiral catalyst in the cholesteric liquid crystal (ChLC) [189].

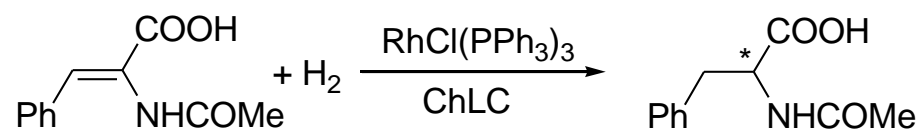

The temperature maximum of hydrogenation enantioselectivity $\left(e e=16 \%\right.$ at $60-70{ }^{\circ} \mathrm{C}$ ) coincides with the temperature maximum of ChLC (cholesteryl tridecanoate) helical ordering. Mirror symmetry breaking in this case is contrary to common sense. Indeed, molecule sizes of $\alpha$-acetamidocinnamic acid and the $\mathrm{RhCl}\left(\mathrm{PPh}_{3}\right)_{3}$ catalyst are much smaller than the ChLC helical pitch (300-400 nm). Therefore, asymmetric induction at the stage of coordination of substrate and catalyst molecules cannot only occur under the influence of ChLC helical chirality. A possible explanation of mirror symmetry 
breaking in this experiment is the effect of the chiral field on individual molecules of the substrate and catalyst $[194,195]$. Indeed, it was shown by the method of induced circular dichroism that helical ordering was built by achiral reactant molecules as well as from achiral Wilkinson's catalyst molecules in the conditions of the hydrogenation reaction in the ChLC medium. Thus, the chiral structure of the key intermediate in this reaction was provided by the action of the chiral field $[194,195]$.

A strong chiral field was shown to exist between two flat aromatic "pincers" (tweezers) [196,197] separated by some kind of a more or less rigid "teter" with a chiral moiety as a chirality inductor. Porphyrin or metalloporphyrin groups at the chain ends with the chiral inductor in the middle of this host molecule, for example 50, can be used as tweezers [198-201]. The length of the chain the inductor and porphyrin group separating can exceed 13 single and double bonds ${ }^{173}$. In the absence of a chiral inductor, such structure is used to study molecular chirality of chiral bidentate guest molecules by circular dichroism of metalloporphyrin hosts as a sensor of chirality [202-207]. End porphyrin groups can be located at a considerable distance from each other in formulations such as dibenzo30-crown-10 skeleton 51 [208].

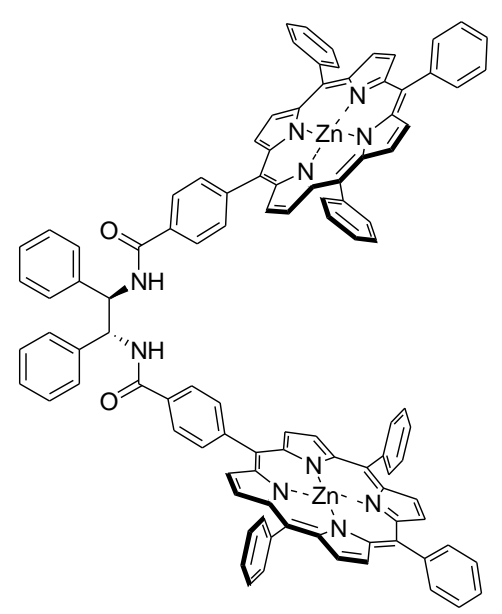

50

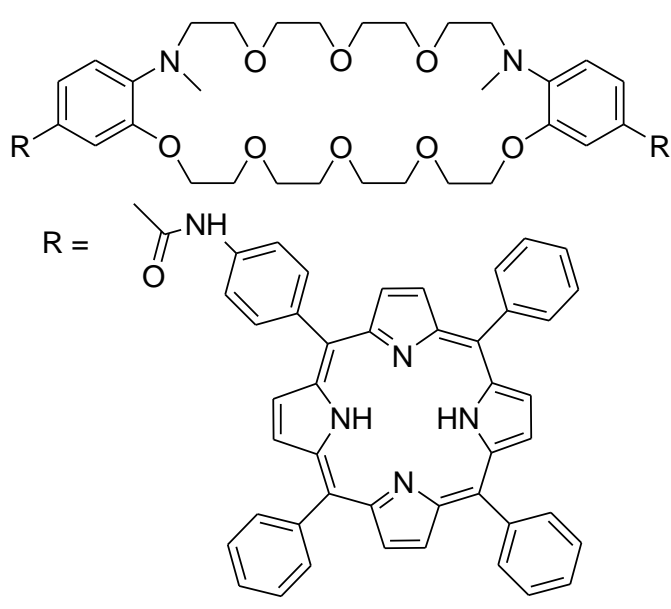

51

There is an assumption that tweezer's architecture of $\mathbf{5 1}$ lead to the mesostructure formation. Mmirror symmetry of $\mathrm{N}$-atoms in $\mathbf{5 1}$ is realized through the $\pi-\pi^{*}$ interaction of porphirin groups. This structure provides a strong racemic field between flat porphirin groups. Chirality of self-assembled achiral porphyrins (imprinted chirality) in host-chiral guest structures persists after a removal of the chiral guest-inductor which caused this chirality [209]. This is a new example of chiral memory.

A property of silica gel to retain information ("remember"it) about complex or chiral molecules dissolved in it during molding was noticed long ago [210-213]. After their removal, silica gel could selectively adsorb these molecules or enantiomers. This selectivity of silica gel could be attributed individually to silylium ions [214]. However, the experimental variety of the ability to memorize structural information, which is characteristic of different gels, allows us to attribute this property to physical gels [215-223].

The discotic trisamides and trisureas of the $\mathbf{5 2}$ and $\mathbf{5 3}$ type form fibers and organic gels [224-226]. 
<smiles>[R]CC(=O)c1cc(C(=O)N[R])cc(C(=O)N[R])c1</smiles>

52<smiles>[R]NC(=O)Nc1cc(NC(=O)N[R])cc(NC(=O)N[2H])c1</smiles>

53

A minor structural variation in this type molecules may dramatically disturb helical columnar superstructures built on the basis of these molecules. The structure and properties variability of these helical columnar aggregates may be related to the gel structure as well as $\pi-\pi^{*}$ stacking and $\mathrm{H}$-bonding. It is believed that the gel formation leads to reaction medium structuring. Together with $\pi-\pi^{*}$ stacking [227,228], H-bonding [229], and donor-acceptor interaction [230], this structuring facilitates the chiral information transfer. Polymers $\mathbf{5 4}$ and $\mathbf{5 5}$ form co-gels with the $N, N^{\prime}$-bis(octadecyl)L(D)-Boc-glutamic gelator [218].

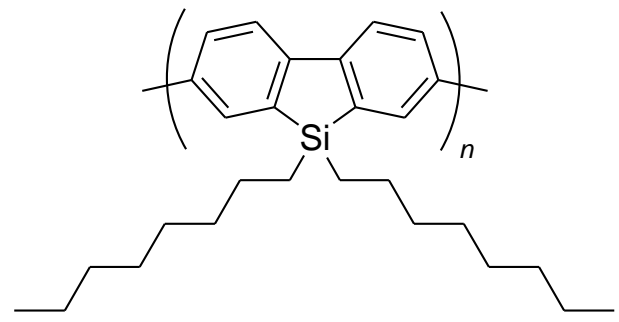

54

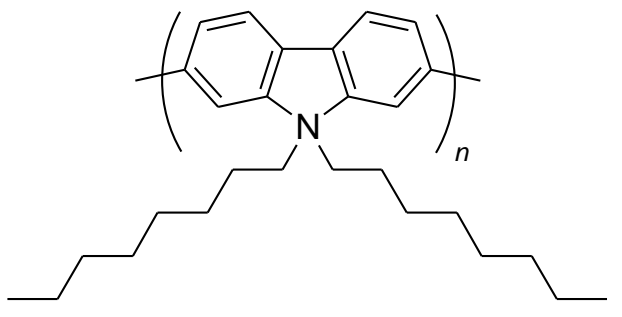

55

Supramolecular chirality of polymers 54 and 55 follows the chirality type of the gelator. Helicity of the polymer assemblies can be memorized even after a removal of gelator molecules. Reaction mixture structuring by means of physical gel and $\pi-\pi^{*}$ stacking or H-bonding relationships of interacting molecules is necessary for displaying chiral memory in the formation of chiral superstructures. These relations and the chiral memory effect were observed for self-assembly of molecules 56 [231] and 57 [216], and other aromatic molecules in the presence of molecular low weight gelators [217,229-231]. The idea of reaction mixture media structuring with gel has been further evolved experimentally [232-235]. 


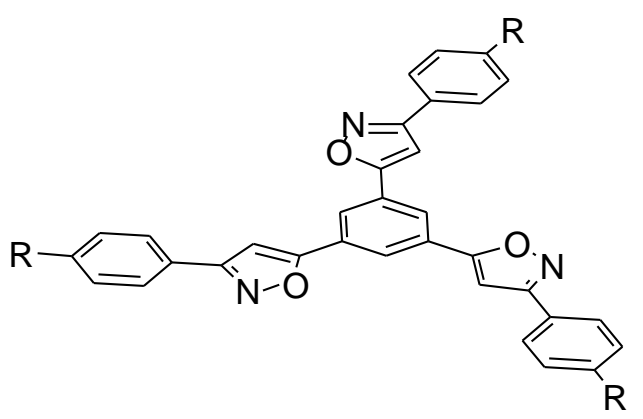

56<smiles>C#CCNC(=O)CC(c1ccccc1)(c1ccccc1)c1ccccc1</smiles>

57

Numerous examples of the chiral memory effect have been observed in polymerization [236-243]. Polymerization creates higher-order structural ordering than the structural arrangement by gel. Therefore, $\pi-\pi^{*}$ stacking, in addition to structural ordering during polymerization, creates conditions for the emergence of chiral memory. The chiral memory effect in polymerization of oligomers is also observed with the participation of hydrogen bonding [244]. It is also possible that other factors may contribute to chiral structuring of the medium during polymerization, e.g., vicinal chirality (Figure 29) [245].

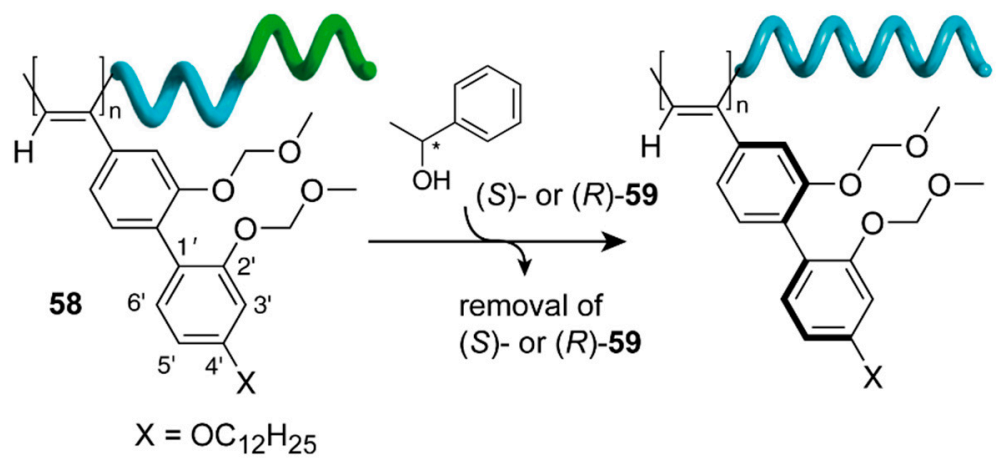

Figure 29. Illustration of the chiral memory effect in poly(biphenylacetylene)s.

We believe that all above-mentioned examples of chiral memory can be explained by the existence of a chiral field. The conditions of the chiral field existence and preservation correspond to the necessity of structural ordering in the overall variety of chiral memory examples.

Chiral effects are known to have only a small energy barrier (see, e.g., reactions (3) and (4) with the $P-M$ transition) [107-111]). Therefore, for example, the $P-M$ conversion occurs when the temperature changes within $30^{\circ} \mathrm{C}$ [101-111]. The chiral field effect may be compared with the chiral effect of other fields or inductors. An example is the chiral effect of ultrasound radiation on chiral amplification [95] in crystallization. It is of interest that the chiral memory motif is also observed in chirality amplification during porphyrin self-assembling [246].

A racemic field is misappreciated in comparison with a chiral field. Perhaps, a reason for this is a kinetic dependence, in which an asymmetric reaction (without an asymmetric inductor) produces the same number of "right" and "left" products. With a high energy of this reaction, the racemic field may not be noticed. Therefore, the comparison between the racemic field and the chiral field can be valid only for not high-energy reactions such as crystallization [247]. Thomas and Tor [248] synthesized a novel 1.10-phenanthroline ligand with branched multifunctional dentritic groups. When an octahedral metal ion self-assembled with these ligands two enantiomers, $\Delta$ and $\Lambda$, were formed (Figure 30). This can apparently be considered as an example of racemic field impact. 


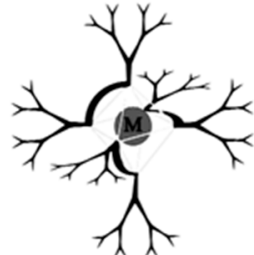

$\Lambda$

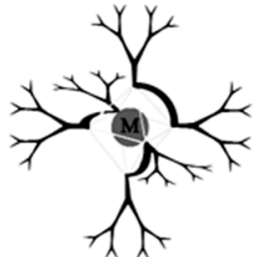

$\Delta$

Figure 30. Dendritic fragments assembled around an octahedral metal ion from $\Lambda$ and $\Delta$ enantiomers [248].

A colourless crystal of helical $\left[\mathrm{Cu}_{4} \mathrm{Cl}_{4}(\text { ally })_{4}\right]_{\infty}$ was formed after neat triallylamine (ally) addition to copper (I) chloride at ambient temperature [249] (Figure 31). Out of the five crystallizations three resulted in the predominantly $P$-helix and two in the predominantly $M$-helix. Those examples can be considered as a manifestation of the stochastic action of the chiral fieid (Figure 31) as well as the racemic field (Figure 30).

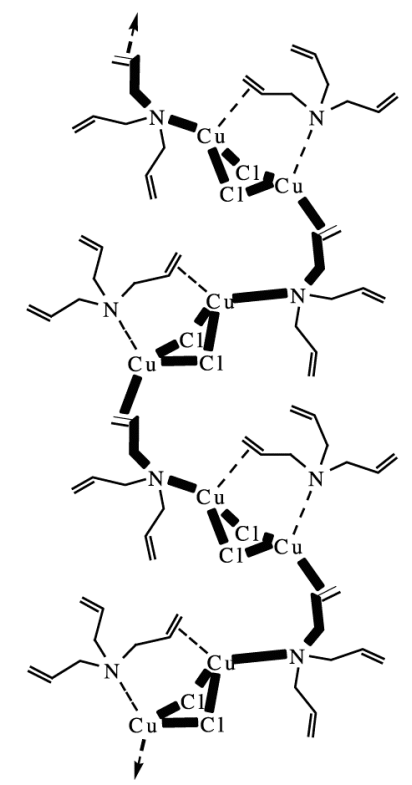

Figure 31. Schematical view of the $\left[\mathrm{Cu}_{4} \mathrm{Cl}_{4}(\text { ally })_{4}\right]_{\infty}$ helix [249].

These cases demonstrate an analogy with crystallization of sodium chlorate (Scheme 2) and the stochastic helicity formation (Section 6).

There is abundant evidence that a collection of right- and left-handed enantiomers possesses other physical properties than a collection of pure enantiomers [39]. It is reflected in tighter packing (more than $4 \%$ denser) or higher melting points of racemates than those of their enantiomers (Wallach's rule) [250-252]. Also, data on solubility and some other physical properties show that racemates tend to be slightly more stable than pure enantiomers. The simplest explanation of Wallach's phenomenon is associated with a difference in hydrogen bonding energies of "true" racemates and pure enantiomers [253-260]. Opponents of this concept validity believe that "true" racemates and pure enantiomers with analogous H-bonding are not rare in occurrence [261-266]. The discussion is complicated by the fact that there are the examples of anti-Wallach's rule [267]. Therefore, the cause of Wallach's phenomenon has not been completely understood up to now. Some researchers designated Wallach's rule as "mutually exclusive binding" in "true" racemates [268].

Thus, the differences in the physical properties of racemate and enantiomer crystals as well as mirror symmetry breaking or conservation in crystallization of sodium chlorate (Scheme 2) or dendritic complexes (Figure 30) and triallylamine complexes (Figure 31) suggest the existence of a racemic field 
alongside with a chiral field. It is possible that the existence of mirror symmetry in the form of a racemic field is global (mirror symmetry space). After all, our Galaxy has a mesostructure (Figure 3).

There are direct evidences of sophisticated structures of racemates. For example, collagen peptides form tight ridges-in-grooves packing of right- and left-handed triple helices (Figure 32) [269].
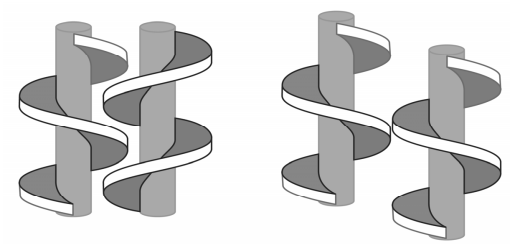

Figure 32. Illustration of triple helices of collagen LD (left) and LL (right) conformations [269].

It seems there is a force which provides an energy advantage for the synthesis of a denser racemate structure. The difference between racemic and chiral fields could explain this experimental observation.

Racemic compounds exist in solution as well (Scheme 4). According to Kagan and Noyori's models racemates and homochiral dimers function as real actors in catalytic asymmetric reactions with nonlinear effects (see Section 5).

Racemic superstructures formed by $P$ - and $M$-helices represent a large group of racemates [39,270-272]. There is no consensus about a reason for the structural difference between heterochiral (racemic) and homochiral dimers [273-275].

\section{B-Z DNA Conformational Transition}

Having a seemingly stable molecular structure, the DNA molecule is a vulnerable object. For example, there are more than a hundred of oxidative damages of the DNA molecular structure. Alongside with the structural damages, the DNA molecule may be subject to conformational distortions (Table 7) [276]. All these conformations of canonical B-DNA (right-handed double helix) lead to genetic instability and genetic diseases [277-283]. From this viewpoint, the conversion of right-handed B-DNA into left-handed Z-DNA attracts widespread attention.

Table 7. DNA conformations [276-278].

Name Conformation Slipped (hairpin) structures

Harvey [284] presented a schematic structure (Figure 33) of $B$ - and Z-DNA molecules after the inversion point. The base pairs in Z-DNA are directed opposite (arrows) from those in $B$-DNA. 


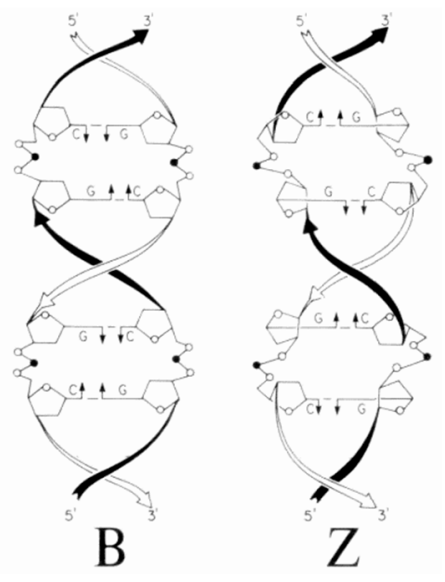

Figure 33. $B \rightarrow Z$ DNA after the inversion point.

It is unlikely that a transition of right-handed B-DNA into left-handed Z-DNA shown in Table 7 occurs linearly without changing the angle of the DNA thread. It is known that the angle between the polymer helices of opposite senses is about $130^{\circ}$ (Figure 34) $[285,286]$, which has been confirmed by other experimental data (see Figure $27 \mathrm{c}, \mathrm{d}$ ).

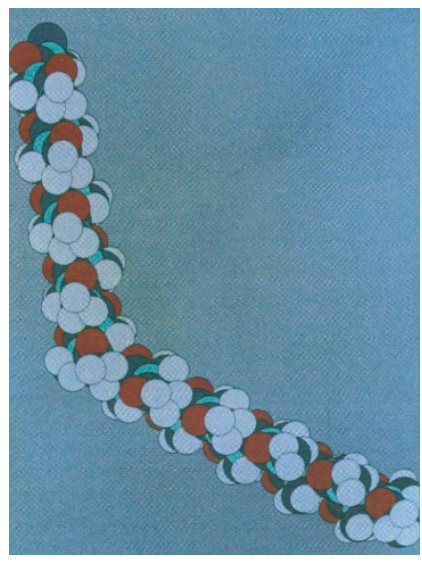

Figure 34. Calculated helical reversal of poly(ethyl isocyanate) [285].

Lee et al. [287] calculated a free energy difference between $B$-DNA and Z-DNA which is $0.9 \mathrm{kcal} / \mathrm{mol}$ per dinucleotide unit. The low energy of this transition was confirmed by the influence of relatively weak chemical factors on this transition. Indeed, ions, especially cations, strongly affect $B-Z$ DNA transitions [288,289]. This influence can be explained by reducing phosphate-phosphate interactions between phosphate groups on opposite strands. Phosphate groups got closer to each other in Z-DNA than in B-DNA (7.7 $\AA$ in Z-DNA compared to $11.7 \AA$ in B-DNA) [290]. Therefore, cations clustering around the negatively charged phosphate group affected $B$-DNA and Z-DNA in a different manner. It is not surprising that ions with higher valencies appeared more effective than monovalent ions [291-293]. The agents that change the dielectric constant of water (or alcohol) were found to stabilize Z-DNA [294-296]. Small molecules affected $B \boxminus Z$ equilibrium as well $[297,298]$. The $B-Z$ DNA transition was also influenced by $\mathrm{Co}, \mathrm{Mn}, \mathrm{Ru}$ and Pt complexes [299-301]. Nevertheless, chiral metal complexes failed to convert $B$-DNA to Z-DNA (see also [302-306]).

$\mathrm{Xu}$ et al. [307] first reported that the $(P)$ and $(M)$ helicene 60 helix molecule (Figure 35) displayed structural selectivity in binding to DNA. The circular dichroism $(C D)$ spectra of the $(P)-60 / Z-D N A$ mixture showed the $70 \%$ decrease in intensity of $C D$ whereas no change occurred in binding of $(P)-60$ to B-DNA. No discrimination was seen in the CD spectra of the (M)-60/B-DNA and (M)-60/Z-DNA mixture. There was only the $20 \%$ decrease in CD intensity. 


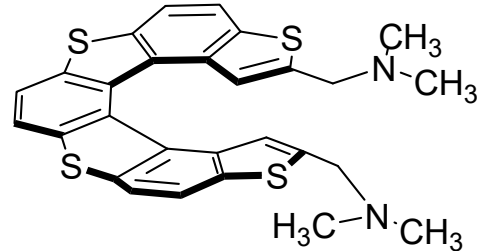

(M)-60

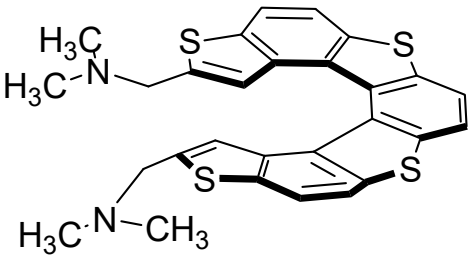

$(P)-60$

Figure 35. Enantiomeric helical pair of helicene 60.

This observation allows a very important and fundamental conclusion: an external chiral inductor can affect B-Z DNA conformations or their equilibrium. The influence of this inductor is apparently not related to the chemical interaction. Optically active hexahelicen and its derivatives are known for their huge optical rotational ability (CD activity and chiral field). Therefore, their effect on chiral conformations of DNA is due to a greater degree of the helicene chiral field.

By analogy, Tsuji et al. [308] showed that an optically active helicene-spermine conjugate (Figure 36) might discriminate $B-Z$ DNA conformations as well. The authors proposed a schematic illustration of the intermediate complex of the B-DNA and Z-DNA interaction with $(P)-64$ and $(M)-64$, respectively (Scheme 10).

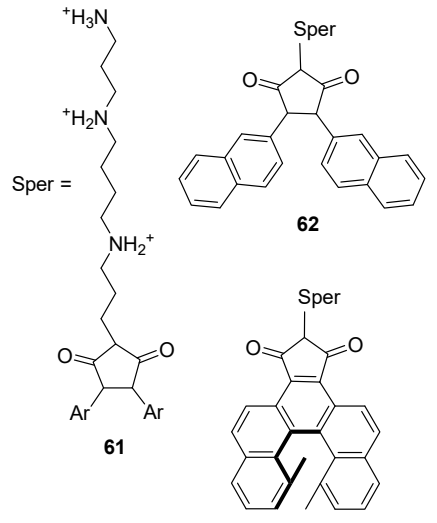

(P)-64

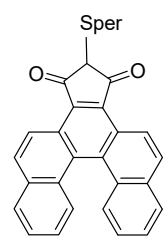

63

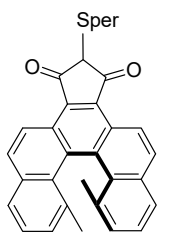

(M)-64

Figure 36. Structures of several spermine-conjugated ligands.
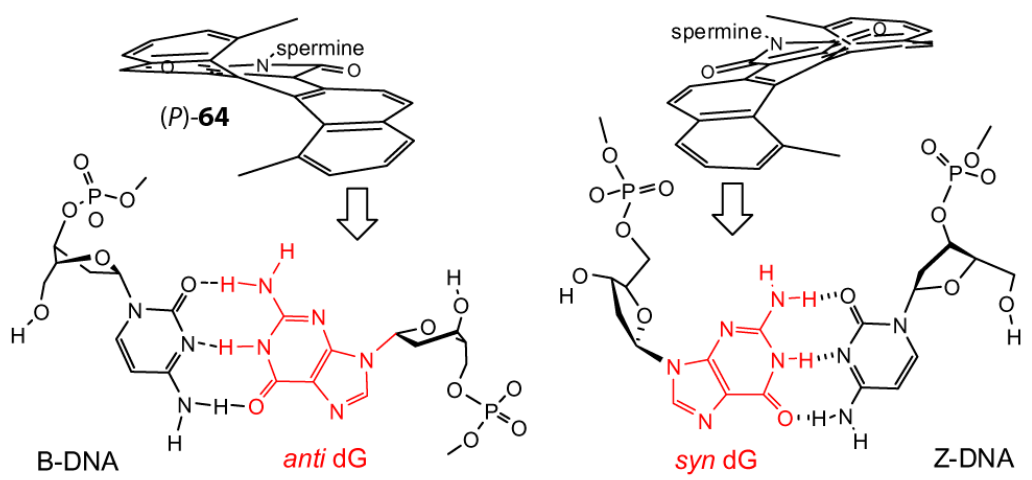

Scheme 10. Schematic illustration of B-DNA and Z-DNA intermediate complexes with $(P)-64$ and $(M)-64$.

Electrostatic interactions of cationic spermine 64 along the phosphate backbone of the DNA minor groove led to the steric hindrance in the case of Z-DNA and (M)-64. Qu et al. [309] reported that an 
anticancer agent (+)-dunorubicin and its novel (-)-enantiomer (WP 900) exhibited enantioselectivity in binding to DNA.

Apart from the above-mentioned chiral inductors, complex structures containing large aromatic ensembles can exert a discriminatory effect on DNA. Doi et al. [310] found that spermine achiral conjugate 65 affected the $\mathrm{B} \rightarrow Z$ transition of $\mathrm{d}(\mathrm{CGCGCG})_{2}$ at a low salt concentration. Haque et al. [311] observed an opposite transition of left-handed Z-DNA into B-DNA in the presence of benzophenanthridine plant alkaloid chelerythrine $6 \mathbf{6 6}$.

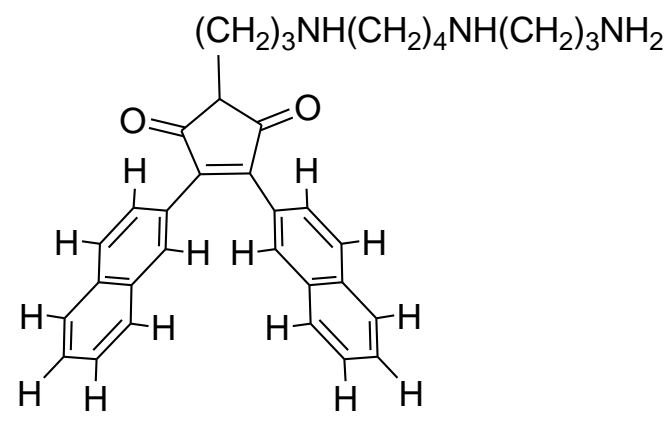

65<smiles></smiles>

66

An analysis of the discriminatory ability of irradiations and electromagnetic fields to initiate DNA degradation shows that almost each of them exerts impact on DNA, alone or jointly with some other factors. For example, a magnetic field with an extremely low frequency can induce a DNA double-strand break (the most potent form of DNA damage and genomic instability) [312]. A similar effect was observed for DNA marker exposure under a pulsed magnetic field $(25 \mathrm{~Hz})$ [313]. The pulsed magnetic field increased a spontaneous genomic DNA degradation in this case. The pulsed magnetic field enhanced the cell-killing effect of UV radiation [314].

Impact of the electromagnetic field on DNA obeys the same pattern as that of the magnetic field. It appears that a stable electromagnetic field does not affect DNA. These are only low frequency electromagnetic fields that exert a genotoxic effect on DNA [315]. For example, $50 \mathrm{~Hz}$ low frequency electromagnetic fields enhanced cell proliferation and DNA damage [316]. Genotoxic effects were observed in human fibroblasts after intermittent exposure to $50 \mathrm{~Hz}$ electromagnetic fields [317] (see also [318,319]). Regretfully, a combination of two factors (ionizing radiation and a presence of organic salts) is required to protect DNA from damage. Zheng and Sanche [320] marked that organic salts were efficient in protecting DNA from damage by electrons of $1 \mathrm{eV}$ to $60 \mathrm{keV}$. The authors suggest that anions of organic salts create additional electric fields within the DNA groove which protect the molecule (see also [321]).

Therefore, usually, a low frequency electromagnetic or a low frequency magnetic field (alone or in combination with other factors) can affect DNA; however, some scientists disagree with this opinion [322,323].

Investigations of the static magnetic field effect on DNA have led to less definite conclusions. Li et al. [324] showed that a "magnetic field could potentiate the activity of oxidant radicals" and could bring about "both stabilizing and destabilizing effects to DNA". According to Ruiz-Gomez et al. [325] the magnetic field effect on DNA is not certain. Aydin et al. [326] believe that a low intensity static magnetic field may trigger genomic instability. "But this genotoxic effect of the magnetic field, however, is minimized in living organisms due to the presence of protectic cellular responses" [327] (see, however [328]).

This assumption has sound grounds. It is now known that each type of DNA damage corresponds to a certain repair mechanism in a living cell such as nucleotide excision repair, base excision repair, mismatch repair, and so on [329]. It is logical to assume that impact of a stable factor of the Earth's 
magnetic field over millions of years of evolution has led to the development of a living cell protective mechanism, alongside with a corresponding DNA repair mechanism. However, since the pulsed magnetic field is not found in nature, DNA has no protective mechanism from it. Probably, that is why the static magnetic field has little effect on DNA and the cell in vivo whereas the pulsated magnetic field affects DNA and the cell radically [320-322,330]. According to the same logic we can suggest that periodic long-term gravitational pulsations (lunar tides), as a common phenomenon on Earth, have a protective mechanism against DNA damage (corresponding DNA repair mechanism) whereas static gravitation is uncommon for living organisms on Earth. Indeed, gravitational impact on the Moon (by Earth) has no pulsation. This impact is constant because only one side of the Moon faces the Earth. Therefore, living organisms may have difficulties with the $B-Z$ DNA transition as there is no protection from static gravity.

\section{Conclusions}

An obvious advantage of the right-handed helical structure of the most important biological macromolecules is possible evidence of the existence of an external chiral inductor with similar symmetry.

Effects of chiral and racemic fields as possible inductors and conductors of the corresponding influence explain chemical processes with mirror symmetry breaking or retention.

It is possible that the mirror symmetry effect of a racemic field generates additional energy for material objects. This effect may probably explain the mesostructure of galaxies or the formation of chiral crystals of different signs in equal proportions in Earth's deposits. Also, this effect may account for the difference in the physical properties of racemic and enantiomeric crystals (Wallach's rule) or spontaneous chiral ordering of achiral molecules in the form of domains of different chirality signs in approximately equal proportions. The physical basis of mirror symmetry breaking and mirror symmetry retention effects can be found in stochastic chemical reactions running by two routes: with the formation either of racemic or chiral products.

External inductor's impact on these reactions and processes has been also discussed. This influence corresponds to the mesostructure of our Galaxy as a source of chiral and racemic gravitational fields. The fields can serve as a chiral (chiral environment) or racemic inductor and trigger.

These fields, in turn, can affect all biological processes in living organisms. This is especially relevant for Z-DNA areas of native DNA damage with the left-handed conformational conversion. Indeed, there are mechanisms in Nature that protect DNA from destructive factors (mismatch repair, nucleotide or base excision repair, oxidative defects repair, and so on). It is highly likely that Nature has a corresponding DNA repair mechanism against DNA conformational damage caused by the pulsed gravitational field of Earth (Moon tides). Changing of this status quo in lunar settlements (stable gravity and zero magnetic field) can be dangerous for living organisms. Indeed, it is possible that DNA molecules (especially Z-DNA fragments) in organisms placed in the other chiral gravitational environment could behave via a different mechanism and become more vulnerable. Moreover, the corresponding DNA repair mechanism will function in a different manner.

Author Contributions: The contribution of the authors is equivalent and approximately proportional to their order in order.

Funding: Work on the review received no external funding.

Conflicts of Interest: The authors declare no conflict of interest, financial or otherwise.

\section{References}

1. Curie, P. Sur la symétrie dans les phénomènes physiques, symétrie d'un champ électrique et d'un champ magnétique. J. Phys. Theor. Appl. 1894, 3, 393-415. [CrossRef]

2. Pavlov, V.A. C2 and C1 Symmetry of chiral auxiliaries in catalytic reactions on metal complexes. Tetrahedron 2008, 64, 1147-1179. [CrossRef] 
3. Pavlov, V.A.; Klabunovskii, E.I. The origin of homochirality in nature: A possible version. Russ. Chem. Rev. 2015, 84, 121-133. [CrossRef]

4. Pavlov, V.; Klabunovskii, E. Homochirality Origin in Nature: Possible Versions. Curr. Org. Chem. 2014, 18, 93-114. [CrossRef]

5. Breslow, R. Formation of L Amino Acids and D Sugars, and Amplification of their Enantioexcesses in Aqueous Solutions, Under Simulated Prebiotic Conditions. Isr. J. Chem. 2011, 51, 990-996. [CrossRef]

6. Weissbuch, I.; Lahav, M. Crystalline architectures as templates of relevance to the origins of homochirality. Chem. Rev. 2011, 111, 3236-3267. [CrossRef] [PubMed]

7. Meierhenrich, U.J. Amino Acids and the Asymmetry of Life. Eur. Rev. 2013, 21, 190-199. [CrossRef]

8. Lente, G. Open system approaches in deterministic models of the emergence of homochirality. Chirality 2010, 22, 907-913. [CrossRef]

9. Toxvaerd, S. Origin of homochirality in biosystems. Int. J. Mol. Sci. 2009, 10, 1290-1299. [CrossRef] [PubMed]

10. Plasson, R.; Kondepudi, D.K.; Bersini, H.; Commeyras, A.; Asakura, K. Emergence of homochirality in far-from-equilibrium systems: Mechanisms and role in prebiotic chemistry. Chirality 2007, 19, 589-600. [CrossRef]

11. Pizzarello, S. The chemistry of life's origin: A carbonaceous meteorite perspective. Acc. Chem. Res. 2006, 39, 231-237. [CrossRef]

12. Jorissen, A.; Cerf, C. Asymmetric Photoreactions as the Origin of Biomolecular Homochirality: A Critical Review. Orig. Life Evol. Biosph. 2002, 32, 129-142. [CrossRef]

13. Podlech, J. Origin of organic molecules and biomolecular homochirality. Cell Mol. Life Sci. 2001, 58, 44-60. [CrossRef]

14. Feringa, B.L.; van Delden, R.A. Absolute Asymmetric Synthesis: The Origin, Control, and Amplification of Chirality. Angew. Chem. Int. Ed. 1999, 38, 3418-3438. [CrossRef]

15. Prelog, V. Chirality in chemistry. Science 1976, 193, 17-24. [CrossRef]

16. Chandrasekhar, S. Molecular homochirality and the parity-violating energy difference. A critique with new proposals. Chirality 2008, 20, 84-95. [CrossRef]

17. Carroll, J.D. A new definition of life. Chirality 2009, 21, 354-358. [CrossRef] [PubMed]

18. Kuttel, M.; Ravenscroft, N.; Foschiatti, M.; Cescutti, P.; Rizzo, R. Conformational properties of two exopolysaccharides produced by Inquilinus limosus, a cystic fibrosis lung pathogen. Carbohydr. Res. 2012, 350, 40-48. [CrossRef]

19. Hsien-Chih, H.W.; Sarko, A. The double-helical molecular structure of crystalline a-amylose. Carbohydr. Res. 1978, 61, 27-40. [CrossRef]

20. Hsein-Chih, H.W.; Sarko, A. The double-helical molecular structure of crystalline b-amylose. Carbohydr. Res. 1978, 61, 7-25. [CrossRef]

21. French, A.; Zaslow, B. Conformation of the "V" amylose helix. J. Chem. Soc. Chem. Commun. 1972, 0, 41-42. [CrossRef]

22. Sarko, A.; Biloski, A. Crystal structure of the koh-amylose complex. Carbohydr. Res. 1980, 79, 11-21. [CrossRef]

23. Nishiyama, Y.; Mazeau, K.; Morin, M.; Cardoso, M.B.; Chanzy, H.; Putaux, J.-L. Molecular and Crystal Structure of 7-Fold V-Amylose Complexed with 2-Propanol. Macromolecules 2010, 43, 8628-8636. [CrossRef]

24. Lopez, C.A.; de Vries, A.H.; Marrink, S.J. Amylose folding under the influence of lipids. Carbohydr. Res. 2012, 364, 1-7. [CrossRef]

25. Janaswamy, S.; Chandrasekaran, R. Heterogeneity in iota-carrageenan molecular structure: Insights for polymorph II->III transition in the presence of calcium ions. Carbohydr. Res. 2008, 343, 364-373. [CrossRef]

26. Matsuda, Y.; Biyajima, Y.; Sato, T. Thermal Denaturation, Renaturation, and Aggregation of a Double-Helical Polysaccharide Xanthan in Aqueous Solution. Polym. J. 2009, 41, 526. [CrossRef]

27. Sheehan, J.K.; Gardner, K.H.; Atkins, E.D.T. Hyaluronic acid: A double-helical structure in the presence of potassium at low $\mathrm{pH}$ and found also with the cations ammonium, rubidium and caesium. J. Mol. Biol. 1977, 117, 113-135. [CrossRef]

28. Numata, M.; Shinkai, S. 'Supramolecular wrapping chemistry' by helix-forming polysaccharides: A powerful strategy for generating diverse polymeric nano-architectures. Chem. Commun. 2011,47,1961-1975. [CrossRef]

29. Pavlov, V.; Pavlova, T. Paradoxes of Symmetry: Homochirality; Cryptochiral Reactions; Chiral Field, Memory, and Induction; Chiral and Racemic Environment. Curr. Org. Chem. 2017, 21, 872-888. [CrossRef] 
30. Wang, X.; Zhang, Y.; Zhang, L.; Ding, Y. Multiple conformation transitions of triple helical lentinan in DMSO/water by microcalorimetry. J. Phys. Chem. B 2009, 113, 9915-9923. [CrossRef]

31. Bocchinfuso, G.; Mazzuca, C.; Sandolo, C.; Margheritelli, S.; Alhaique, F.; Coviello, T.; Palleschi, A. Guar gum and scleroglucan interactions with borax: Experimental and theoretical studies of an unexpected similarity. J. Phys. Chem. B 2010, 114, 13059-13068. [CrossRef] [PubMed]

32. Miyoshi, K.; Uezu, K.; Sakurai, K.; Shinkai, S. Inter-chain and arrayed hydrogen bonds in $\beta-1,3-d-x y l a n$ triple helix predicted by quantum mechanics calculation. Carbohydr. Polym. 2006, 66, 352-356. [CrossRef]

33. Okobira, T.; Miyoshi, K.; Uezu, K.; Sakurai, K.; Shinkai, S. Molecular dynamics studies of side chain effect on the beta-1,3-D-glucan triple helix in aqueous solution. Biomacromolecules 2008, 9, 783-788. [CrossRef] [PubMed]

34. Villares, A. Polysaccharides from the edible mushroom Calocybe gambosa: Structure and chain conformation of a (1->4),(1->6)-linked glucan. Carbohydr. Res. 2013, 375, 153-157. [CrossRef]

35. Gagnon, M.A.; Lafleur, M. From curdlan powder to the triple helix gel structure: An attenuated total reflection-infrared study of the gelation process. Appl. Spectrosc. 2007, 61, 374-378. [CrossRef]

36. Harrington, J.C.; Morris, E.R. Conformational ordering and gelation of gelatin in mixtures with soluble polysaccharides. Food Hydrocoll. 2009, 23, 327-336. [CrossRef]

37. Yanaki, T.; Norisuye, T.; Fujita, H. Triple Helix of Schizophyllum commune Polysaccharide in Dilute Solution. 3. Hydrodynamic Properties in Water. Macromolecules 1980, 13, 1462-1466. [CrossRef]

38. Yanaki, T.; Ito, W.; Tabata, K.; Kojima, T.; Norisuye, T.; Takano, N.; Fujita, H. Correlation between the antitumor activity of a polysaccharide schizophyllan and its triple-helical conformation in dilute aqueous solution. Biophys. Chem. 1983, 17, 337-342. [CrossRef]

39. Pavlov, V.A.; Zlotin, S.G. Homochirality, Stochastic Chiral Reactions, Spontaneous Chiral Ordering of Achiral Molecules, and Similar Chiral Effects. Is there a Physical Basis for these Mirror Symmetry Breaking Phenomena? Curr. Org. Chem. 2018, 22, 2029-2054. [CrossRef]

40. Davankov, V. Chirality as an inherent general property of matter. Chirality 2006, 18, 459-461. [CrossRef]

41. Kane, A.; Shao, R.-F.; Maclennan, J.E.; Wang, L.; Walba, D.M.; Clark, N.A. Cover Picture: Electric Field-Driven Deracemization (ChemPhysChem 1/2007). ChemPhysChem 2007, 8, 170-174. [CrossRef] [PubMed]

42. Baranova, N.B.; Zel'dovich, B.Y. Separation of mirror isomeric molecules by radio-frequency electric field of rotating polarization. Chem. Phys. Lett. 1978, 57, 435-437. [CrossRef]

43. Pavlov, V.A. Mechanisms of asymmetric induction in catalytic hydrogenation, hydrosilylation and cross-coupling on metal complexes. Russ. Chem. Rev. 2002, 71, 33-48. [CrossRef]

44. Klabunovskii, E.I. Homochirality and its significance for biosphere and the origin of life theory. Russ. J. Org. Chem. 2012, 48, 881-901. [CrossRef]

45. Takano, Y.; Takahashi, J.-I.; Kaneko, T.; Marumo, K.; Kobayashi, K. Asymmetric synthesis of amino acid precursors in interstellar complex organics by circularly polarized light. Earth Planet. Sci. Lett. 2007, 254, 106-114. [CrossRef]

46. Managadze, G.G.; Engel, M.H.; Getty, S.; Wurz, P.; Brinckerhoff, W.B.; Shokolov, A.G.; Sholin, G.V.; Terent'ev, S.A.; Chumikov, A.E.; Skalkin, A.S.; et al. Excess of L-alanine in amino acids synthesized in a plasma torch generated by a hypervelocity meteorite impact reproduced in the laboratory. Planet. Space Sci. 2016, 131, 70-78. [CrossRef]

47. Davankov, V.A. Inherent homochirality of primary particles and meteorite impacts as possible source of prebiotic molecular chirality. Russ. J. Phys. Chem. A 2009, 83, 1247-1256. [CrossRef]

48. Ivanova, T.A.; Kuznettsov, S.N.; Logachev, Y.I.; Sosnovetc, E.N. North-south asymmetry and anisotropy of solar cosmic rays during the flare of April18, 1972. Kosmicheskie Issledovaniya 1976, 14, 235-238.

49. Svirzhevsky, N.S.; Svirzhevskaya, A.K.; Bazilevskaya, G.A.; Stozhkov, Y.I. North-South asymmetry in cosmic ray fluxes as measured in the stratosphere and in selected solar wind parameters in the near-Earth space. Adv. Space Res. 2005, 35, 671-676. [CrossRef]

50. Barron, L.D. True and false chirality and absolute asymmetric synthesis. J. Am. Chem. Soc. 1986, 108, 5539-5542. [CrossRef]

51. He, Y.J.; Qi, F.; Qi, S.C. Earth's orbital chirality and driving force of biomolecular evolution. Med. Hypotheses 2001, 56, 493-496. [CrossRef]

52. Stone, E.C.; Cummings, A.C.; McDonald, F.B.; Heikkila, B.C.; Lal, N.; Webber, W.R. Voyager 1 explores the termination shock region and the heliosheath beyond. Science 2005, 309, 2017-2020. [CrossRef] 
53. Shu, F.H. The Physical Universe: An Introduction to Astronomy; University Science Books, Mill Valley, CA: Sasalito, CA, USA, 1982.

54. Decker, R.B.; Krimigis, S.M.; Roelof, E.C.; Hill, M.E.; Armstrong, T.P.; Gloeckler, G.; Hamilton, D.C.; Lanzerotti, L.J. Voyager 1 in the foreshock, termination shock, and heliosheath. Science 2005, 309, 2020-2024. [CrossRef]

55. Vidal-Madjar, A.; Laurent, C.; Bruston, P.; Audouze, J. Is the solar system entering a nearby interstellar cloud. Astrophys. J. 1978, 223. [CrossRef]

56. Grande, C.; Patel, N.H. Nodal signalling is involved in left-right asymmetry in snails. Nature 2009, 457, 1007-1011. [CrossRef]

57. Mineo, P.; Villari, V.; Scamporrino, E.; Micali, N. New Evidence about the Spontaneous Symmetry Breaking: Action of an Asymmetric Weak Heat Source. J. Phys. Chem. B 2015, 119, 12345-12353. [CrossRef]

58. Erschov, V.E.; Cantor, J.I. Sea Shells. Concise Guide; “Kursiv”: Moscow, Russia, 2008.

59. Reiss, H.R. Nuclear beta decay induced by intense electromagnetic fields: Basic theory. Phys. Rev. C 1983, 27, 1199-1228. [CrossRef]

60. Fischbach, E.; Buncher, J.B.; Gruenwald, J.T.; Jenkins, J.H.; Krause, D.E.; Mattes, J.J.; Newport, J.R. Time-Dependent Nuclear Decay Parameters: New Evidence for New Forces? Space Sci. Rev. 2009, 145, 285-335. [CrossRef]

61. Fischbach, E.; Chen, K.J.; Gold, R.E.; Goldsten, J.O.; Lawrence, D.J.; McNutt, R.J.; Rhodes, E.A.; Jenkins, J.H.; Longuski, J. Solar influence on nuclear decay rates: Constraints from the MESSENGER mission. Astrophys. Space Sci. 2011, 337, 39-45. [CrossRef]

62. Sturrock, P.A.; Buncher, J.B.; Fischbach, E.; Javorsek, D., II; Jenkins, J.H.; Mattes, J.J. Concerning the Phases of the Annual Variations of Nuclear Decay Rates. Astrophys. J. 2011, 737. [CrossRef]

63. Silverman, M.P. Search for anomalies in the decay of radioactive Mn-54. EPL 2016, 114, 62001. [CrossRef]

64. O'Keefe, D.; Morreale, B.L.; Lee, R.H.; Buncher, J.B.; Jenkins, J.H.; Fischbach, E.; Gruenwald, T.; Javorsek, D.; Sturrock, P.A. Spectral content of $22 \mathrm{Na} / 44 \mathrm{Ti}$ decay data: Implications for a solar influence. Astrophys. Space Sci. 2013, 344, 297-303. [CrossRef]

65. Norman, E.B.; Browne, E.; Shugart, H.A.; Joshi, T.H.; Firestone, R.B. Evidence against correlations between nuclear decay rates and Earth-Sun distance. Astropart. Phys. 2009, 31, 135-137. [CrossRef]

66. El-Borie, M.A.; El-Abshehy, M.; Talaat, S.; Taleb, W.M.A. North-south asymmetry in solar, interplanetary, and geomagnetic indices. Astrophysics 2012, 55, 127-139. [CrossRef]

67. Kondepudi, D.K.; Kaufman, R.J.; Singh, N. Chiral symmetry breaking in sodium chlorate crystallizaton. Science 1990, 250, 975-976. [CrossRef]

68. Kondepudi, D.K.; Asakura, K. Chiral Autocatalysis, Spontaneous Symmetry Breaking, and Stochastic Behavior. Acc. Chem. Res. 2001, 34, 946-954. [CrossRef]

69. Kondepudi, D.K.; Laudadio, J.; Asakura, K. Chiral Symmetry Breaking in Stirred Crystallization of 1,1'-Binaphthyl Melt. J. Am. Chem. Soc. 1999, 121, 1448-1451. [CrossRef]

70. Asakura, K.; Soga, T.; Uchida, T.; Osanai, S.; Kondepudi, D.K. Probability distributions of enantiomeric excess in unstirred and stirred crystallization of 1,1'-binaphthyl melt. Chirality 2002, 14, 85-89. [CrossRef]

71. Cintas, P.; Viedma, C. On the physical basis of asymmetry and homochirality. Chirality 2012, 24, 894-908. [CrossRef]

72. Viedma, C. Chiral symmetry breaking during crystallization: Complete chiral purity induced by nonlinear autocatalysis and recycling. Phys. Rev. Lett. 2005, 94, 065504. [CrossRef]

73. Kondepudi, D.K.; Bullock, K.L.; Digits, J.A.; Hall, J.K.; Miller, J.M. Kinetics of chiral symmetry breaking in crystallization. J. Am. Chem. Soc. 1993, 115, 10211-10216. [CrossRef]

74. McBride, J.M.; Carter, R.L. Spontaneous Resolution by Stirred Crystallization. Angew. Chem. Int. Ed. Engl. 1991, 30, 293-295. [CrossRef]

75. Tsogoeva, S.B.; Wei, S.; Freund, M.; Mauksch, M. Generation of highly enantioenriched crystalline products in reversible asymmetric reactions with racemic or achiral catalysts. Angew. Chem. Int. Ed. Engl. 2009, 48, 590-594. [CrossRef]

76. Wei, S.; Mauksch, M.; Tsogoeva, S.B. Autocatalytic enantiomerisation at the crystal surface in deracemisation of scalemic conglomerates. Chemistry 2009, 15, 10255-10262. [CrossRef] [PubMed]

77. Kondepudi, D.K.; Bullock, K.L.; Digits, J.A.; Yarborough, P.D. Stirring Rate as a Critical Parameter in Chiral Symmetry Breaking Crystallization. J. Am. Chem. Soc. 1995, 117, 401-404. [CrossRef] 
78. Osuna-Esteban, S.; Zorzano, M.P.; Menor-Salvan, C.; Ruiz-Bermejo, M.; Veintemillas-Verdaguer, S. Asymmetric chiral growth of micron-size $\mathrm{NaClO} 3$ crystals in water aerosols. Phys. Rev. Lett. 2008, 100, 146102. [CrossRef] [PubMed]

79. Levilain, G.; Rougeot, C.; Guillen, F.; Plaquevent, J.-C.; Coquerel, G. Attrition-enhanced preferential crystallization combined with racemization leading to redissolution of the antipode nuclei. Tetrahedron Asymmetry 2009, 20, 2769-2771. [CrossRef]

80. Cartwright, J.H.; Piro, O.; Tuval, I. Ostwald ripening, chiral crystallization, and the common-ancestor effect. Phys. Rev. Lett. 2007, 98, 165501. [CrossRef]

81. Noorduin, W.L.; Meekes, H.; van Enckevort, W.J.; Millemaggi, A.; Leeman, M.; Kaptein, B.; Kellogg, R.M.; Vlieg, E. Complete deracemization by attrition-enhanced ostwald ripening elucidated. Angew. Chem. Int. Ed. Engl. 2008, 47, 6445-6447. [CrossRef] [PubMed]

82. Cartwright, J.H.; Garcia-Ruiz, J.M.; Piro, O.; Sainz-Diaz, C.I.; Tuval, I. Chiral symmetry breaking during crystallization: An advection-mediated nonlinear autocatalytic process. Phys. Rev. Lett. 2004, 93, 035502. [CrossRef]

83. Noorduin, W.L.; van Enckevort, W.J.; Meekes, H.; Kaptein, B.; Kellogg, R.M.; Tully, J.C.; McBride, J.M.; Vlieg, E. The driving mechanism behind attrition-enhanced deracemization. Angew. Chem. Int. Ed. Engl. 2010, 49, 8435-8438. [CrossRef]

84. Plasson, R.; Kondepudi, D.K.; Asakura, K. Three-dimensional description of the spontaneous onset of homochirality on the surface of a conglomerate crystal phase. J. Phys. Chem. B 2006, 110, 8481-8487. [CrossRef]

85. El-Hachemi, Z.; Arteaga, O.; Canillas, A.; Crusats, J.; Llorens, J.; Ribo, J.M. Chirality generated by flows in pseudocyanine dye J-aggregates: Revisiting 40 years old reports. Chirality 2011, 23, 585-592. [CrossRef]

86. Noorduin, W.L.; van der Asdonk, P.; Meekes, H.; van Enckevort, W.J.; Kaptein, B.; Leeman, M.; Kellogg, R.M.; Vlieg, E. Complete chiral resolution using additive-induced crystal size bifurcation during grinding. Angew. Chem. Int. Ed. Engl. 2009, 48, 3278-3280. [CrossRef]

87. Hein, J.E.; Cao, B.H.; Viedma, C.; Kellogg, R.M.; Blackmond, D.G. Pasteur's tweezers revisited: On the mechanism of attrition-enhanced deracemization and resolution of chiral conglomerate solids. J. Am. Chem. Soc. 2012, 134, 12629-12636. [CrossRef]

88. Viedma, C.; Cintas, P. Homochirality beyond grinding: Deracemizing chiral crystals by temperature gradient under boiling. Chem. Commun. 2011, 47, 12786-12788. [CrossRef]

89. Viedma, C.; Noorduin, W.L.; Ortiz, J.E.; de Torres, T.; Cintas, P. Asymmetric amplification in amino acid sublimation involving racemic compound to conglomerate conversion. Chem. Commun. 2011, 47, 671-673. [CrossRef]

90. Viedma, C. Selective Chiral Symmetry Breaking during Crystallization: Parity Violation or Cryptochiral Environment in Control? Cryst. Growth Des. 2007, 7, 553-556. [CrossRef]

91. Steendam, R.R.E.; Harmsen, B.; Meekes, H.; Enckevort, W.J.P.v.; Kaptein, B.; Kellogg, R.M.; Raap, J.; Rutjes, F.P.J.T.; Vlieg, E. Controlling the Effect of Chiral Impurities on Viedma Ripening. Cryst. Growth Des. 2013, 13, 4776-4780. [CrossRef]

92. Zhang, Q.; Jia, L.; Wang, J.-R.; Mei, X. Absolute asymmetric synthesis of a sanguinarine derivative through crystal-solution interactions. CrystEngComm 2016, 18, 8834-8837. [CrossRef]

93. Spix, L.; Meekes, H.; Blaauw, R.H.; van Enckevort, W.J.P.; Vlieg, E. Complete Deracemization of Proteinogenic Glutamic Acid Using Viedma Ripening on a Metastable Conglomerate. Cryst. Growth Des. 2012, 12, 5796-5799. [CrossRef]

94. El-Hachemi, Z.; Crusats, J.; Ribo, J.M.; McBride, J.M.; Veintemillas-Verdaguer, S. Metastability in supersaturated solution and transition towards chirality in the crystallization of $\mathrm{NaClO}_{3}$. Angew. Chem. Int. Ed. Engl. 2011, 50, 2359-2363. [CrossRef]

95. Medina, D.D.; Gedanken, A.; Mastai, Y. Chiral amplification in crystallization under ultrasound radiation. Chemistry 2011, 17, 11139-11142. [CrossRef]

96. Han, B.; Shen, F.; Su, H.; Zhang, X.; Shen, Y.; Zhang, T. Self-assembly of achiral monomer into left-handed helical polyanthracene nanofibers. Mater. Express 2016, 6, 88-92. [CrossRef]

97. Ziach, K.; Jurczak, J. Mirror symmetry breaking upon spontaneous crystallization from a dynamic combinatorial library of macrocyclic imines. Chem. Commun. 2015, 51, 4306-4309. [CrossRef] 
98. Yagishita, F.; Kato, M.; Uemura, N.; Ishikawa, H.; Yoshida, Y.; Mino, T.; Kasashima, Y.; Sakamoto, M. Asymmetric Synthesis Using Chiral Crystals of Coumarin-3-carboxamides and Carbenoids. Chem. Lett. 2016, 45, 1310-1312. [CrossRef]

99. Sakamoto, M.; Kato, M.; Aida, Y.; Fujita, K.; Mino, T.; Fujita, T. Photosensitized $2+2$ cycloaddition reaction using homochirality generated by spontaneous crystallization. J. Am. Chem. Soc. 2008, 130, 1132-1133. [CrossRef]

100. Sakamoto, M.; Yagishita, F.; Ando, M.; Sasahara, Y.; Kamataki, N.; Ohta, M.; Mino, T.; Kasashima, Y.; Fujita, T. Generation and amplification of optical activity of axially chiral $N$-(1-naphthyl)-2(1H) pyrimidinethione by crystallization. Org. Biomol. Chem. 2010, 8, 5418-5422. [CrossRef]

101. Fujiki, M. Helix Magic. Thermo-Driven Chiroptical Switching and Screw-Sense Inversion of Flexible Rod Helical Polysilylenes. J. Am. Chem. Soc. 2000, 122, 3336-3343. [CrossRef]

102. Fujiki, M. Optically Active Polysilylenes: State-of-the-Art Chiroptical Polymers. Macromol. Rapid Commun. 2001, 22, 539-563. [CrossRef]

103. Fujiki, M. Helix Generation, Amplification, Switching, and Memory of Chromophoric Polymers. In Amplification of Chirality; Soai, K., Ed.; Springer: Berlin/Heidelberg, Germany, 2008; pp. 119-186. [CrossRef]

104. Tabei, J.; Nomura, R.; Sanda, F.; Masuda, T. Design of Helical Poly(N-propargylamides) that Switch the Helix Sense with Thermal Stimuli. Macromolecules 2004, 37, 1175-1179. [CrossRef]

105. Koe, J.R.; Fujiki, M.; Nakashima, H.; Motonaga, M. Tempera ture-dependent helix-helix transition of an optically active poly(diarylsilylene). Chem. Commun. 2000, 389-390. [CrossRef]

106. Watanabe, J.; Okamoto, S.; Satoh, K.; Sakajiri, K.; Furuya, H.; Abe, A. Reversible Helix-Helix Transition of Poly( $\beta$-phenylpropyllaspartate) Involving a Screw-Sense Inversion in the Solid State. Macromolecules 1996, 29, 7084-7088. [CrossRef]

107. Yashima, E.; Maeda, K.; Sato, O. Switching of a Macromolecular Helicity for Visual Distinction of Molecular Recognition Events. J. Am. Chem. Soc. 2001, 123, 8159-8160. [CrossRef]

108. Green, M.M.; Park, J.-W.; Sato, T.; Teramoto, A.; Lifson, S.; Selinger, R.L.B.; Selinger, J.V. The Macromolecular Route to Chiral Amplification. Angew. Chem. Int. Ed. 1999, 38, 3138-3154. [CrossRef]

109. Okamoto, Y.; Nakano, T.; Ono, E.; Hatada, K. Synthesis and Reversible Stereomutation of Optically Active Poly[(S)-diphenyl(1-methylpyrrolidin-2-yl)methyl methacrylate]. Chemistry Letters 1991, 20, 525-528. [CrossRef]

110. Gu, H.; Nakamura, Y.; Sato, T.; Teramoto, A.; Green, M.M.; Andreola, C.; Peterson, N.C.; Lifson, S. Molecular-Weight Dependence of the Optical Rotation of Poly((R)-2-deuterio-n-hexyl isocyanate). Macromolecules 1995, 28, 1016-1024. [CrossRef]

111. Okamoto, N.; Mukaida, F.; Gu, H.; Nakamura, Y.; Sato, T.; Teramoto, A.; Green, M.M.; Andreola, C.; Peterson, N.C.; Lifson, S. Molecular Weight Dependence of the Optical Rotation of Poly((R)-1-deuterio-n-hexyl isocyanate) in Dilute Solution. Macromolecules 1996, 29, 2878-2884. [CrossRef]

112. Cai, Y.; Bernasek, S.L. Adsorption-induced asymmetric assembly from an achiral adsorbate. J. Am. Chem. Soc. 2004, 126, 14234-14238. [CrossRef]

113. Humblot, V.; Lorenzo, M.O.; Baddeley, C.J.; Haq, S.; Raval, R. Local and global chirality at surfaces: Succinic acid versus tartaric acid on Cu110. J. Am. Chem. Soc. 2004, 126, 6460-6469. [CrossRef]

114. Raval, R. Chiral expression from molecular assemblies at metal surfaces: Insights from surface science techniques. Chem. Soc. Rev. 2009, 38, 707-721. [CrossRef]

115. Elemans, J.A.; De Cat, I.; Xu, H.; De Feyter, S. Two-dimensional chirality at liquid-solid interfaces. Chem. Soc. Rev. 2009, 38, 722-736. [CrossRef]

116. Ernst, K.H. Surface chemistry: Single handedness in flatland. Nat. Chem. 2017, 9, 195-196. [CrossRef]

117. Satyanarayana, T.; Abraham, S.; Kagan, H.B. Nonlinear effects in asymmetric catalysis. Angew. Chem. Int. Ed. Engl. 2009, 48, 456-494. [CrossRef]

118. Ercolani, G. Principles for designing an achiral receptor promoting asymmetric autocatalysis with amplification of chirality. Tetrahedron Asymmetry 2014, 25, 405-410. [CrossRef]

119. Steigelmann, M.; Nisar, Y.; Rominger, F.; Goldfuss, B. Homo- and Heterochiral Alkylzinc Fencholates: Linear or Nonlinear Effects in Dialkylzinc Additions to Benzaldehyde. Chem. Eur. J. 2002, 8, 5211-5218. [CrossRef]

120. Chen, Y.K.; Costa, A.M.; Walsh, P.J. Substrate Dependence of Nonlinear Effects: Mechanistic Probe and Practical Applications. J. Am. Chem. Soc. 2001, 123, 5378-5379. [CrossRef] 
121. Balsells, J.; Davis, T.J.; Carroll, P.; Walsh, P.J. Insight into the Mechanism of the Asymmetric Addition of Alkyl Groups to Aldehydes Catalyzed by Titanium-BINOLate Species. J. Am. Chem. Soc. 2002, 124, 10336-10348. [CrossRef]

122. Mori, M.; Imma, H.; Nakai, T. Asymmetric Catalytic Cyanosilylation of Aldehydes Using a Chiral Binaphthol-Titanium Complex. Tetrahedron Lett. 1997, 38, 6229-6232. [CrossRef]

123. Kitamura, M.; Suga, S.; Oka, H.; Noyori, R. Quantitative Analysis of the Chiral Amplification in the Amino Alcohol-Promoted Asymmetric Alkylation of Aldehydes with Dialkylzincs. J. Am. Chem. Soc. 1998, 120, 9800-9809. [CrossRef]

124. Hua, Y.Z.; Han, X.W.; Yang, X.C.; Song, X.; Wang, M.C.; Chang, J.B. Enantioselective Friedel-Crafts alkylation of pyrrole with chalcones catalyzed by a dinuclear zinc catalyst. J. Org. Chem. 2014, 79, 11690-11699. [CrossRef]

125. Du, H.; Long, J.; Hu, J.; Li, X.; Ding, K. 3,3'-Br2-BINOL-Zn complex: A highly efficient catalyst for the enantioselective hetero-Diels-Alder reaction. Org. Lett. 2002, 4, 4349-4352. [CrossRef]

126. Yearick, K.; Wolf, C. Catalytic enantioselective addition of diethylzinc to trifluoromethyl ketones. Org. Lett. 2008, 10, 3915-3918. [CrossRef]

127. ShengJian, L.; Yaozhong, J.; Aiqiao, M. Asymmetric synthesis XVII. New chiral catalysts for the stereocontrolled addition of benzaldehyde by diethylzinc. Tetrahedron Asymmetry 1992, 3, 1467-1474. [CrossRef]

128. Soai, K.; Ookawa, A.; Kaba, T.; Ogawa, K. Catalytic asymmetric induction. Highly enantioselective addition of dialkylzincs to aldehydes using chiral pyrrolidinylmethanols and their metal salts. J. Am. Chem. Soc. 1987, 109, 7111-7115. [CrossRef]

129. Yang, X.; Shen, J.; Da, C.; Wang, R.; Choi, M.C.K.; Yang, L.; Wong, K.-Y. Chiral pyrrolidine derivatives as catalysts in the enantioselective addition of diethylzinc to aldehydes. Tetrahedron Asymmetry 1999, 10, 133-138. [CrossRef]

130. Ding, K.; Ishii, A.; Mikami, K. Super High Throughput Screening (SHTS) of Chiral Ligands and Activators: Asymmetric Activation of Chiral Diol-Zinc Catalysts by Chiral Nitrogen Activators for the Enantioselective Addition of Diethylzinc to Aldehydes. Angew. Chem. Int. Ed. 1999, 38, 497-501. [CrossRef]

131. Vyskočil, Š.; Jaracz, S.; Smrčina, M.; Štícha, M.; Hanuš, V.; Polášek, M.; Kočovský, P. Synthesis of N-Alkylated and N-Arylated Derivatives of 2-Amino-2'-hydroxy-1,1'-binaphthyl (NOBIN) and 2,2'-Diamino-1,1'-binaphthyl and Their Application in the Enantioselective Addition of Diethylzinc to Aromatic Aldehydest. J. Org. Chem. 1998, 63, 7727-7737. [CrossRef]

132. Le Goanvic, D.; Holler, M.; Pale, P. Chiral tridentate versus bidentate pyridines as catalysts in the enantioselective alkylation of benzaldehyde with diethylzinc. Tetrahedron Asymmetry 2002, 13, 119-121. [CrossRef]

133. Rosner, T.; Sears, P.J.; Nugent, W.A.; Blackmond, D.G. Kinetic Investigations of Product Inhibition in the Amino Alcohol-Catalyzed Asymmetric Alkylation of Benzaldehyde with Diethylzinc. Org. Lett. 2000, 2, 2511-2513. [CrossRef]

134. Chen, S.-K.; Peng, D.; Zhou, H.; Wang, L.-W.; Chen, F.-X.; Feng, X.-M. Highly Enantioselective Cyanoformylation of Aldehydes Catalyzed by a Mononuclear Salen-Ti(OiPr)4 Complex Produced In Situ. Eur. J. Org. Chem. 2007, 2007, 639-644. [CrossRef]

135. Bandini, M.; Cozzi, P.G.; Umani-Ronchi, A. Enantioselective catalytic addition of allyl organometallic reagents to aldehydes promoted by $[\mathrm{Cr}($ Salen)]: The hidden role played by weak Lewis acids in metallo-Salen promoted reactions. Tetrahedron 2001, 57, 835-843. [CrossRef]

136. Mikami, K.A.; Yamanaka, M. Negative nonlinear effect in aquo palladium catalysis depending on tropos biphenylphosphine ligand chirality controlled by chiral diaminobinaphthyl activator. Pure Appl. Chem. 2004, 76, 537-540. [CrossRef]

137. Feng, X.; Liu, Y.; Liu, X.; Xin, J. Asymmetric Cyanosilylation of Aldehydes Catalyzed by Novel Chiral Tetraaza-Titanium Complexes. Synlett 2006, 2006, 1085-1089. [CrossRef]

138. Gamez, P.; Fache, F.; Mangeney, P.; Lamaire, M. Enantioselective catalytic reduction of ketones using C2-symmetric diamines as chiral ligands. Tetrahedron Lett. 1993, 34, 6897-6898. [CrossRef]

139. Spogliarich, R.; Kašpar, J.; Graziani, M.; Morandini, F. Asymmetric transfer hydrogenation of ketones catalyzed by phosphine-rhodium(I) and -iridium(I) complexes. J. Organomet. Chem. 1986, 306, 407-412. [CrossRef] 
140. Gamez, P.; Fache, F.; Lemaire, M. Asymmetric catalytic reduction of carbonyl compounds using C2 symmetric diamines as chiral ligands. Tetrahedron Asymmetry 1995, 6, 705-718. [CrossRef]

141. Brown, M.K.; Blewett, M.M.; Colombe, J.R.; Corey, E.J. Mechanism of the enantioselective oxidation of racemic secondary alcohols catalyzed by chiral $\mathrm{Mn}(\mathrm{III})$-salen complexes. J. Am. Chem. Soc. 2010, 132, 11165-11170. [CrossRef]

142. Zlotin, S.G.; Kochetkov, S.V. C2-Symmetric diamines and their derivatives as promising organocatalysts for asymmetric synthesis. Russ. Chem. Rev. 2015, 84, 1077-1099. [CrossRef]

143. Kucherenko, A.S.; Siyutkin, D.E.; Nigmatov, A.G.; Chizhov, A.O.; Zlotin, S.G. Chiral Primary Amine Tagged to Ionic Group as Reusable Organocatalyst for Asymmetric Michael Reactions of C-Nucleophiles with $\alpha, \beta$-Unsaturated Ketones. Adv. Synth. Catal. 2012, 354, 3078-3086. [CrossRef]

144. Kucherenko, A.S.; Kostenko, A.A.; Gerasimchuk, V.V.; Zlotin, S.G. Stereospecific diaza-Cope rearrangement as an efficient tool for the synthesis of DPEDA pyridine analogs and related C2-symmetric organo catalysts. Org. Biomol. Chem. 2017, 15, 7028-7033. [CrossRef]

145. Kucherenko, A.S.; Kostenko, A.A.; Zhdankina, G.M.; Kuznetsova, O.Y.; Zlotin, S.G. Green asymmetric synthesis of Warfarin and Coumachlor in pure water catalyzed by quinoline-derived 1,2-diamines. Green Chem. 2018, 20, 754-759. [CrossRef]

146. Boucherif, A.; Duan, S.-W.; Yuan, Z.-G.; Lu, L.-Q.; Xiao, W.-J. Catalytic Asymmetric Allylation of 3-Aryloxindoles by Merging Palladium Catalysis and Asymmetric H-Bonding Catalysis. Adv. Synth. Catal. 2016, 358, 2594-2598. [CrossRef]

147. Nájera, C.; Yus, M. Chiral benzimidazoles as hydrogen bonding organocatalysts. Tetrahedron Lett. 2015, 56, 2623-2633. [CrossRef]

148. Palomo, C.; Oiarbide, M.; Laso, A. Recent Advances in the Catalytic Asymmetric Nitroaldol (Henry) Reaction. Eur. J. Org. Chem. 2007, 2007, 2561-2574. [CrossRef]

149. Lisnyak, V.G.; Kucherenko, A.S.; Valeev, E.F.; $\quad$ Zlotin, S.G. (1,2-Diaminoethane-1,2-diyl)bis(N-methylpyridinium) Salts as a Prospective Platform for Designing Recyclable Prolinamide-Based Organocatalysts. J. Org. Chem. 2015, 80, 9570-9577. [CrossRef]

150. Kucherenko, A.S.; Lisnyak, V.G.; Kostenko, A.A.; Kochetkov, S.V.; Zlotin, S.G. C2-Symmetric pyrrolidine-derived squaramides as recyclable organocatalysts for asymmetric Michael reactions. Org. Biomol. Chem. 2016, 14, 9751-9759. [CrossRef]

151. Yang, Z.Y.; Zeng, J.L.; Ren, N.; Meng, W.; Nie, J.; Ma, J.A. C2-Symmetric Chiral Bisoxazolines as Hydrogen-Bond-Acceptor Catalysts in Enantioselective Aldol Reaction of beta-Carbonyl Acids with Trifluoroacetaldehyde Hemiacetals. Org. Lett. 2016, 18, 6364-6367. [CrossRef]

152. Servín, F.A.; Madrigal, D.; Romero, J.A.; Chávez, D.; Aguirre, G.; Anaya de Parrodi, C.; Somanathan, R. Synthesis of $\mathrm{C}_{2}$-symmetric 1,2-diamine-functionalized organocatalysts: Mimicking enzymes in enantioselective Michael addition reactions. Tetrahedron Lett. 2015, 56, 2355-2358. [CrossRef]

153. Ogasawara, M.; Kotani, S.; Nakajima, H.; Furusho, H.; Miyasaka, M.; Shimoda, Y.; Wu, W.Y.; Sugiura, M.; Takahashi, T.; Nakajima, M. Atropisomeric chiral dienes in asymmetric catalysis: C(2)-symmetric (Z,Z)-2,3-bis[1-(diphenylphosphinyl)ethylidene]tetralin as a highly active Lewis base organocatalyst. Angew. Chem. Int. Ed. Engl. 2013, 52, 13798-13802. [CrossRef]

154. Gomez-Torres, E.; Alonso, D.A.; Gomez-Bengoa, E.; Najera, C. Conjugate addition of 1,3-dicarbonyl compounds to maleimides using a chiral C2-symmetric bis(2-aminobenzimidazole) as recyclable organocatalyst. Org. Lett. 2011, 13, 6106-6109. [CrossRef]

155. Delaney, J.P.; Brozinski, H.L.; Henderson, L.C. Synergistic effects within a C2-symmetric organocatalyst: The potential formation of a chiral catalytic pocket. Org. Biomol. Chem. 2013, 11, 2951-2960. [CrossRef] [PubMed]

156. Sohtome, Y.; Hashimoto, Y.; Nagasawa, K. Guanidine-Thiourea Bifunctional Organocatalyst for the Asymmetric Henry (Nitroaldol) Reaction. Adv. Synth. Catal. 2005, 347, 1643-1648. [CrossRef]

157. Ginotra, S.K.; Singh, V.K. Enantioselective Henry reaction catalyzed by a $\mathrm{C}_{2}$-symmetric bis(oxazoline $) \mathrm{Cu}(\mathrm{OAc})_{2} . \mathrm{H}_{2} \mathrm{O}$ complex. Org. Biomol. Chem. 2007, 5, 3932-3937. [CrossRef] [PubMed]

158. Le, K.V.; Takezoe, H.; Araoka, F. Chiral Superstructure Mesophases of Achiral Bent-Shaped Molecules-Hierarchical Chirality Amplification and Physical Properties. Adv. Mater. 2017, 29, 1602737. [CrossRef] [PubMed] 
159. Otani, T.; Araoka, F.; Ishikawa, K.; Takezoe, H. Enhanced optical activity by achiral rod-like molecules nanosegregated in the B4 structure of achiral bent-core molecules. J. Am. Chem. Soc. 2009, 131, 12368-12372. [CrossRef] [PubMed]

160. Hough, L.E.; Spannuth, M.; Nakata, M.; Coleman, D.A.; Jones, C.D.; Dantlgraber, G.; Tschierske, C.; Watanabe, J.; Korblova, E.; Walba, D.M.; et al. Chiral isotropic liquids from achiral molecules. Science 2009, 325, 452-456. [CrossRef]

161. Takanishi, Y.; Shin, G.J.; Jung, J.C.; Choi, S.-W.; Ishikawa, K.; Watanabe, J.; Takezoe, H.; Toledano, P. Observation of very large chiral domains in a liquid crystal phase formed by mixtures of achiral bent-core and rod molecules. J. Mater. Chem. 2005, 15. [CrossRef]

162. Kim, K.; Kim, H.; Jo, S.Y.; Araoka, F.; Yoon, D.K.; Choi, S.W. Photomodulated Supramolecular Chirality in Achiral Photoresponsive Rodlike Compounds Nanosegregated from the Helical Nanofilaments of Achiral Bent-Core Molecules. ACS Appl. Mater. Interfaces 2015, 7, 22686-22691. [CrossRef]

163. Nagayama, H.; Varshney, S.K.; Goto, M.; Araoka, F.; Ishikawa, K.; Prasad, V.; Takezoe, H. Spontaneous deracemization of disc-like molecules in the columnar phase. Angew. Chem. Int. Ed. Engl. 2010, 49, 445-448. [CrossRef]

164. Gortz, V.; Goodby, J.W. Enantioselective segregation in achiral nematic liquid crystals. Chem. Commun. 2005, 3262-3264. [CrossRef]

165. Zhang, C.; Diorio, N.; Lavrentovich, O.D.; Jakli, A. Helical nanofilaments of bent-core liquid crystals with a second twist. Nat. Commun. 2014, 5, 3302. [CrossRef]

166. Hazen, R.M.; Sholl, D.S. Chiral selection on inorganic crystalline surfaces. Nat. Mater. 2003, 2, 367-374. [CrossRef]

167. Weissbuch, I.; Addadi, L.; Leiserowitz, L. Molecular recognition at crystal interfaces. Science 1991, 253, 637-645. [CrossRef]

168. Koretsky, C.M.; Sverjensky, D.A.; Sahai, N. A model of surface site types on oxide and silicate minerals based on crystal chemistry; implications for site types and densities, multi-site adsorption, surface infrared spectroscopy, and dissolution kinetics. Am. J. Sci. 1998, 298, 349-438. [CrossRef]

169. Dana, E.S. A Text-Book of Mineralogy: With an Extended Treatise on Crystallography and Physical Mineralogy; Wiley: Hoboken, NJ, USA, 1898.

170. Hazen, R.M.; Filley, T.R.; Goodfriend, G.A. Selective adsorption of L- and D-amino acids on calcite: Implications for biochemical homochirality. Proc. Natl. Acad. Sci. USA 2001, 98, 5487-5490. [CrossRef]

171. Van Cappellen, P.; Charlet, L.; Stumm, W.; Wersin, P. A surface complexation model of the carbonate mineral-aqueous solution interface. Geochim. Cosmochim. Acta 1993, 57, 3505-3518. [CrossRef]

172. Stipp, S.L.; Hochella, M.F. Structure and bonding environments at the calcite surface as observed with X-ray photoelectron spectroscopy (XPS) and low energy electron diffraction (LEED). Geochim. Cosmochim. Acta 1991, 55, 1723-1736. [CrossRef]

173. Babel, M. Crystal lography and genesis of the giant intergrowths of gypsum from the Miocene evaporites of Poland. Arch. Miner. 1990, 44, 103-135.

174. Cody, A.M.; Cody, R.D. Chiral habit modifications of gypsum from epitaxial-like adsorption of stereospecific growth inhibitors. J. Cryst. Growth 1991, 113, 508-519. [CrossRef]

175. Steendam, R.R.; Verkade, J.M.; van Benthem, T.J.; Meekes, H.; van Enckevort, W.J.; Raap, J.; Rutjes, F.P.; Vlieg, E. Emergence of single-molecular chirality from achiral reactants. Nat. Commun. 2014, 5, 5543. [CrossRef]

176. Dressel, C.; Liu, F.; Prehm, M.; Zeng, X.; Ungar, G.; Tschierske, C. Dynamic mirror-symmetry breaking in bicontinuous cubic phases. Angew. Chem. Int. Ed. Engl. 2014, 53, 13115-13120. [CrossRef]

177. Alaasar, M.; Poppe, S.; Dong, Q.; Liu, F.; Tschierske, C. Isothermal Chirality Switching in Liquid-Crystalline Azobenzene Compounds with Non-Polarized Light. Angew. Chem. Int. Ed. Engl. 2017, 56, 10801-10805. [CrossRef]

178. Alaasar, M.; Prehm, M.; Tschierske, C. Helical Nano-crystallite (HNC) Phases: Chirality Synchronization of Achiral Bent-Core Mesogens in a New Type of Dark Conglomerates. Chemistry 2016, 22, 6583-6597. [CrossRef]

179. Dressel, C.; Reppe, T.; Prehm, M.; Brautzsch, M.; Tschierske, C. Chiral self-sorting and amplification in isotropic liquids of achiral molecules. Nat. Chem. 2014, 6, 971-977. [CrossRef] 
180. Ueda, T.; Masuko, S.; Araoka, F.; Ishikawa, K.; Takezoe, H. A General Method for the Enantioselective Formation of Helical Nanofilaments. Angew. Chem. 2013, 125, 7001-7004. [CrossRef]

181. Hu, J.; Gao, L.; Zhu, Y.; Wang, P.; Lin, Y.; Sun, Z.; Yang, S.; Wang, Q. Chiral Assemblies from an Achiral Pyridinium-Tailored Anthracene. Chemistry 2017, 23, 1422-1426. [CrossRef]

182. Akine, S.; Sairenji, S.; Taniguchi, T.; Nabeshima, T. Stepwise helicity inversions by multisequential metal exchange. J. Am. Chem. Soc. 2013, 135, 12948-12951. [CrossRef]

183. La, D.D.; Al Kobaisi, M.; Gupta, A.; Bhosale, S.V. Chiral Assembly of AIE-Active Achiral Molecules: An Odd Effect in Self-Assembly. Chem. Eur. J. 2017, 23, 3950-3956. [CrossRef]

184. Tschierske, C.; Ungar, G. Mirror Symmetry Breaking by Chirality Synchronisation in Liquids and Liquid Crystals of Achiral Molecules. ChemPhysChem 2016, 17, 9-26. [CrossRef]

185. Chen, D.; Nakata, M.; Shao, R.; Tuchband, M.R.; Shual, M.; Baumeister, U.; Weissflog, W.; Walba, D.M.; Glaser, M.A.; Maclennan, J.E.; Clark, N.A. Twist-bend heliconical chiral nematic liquid crystal phase of an achiral rigid bent-core mesogen. Phys. Rev. E 2014, 89, 022506. [CrossRef]

186. Kohler, K.; Forster, G.; Hauser, A.; Dobner, B.; Heiser, U.F.; Ziethe, F.; Richter, W.; Steiniger, F.; Drechsler, M.; Stettin, H.; et al. Temperature-dependent behavior of a symmetric long-chain bolaamphiphile with phosphocholine headgroups in water: From hydrogel to nanoparticles. J. Am. Chem. Soc. 2004, 126, 16804-16813. [CrossRef]

187. Roche, C.; Sun, H.J.; Prendergast, M.E.; Leowanawat, P.; Partridge, B.E.; Heiney, P.A.; Araoka, F.; Graf, R.; Spiess, H.W.; Zeng, X.; et al. Homochiral columns constructed by chiral self-sorting during supramolecular helical organization of hat-shaped molecules. J. Am. Chem. Soc. 2014, 136, 7169-7185. [CrossRef]

188. Singh, G.; Chan, H.; Baskin, A.; Gelman, E.; Repnin, N.; Kral, P.; Klajn, R. Self-assembly of magnetite n5anocubes into helical superstructures. Science 2014, 345, 1149-1153. [CrossRef]

189. Pokropivny, V.V. Powder. Metal. Met. Ceram. 2001, 40, 582-594. [CrossRef]

190. Celik-Aktas, A.; Zuo, J.M.; Stubbins, J.F.; Tang, C.; Bando, Y. Double-helix structure in multiwall boron nitride nanotubes. Acta Crystallogr. A 2005, 61, 533-541. [CrossRef]

191. Zhi, C.; Bando, Y.; Tang, C.; Golberg, D. Boron nitride nanotubes. Mater. Sci. Eng. R 2010, 70, 92-111. [CrossRef]

192. Wang, Z.L. Zinc oxide nanostructures: Growth, properties and applications. J. Phys. Condens. Matter 2004, 16, R829-R858. [CrossRef]

193. Ma, R.; Bando, Y.; Sato, T. Controlled Synthesis of BN Nanotubes, Nanobamboos, and Nanocables. Adv. Mater. 2002, 14, 366-368. [CrossRef]

194. Pavlov, V.A.; Spitsina, N.I.; Klabunovsky, E.I. Enantioselective hydrogenation in a cholesteric liquid crystal as a chiral matrix. Bull. Acad. Sci. USSR Div. Chem. Sci. 1982, 31, 2509. [CrossRef]

195. Pavlov, V.A.; Spitsina, N.I.; Klabunovsky, E.I. Enantioselective hydrogenation in cholesteryl tridecanoate as a chiral liquid-crystalline matrix. Bull. Acad. Sci. USSR Div. Chem. Sci. 1983, 32, 1501-1503. [CrossRef]

196. Chen, C.W.; Whitlock, H.W. Molecular tweezers: A simple model of bifunctional intercalation. J. Am. Chem. Soc. 1978, 100, 4921-4922. [CrossRef]

197. Zimmerman, S.C. Rigid Molecular Tweezers as Hosts for the Complexation of Neutral Guests; Springer: Berlin/Heidelberg, Germany, 1993; Volume 165, pp. 70-102.

198. Harmata, M. Chiral molecular tweezers. Acc. Chem. Res. 2004, 37, 862-873. [CrossRef] [PubMed]

199. Saha, B.; Ikbal, S.A.; Petrovic, A.G.; Berova, N.; Rath, S.P. Complexation of Chiral Zinc-Porphyrin Tweezer with Achiral Diamines: Induction and Two-Step Inversion of Interporphyrin Helicity Monitored by ECD. Inorg. Chem. 2017, 56, 3849-3860. [CrossRef] [PubMed]

200. Ouyang, Q.; Zhu, Y.Z.; Li, Y.C.; Wei, H.B.; Zheng, J.Y. Diastereoselective synthesis of chiral diporphyrins via intramolecular meso-meso oxidative coupling. J. Org. Chem. 2009, 74, 3164-3167. [CrossRef]

201. Ema, T.; Misawa, S.; Nemugaki, S.; Sakai, T.; Utaka, M. New Optically Active Diporphyrin Having a Chiral Cyclophane as a Spacer. Chem. Lett. 1997, 26, 487-488. [CrossRef]

202. Berova, N.; Pescitelli, G.; Petrovic, A.G.; Proni, G. Probing molecular chirality by CD-sensitive dimeric metalloporphyrin hosts. Chem. Commun. 2009, 5958-5980. [CrossRef]

203. Borovkov, V.V.; Hembury, G.A.; Inoue, Y. Origin, control, and application of supra molecular chirogenesis in bisporphyrin-based systems. Acc. Chem. Res. 2004, 37, 449-459. [CrossRef]

204. Huang, X.; Nakanishi, K.; Berova, N. Porphyrins and metalloporphyrins: Versatile circular dichroic reporter groups for structural studies. Chirality 2000, 12, 237-255. [CrossRef] 
205. D’Urso, A.; Nicotra, P.F.; Centonze, G.; Fragala, M.E.; Gattuso, G.; Notti, A.; Pappalardo, A.; Pappalardo, S.; Parisi, M.F.; Purrello, R. Induction of chirality in porphyrin-(bis)calixarene assemblies: A mixed covalent-non-covalent vs a fully non-covalent approach. Chem. Commun. 2012, 48, 4046-4048. [CrossRef]

206. Gholami, H.; Anyika, M.; Zhang, J.; Vasileiou, C.; Borhan, B. Host-Guest Assembly of a Molecular Reporter with Chiral Cyanohydrins for Assignment of Absolute Stereochemistry. Chemistry 2016, 22, 9235-9239. [CrossRef]

207. Ikbal, S.A.; Dhamija, A.; Brahma, S.; Rath, S.P. A Nonempirical Approach for Direct Determination of the Absolute Configuration of 1,2-Diols and Amino Alcohols Using Mg(II)bisporphyrin. J. Org. Chem. 2016, 81, 5440-5449. [CrossRef]

208. Ishii, Y.; Yoshizawa, T.; Kubo, Y. Dibenzodiaza-30-crown-10-appended bis(zinc porphyrin) tweezers: Synthesis and crown-assisted chiroptical behaviour. Org. Biomol. Chem. 2007, 5, 1210-1217. [CrossRef]

209. Tanasova, M.; Anyika, M.; Borhan, B. Sensing remote chirality: Stereochemical determination of beta-, gamma-, and delta-chiral carboxylic acids. Angew. Chem. Int. Ed. Engl. 2015, 54, 4274-4278. [CrossRef]

210. Beckett, A.H.; Anderson, P. A Method for the Determination of the Configuration of Organic Molecules using 'Stereo-selective Adsorbents'. Nature 1957, 179, 1074-1075. [CrossRef]

211. Bartels, H.; Prijs, B.; Erlenmeyer, H. Über spezifisch adsorbierende Silicagele V. Helv. Chim. Acta 1966, 49, 1621-1625. [CrossRef]

212. Erlenmeyer, H.; Bartels, H. Über das Problem der Ähnlichkeit in der Chemie Über spezifisch adsorbierende Silikagele II [1]. Helv. Chim. Acta 1964, 47, 1285-1288. [CrossRef]

213. Bartels, H.; Erlenmeyer, H. Über das Problem der Ähnlichkeit in der Chemie Über spezifisch adsorbierende Silicagele III. Helv. Chim. Acta 1965, 48, 285-290. [CrossRef]

214. Ducos, P.; Liautard, V.; Robert, F.; Landais, Y. Chiral Memory in Silylium Ions. Chemistry 2015, 21, 11573-11578. [CrossRef]

215. Miyabe, T.; Iida, H.; Ohnishi, A.; Yashima, E. Enantioseparation on poly(phenyl isocyanide)s with macromolecular helicity memory as chiral stationary phases for HPLC. Chem. Sci. 2012, 3, 863-867. [CrossRef]

216. Huang, H.; Deng, J.; Shi, Y. Optically Active Physical Gels with Chiral Memory Ability: Directly Prepared by Helix-Sense-Selective Polymerization. Macromolecules 2016, 49, 2948-2956. [CrossRef]

217. Zhao, Y.; Abdul Rahim, N.A.; Xia, Y.; Fujiki, M.; Song, B.; Zhang, Z.; Zhang, W.; Zhu, X. Supramolecular Chirality in Achiral Polyfluorene: Chiral Gelation, Memory of Chirality, and Chiral Sensing Property. Macromolecules 2016, 49, 3214-3221. [CrossRef]

218. Yang, D.; Zhao, Y.; Lv, K.; Wang, X.; Zhang, W.; Zhang, L.; Liu, M. A strategy for tuning achiral mainchain polymers into helical assemblies and chiral memory systems. Soft. Matter. 2016, 12, 1170-1175. [CrossRef]

219. Sobczuk, A.A.; Tsuchiya, Y.; Shiraki, T.; Tamaru, S.; Shinkai, S. Creation of chiral thixotropic gels through a crown-ammonium interaction and their application to a memory-erasing recycle system. Chemistry 2012, 18, 2832-2838. [CrossRef]

220. De Jong, J.J.; Lucas, L.N.; Kellogg, R.M.; van Esch, J.H.; Feringa, B.L. Reversible optical transcription of supramolecular chirality into molecular chirality. Science 2004, 304, 278-281. [CrossRef]

221. Inoue, K.; Ono, Y.; Kanekiyo, Y.; Ishii, T.; Yoshihara, K.; Shinkai, S. Chiroselective re-binding of saccharides to the fibrous aggregates prepared from organic gels of cholesterylphenylboronic acid. Tetrahedron Lett. 1998, 39, 2981-2984. [CrossRef]

222. Gural'skiy, I.y.A.; Reshetnikov, V.A.; Szebesczyk, A.; Gumienna-Kontecka, E.; Marynin, A.I.; Shylin, S.I.; Ksenofontov, V.; Fritsky, I.O. Chiral spin crossover nanoparticles and gels with switchable circular dichroism. J. Mater. Chem. C 2015, 3, 4737-4741. [CrossRef]

223. Duan, P.; Zhu, X.; Liu, M. Isomeric effect in the self-assembly of pyridine-containing L-glutamic lipid: Substituent position controlled morphology and supramolecular chirality. Chem. Commun. 2011, 47, 5569-5571. [CrossRef]

224. Van Gorp, J.J.; Vekemans, J.A.J.M.; Meijer, E.W. C3-Symmetrical Supramolecular Architectures: Fibers and Organic Gels from Discotic Trisamides and Trisureas. J. Am. Chem. Soc. 2002, 124, 14759-14769. [CrossRef]

225. Tobe, Y.; Utsumi, N.; Kawabata, K.; Nagano, A.; Adachi, K.; Araki, S.; Sonoda, M.; Hirose, K.; Naemura, K. m-Diethynylbenzene Macrocycles: Syntheses and Self-Association Behavior in Solution. J. Am. Chem. Soc. 2002, 124, 5350-5364. [CrossRef] 
226. Lahiri, S.; Thompson, J.L.; Moore, J.S. Solvophobically Driven $\pi$-Stacking of Phenylene Ethynylene Macrocycles and Oligomers. J. Am. Chem. Soc. 2000, 122, 11315-11319. [CrossRef]

227. Xing, P.; Zhao, Y. Controlling Supramolecular Chirality in Multicomponent Self-Assembled Systems. Acc. Chem. Res. 2018, 51, 2324-2334. [CrossRef]

228. Haino, T.; Tanaka, M.; Fukazawa, Y. Self-assembly of tris(phenylisoxazolyl)benzene and its asymmetric induction of supramolecular chirality. Chem. Commun. 2008, 468-470. [CrossRef]

229. Edwards, W.; Smith, D.K. Enantioselective component selection in multicomponent supramolecular gels. J. Am. Chem. Soc. 2014, 136, 1116-1124. [CrossRef]

230. Molla, M.R.; Das, A.; Ghosh, S. Chiral induction by helical neighbour: Spectroscopic visualization of macroscopic-interaction among self-sorted donor and acceptor pi-stacks. Chem. Commun. 2011, 47, 8934-8936. [CrossRef]

231. Tanaka, M.; Ikeda, T.; Mack, J.; Kobayashi, N.; Haino, T. Self-assembly and gelation behavior of tris(phenylisoxazolyl)benzenes. J. Org. Chem. 2011, 76, 5082-5091. [CrossRef]

232. Smith, D.K. Lost in translation? Chirality effects in the self-assembly of nanostructured gel-phase materials. Chem. Soc. Rev. 2009, 38, 684-694. [CrossRef]

233. Shen, Z.; Wang, T.; Liu, M. Macroscopic chirality of supramolecular gels formed from achiral tris(ethyl cinnamate) benzene-1,3,5-tricarboxamides. Angew. Chem. Int. Ed. Engl. 2014, 53, 13424-13428. [CrossRef]

234. Yu, X.; Wang, Z.; Li, Y.; Geng, L.; Ren, J.; Feng, G. Fluorescent and Electrochemical Supramolecular Coordination Polymer Hydrogels Formed from Ion-Tuned Self-Assembly of Small Bis-Terpyridine Monomer. Inorg. Chem. 2017, 56, 7512-7518. [CrossRef]

235. Jin, W.; Fukushima, T.; Niki, M.; Kosaka, A.; Ishii, N.; Aida, T. Self-assembled graphitic nanotubes with one-handed helical arrays of a chiral amphiphilic molecular graphene. Proc. Natl. Acad. Sci. USA 2005, 102, 10801-10806. [CrossRef]

236. Onouchi, H.; Miyagawa, T.; Morino, K.; Yashima, E. Assisted formation of chiral porphyrin homoaggregates by an induced helical poly(phenylacetylene) template and their chiral memory. Angew. Chem. Int. Ed. Engl. 2006, 45, 2381-2384. [CrossRef]

237. Mammana, A.; D'Urso, A.; Lauceri, R.; Purrello, R. Switching off and on the supramolecular chiral memory in porphyrin assemblies. J. Am. Chem. Soc. 2007, 129, 8062-8063. [CrossRef]

238. Randazzo, R.; Mammana, A.; D’Urso, A.; Lauceri, R.; Purrello, R. Reversible "chiral memory" in ruthenium tris(phenanthroline)-anionic porphyrin complexes. Angew. Chem. Int. Ed. Engl. 2008, 47, 9879-9882. [CrossRef]

239. Gaeta, M.; Oliveri, I.P.; Fragala, M.E.; Failla, S.; D’Urso, A.; Di Bella, S.; Purrello, R. Chirality of self-assembled achiral porphyrins induced by chiral $\mathrm{Zn}$ (ii) Schiff-base complexes and maintained after spontaneous dissociation of the templates: A new case of chiral memory. Chem. Commun. 2016, 52, 8518-8521. [CrossRef]

240. Lauceri, R.; Raudino, A.; Scolaro, L.M.; Micali, N.; Purrello, R. From Achiral Porphyrins to Template-Imprinted Chiral Aggregates and Further. Self-Replication of Chiral Memory from Scratch. J. Am. Chem. Soc. 2002, 124, 894-895. [CrossRef]

241. Yashima, E.; Maeda, K.; Okamoto, Y. Memory of macromolecular helicity assisted by interaction with achiral small molecules. Nature 1999, 399, 449. [CrossRef]

242. Hase, Y.; Mitsutsuji, Y.; Ishikawa, M.; Maeda, K.; Okoshi, K.; Yashima, E. Unexpected thermally stable, cholesteric liquid-crystalline helical polyisocyanides with memory of macromolecular helicity. Chem. Asian J. 2007, 2, 755-763. [CrossRef]

243. Ishikawa, M.; Maeda, K.; Mitsutsuji, Y.; Yashima, E. An unprecedented memory of macromolecular helicity induced in an achiral polyisocyanide in water. J. Am. Chem. Soc. 2004, 126, 732-733. [CrossRef]

244. Takashima, S.; Abe, H.; Inouye, M. Unexpected chain length dependence on a chiral memory effect of 'meta-ethynylpyridine' oligomers. Tetrahedron Asymmetry 2013, 24, 527-531. [CrossRef]

245. Ishidate, R.; Shimomura, K.; Ikai, T.; Kanoh, S.; Maeda, K. Macromolecular helicity induction and memory in a poly(biphenylylacetylene) bearing an ester group and its application to a chiral stationary phase for high-performance liquid chromatography. Chem. Lett. 2015, 44, 946-948. [CrossRef]

246. Rosaria, L.; D’Urso, A.; Mammana, A.; Purrello, R. Chiral memory: Induction, amplification, and switching in porphyrin assemblies. Chirality 2008, 20, 411-419. [CrossRef]

247. Sung, B.; de la Cotte, A.; Grelet, E. Chirality-controlled crystallization via screw dislocations. Nat. Commun. 2018, 9, 1405. [CrossRef] 
248. Thomas, C.W.; Tor, Y. Dendrimers and chirality. Chirality 1998, 10, 53-59. [CrossRef]

249. Vestergren, M.; Johansson, A.; Lennartson, A.; Håkansson, M. Non-stochastic homochiral helix crystallization: Cryptochirality in control? Mendeleev Commun. 2004, 14, 258-260. [CrossRef]

250. Wallach, O. Zur Kenntniss der Terpene und der ätherischen Oele. Justus Liebig's Ann. Chem. 1895, 286, 90-118. [CrossRef]

251. Dunitz, J.D.; Gavezzotti, A. Proteogenic amino acids: Chiral and racemic crystal packings and stabilities. J. Phys. Chem. B 2012, 116, 6740-6750. [CrossRef]

252. Brock, C.P.; Schweizer, W.B.; Dunitz, J.D. On the validity of Wallach's rule: On the density and stability of racemic crystals compared with their chiral counterparts. J. Am. Chem. Soc. 1991, 113, 9811-9820. [CrossRef]

253. Slepukhin, P.A.; Gruzdev, D.A.; Chulakov, E.N.; Levit, G.L.; Krasnov, V.P.; Charushin, V.N. Structures of the racemate and (S)-enantiomer of 7,8-difluoro-3-methyl-2,3-dihydro-4H-[1,4]benzoxazine. Russ. Chem. Bull. 2011, 60, 955-960. [CrossRef]

254. Navare, P.S.; MacDonald, J.C. Investigation of Stability and Structure in Three Homochiral and Heterochiral Crystalline Forms of 3-Phenyllactic Acid. Cryst. Growth Des. 2011, 11, 2422-2428. [CrossRef]

255. Sørensen, H.O.; Larsen, S. Hydrogen bonding in enantiomericversusracemic mono-carboxylic acids; a case study of 2-phenoxypropionic acid. Acta Crystallogr. B Struct. Sci. 2003, 59, 132-140. [CrossRef]

256. Assaad, T.; Rukiah, M. Powder X-ray study of racemic (2RS,3RS)-5-amino-3-[4-(3-methoxyphenyl)piperazin1-yl]-1,2,3,4-tetrahydronaphtha len-2-ol. Acta Crystallogr. C 2011, 67, o469-o472. [CrossRef]

257. Husin, H.; Leong, Y.-K.; Liu, J. Molecular attributes of an effective steric agent: Yield stress of dispersions in the presence of pure enantiomeric and racemate malic acids. Adv. Powder Technol. 2012, 23, 459-464. [CrossRef]

258. Sanabria, C.M.; Gomez, S.L.; Palma, A.; Cobo, J.; Glidewell, C. Four 1-naphthyl-substituted tetrahydro-1,4-epoxy-1-benzazepines: hydrogen bonded structures in one, two and three dimensions. Acta Crystallogr. C 2010, 66, o540-o546. [CrossRef]

259. Marthi, K.; Larsen, S.; Ács, M.; Fogassy, E. Enantiomer associations in the crystal structures of racemic and (2S,3S)-(+)-3-hydroxy-2-(4-methoxyphenyl)-2,3-dihydro-1,5-benzothiazepin-4(5H)-one. J. Mol. Struct. 1996, 374, 347-355. [CrossRef]

260. Luger, P.; Weber, M. DL-Cysteine at 298K. Acta Crystallogr. C Cryst. Struct. Commun. 1999, 55, $1882-1885$. [CrossRef]

261. Krishnaswamy, S.; Patil, M.T.; Shashidhar, M.S. Comparison of racemic epi-inosose and (-)-epi-inosose. Acta Crystallogr. C 2011, 67, o435-0438. [CrossRef]

262. Kitoh, S.-I.; Kunimoto, K.-K.; Funaki, N.; Senda, H.; Kuwae, A.; Hanai, K.J. Crystal structures and vibrational spectra of racemic and chiral 4-phenyl-1,3-oxazolidine-2-thione. Chem. Crystallogr. 2002, 32, 547-553. [CrossRef]

263. Pella, E.; Restelli, R. Binary phase diagram of the enantiomers of indoprofen. Mikrochim. Acta 1983, 79, 65-74. [CrossRef]

264. Xie, S.; Nusbaum, D.A.; Stein, H.J.; Pink, M. 4-(3-Methoxy-phen-yl)-2,6-dimethyl-cyclo-hex3-enecarboxylic acid. Acta Crystallogr. E Struct. Rep. Online 2010, 66, o1443-o1449. [CrossRef]

265. Blazis, V.J.; Koeller, K.J.; Rath, N.P.; Spilling, C.D. Application of Wallach's Rule in a Comparison of the X-ray Crystal Structures of the Racemate and the (S) Enantiomer of (1-Hydroxy3-phenyl-2-propenyl) Dimethylphosphonate. Acta Crystallogr. B Struct. Sci. 1997, 53, 838-842. [CrossRef]

266. Simonov, Y.; Bourosh, P.; Kravtsov, V.; Gdanets, M.; Semenishyna, K.; Pavlovsky, V.; Kabanova, T.; Khalimova, O.; Andronati, S. A comparative analysis of the crystal structure of r,s-racemate and r-enantiomer of 7-bromo-3-(2-methoxy)ethoxy-5-phenyl-1,2-dihydro- h-1,4-benzodiazepine-2-one exhibiting a high analgesic activity. Zhurnal Organichnoi ta Farmatsevtichnoi Khimi 2011, 9, 70-73.

267. Patrick, B.O.; Brock, C.P. S,S-1,2-Dicyclohexylethane-1,2-diol and its racemic compound: A striking exception to Wallach's rule. Acta Crystallogr. B 2006, 62, 488-497. [CrossRef]

268. Benson, N.; Snelder, N.; Ploeger, B.; Napier, C.; Sale, H.; Birdsall, N.J.; Butt, R.P.; van der Graaf, P.H. Estimation of binding rate constants using a simultaneous mixed-effects method: Application to monoamine transporter reuptake inhibitor reboxetine. Br. J. Pharmacol. 2010, 160, 389-398. [CrossRef]

269. Xu, F.; Khan, I.J.; McGuinness, K.; Parmar, A.S.; Silva, T.; Murthy, N.S.; Nanda, V. Self-assembly of left- and right-handed molecular screws. J. Am. Chem. Soc. 2013, 135, 18762-18765. [CrossRef] 
270. Kwon, S.; Shin, H.S.; Gong, J.; Eom, J.H.; Jeon, A.; Yoo, S.H.; Chung, I.S.; Cho, S.J.; Lee, H.S. Self-assembled peptide architecture with a tooth shape: Folding into shape. J. Am. Chem. Soc. 2011, 133, 17618-17621. [CrossRef]

271. Chen, C.C.; Hsu, W.; Hwang, K.C.; Hwu, J.R.; Lin, C.C.; Horng, J.C. Contributions of cation-pi interactions to the collagen triple helix stability. Arch. Biochem. Biophys. 2011, 508, 46-53. [CrossRef]

272. Brown, E.M. Development and utilization of a bovine type I collagen microfibril model. Int. J. Biol. Macromol. 2013, 53, 20-25. [CrossRef]

273. Miyoshi, K.; Uezu, K.; Sakurai, K.; Shinkai, S. Proposal of a new hydrogen-bonding form to maintain curdlan triple helix. Chem. Biodivers. 2004, 1, 916-924. [CrossRef]

274. Ishikawa, T.; Morita, T.; Kimura, S. Unique Helical Triangle Molecular Geometry Induced by Dipole-Dipole Interactions. Bull. Chem. Soc. Jpn. 2007, 80, 1483-1491. [CrossRef]

275. Kony, D.B.; Damm, W.; Stoll, S.; van Gunsteren, W.F.; Hunenberger, P.H. Explicit-solvent molecular dynamics simulations of the polysaccharide schizophyllan in water. Biophys. J. 2007, 93, 442-455. [CrossRef]

276. Wells, R.D. Non-B DNA conformations, mutagenesis and disease. Trends Biochem. Sci. 2007, 32, $271-278$. [CrossRef] [PubMed]

277. Wells, R.D.; Dere, R.; Hebert, M.L.; Napierala, M.; Son, L.S. Advances in mechanisms of genetic instability related to hereditary neurological diseases. Nucleic Acids. Res. 2005, 33, 3785-3798. [CrossRef]

278. Zhang, H.; Yu, H.; Ren, J.; Qu, X. Reversible B/Z-DNA transition under the low salt condition and non-B-form polydApolydT selectivity by a cubane-like europium-L-aspartic acid complex. Biophys. J. 2006, 90, 3203-3207. [CrossRef]

279. Mirkin, S.M. DNA structures, repeat expansions and human hereditary disorders. Curr. Opin. Struct. Biol. 2006, 16, 351-358. [CrossRef]

280. Bacolla, A.; Wells, R.D. Non-B DNA conformations, genomic rearrangements, and human disease. J. Biol. Chem. 2004, 279, 47411-47414. [CrossRef]

281. Lupski, J.R. Genomic disorders: Structural features of the genome can lead to DNA rearrangements and human disease traits. Trends Genet. 1998, 14, 417-422. [CrossRef]

282. Lupski, J.R.; Stankiewicz, P. Genomic Disorders: The Genomic BAsis of Desease; Humana Press: New York, NY, USA, 2006.

283. Genetic Instabilities and Neurological Diseases; Academic Press: Houston, TX, USA, 2006.

284. Harvey, S.C. DNA structural dynamics: Longitudinal breathing as a possible mechanism for the $\mathrm{B} \rightleftarrows \mathrm{Z}$ transition. Nucleic Acids Res. 1983, 11, 4867-4878. [CrossRef]

285. Green, M.M.; Peterson, N.C.; Sato, T.; Teramoto, A.; Cook, R.; Lifson, S. A helical polymer with a cooperative response to chiral information. Science 1995, 268, 1860-1866. [CrossRef] [PubMed]

286. Lifson, S.; Felder, C.E.; Green, M.M. Helical conformations, internal motion, and helix sense reversal in polyisocyanates and the preferred helix sense of an optically active polyisocyanate. Macromolecules 1992, 25, 4142-4148. [CrossRef]

287. Lee, J.; Kim, Y.G.; Kim, K.K.; Seok, C. Transition between B-DNA and Z-DNA: Free energy landscape for the B-Z junction propagation. J. Phys. Chem. B 2010, 114, 9872-9881. [CrossRef]

288. Pohl, F.M.; Jovin, T.M. Salt-induced co-operative conformational change of a synthetic DNA: Equilibrium and kinetic studies with poly(dG-dC). J. Mol. Biol. 1972, 67, 375-396. [CrossRef]

289. Zacharias, W.; Martin, J.C.; Wells, R.D. A condensed form of (dG-dC)n.cntdot.(dG-dC)n as an intermediate between the B- and Z-conformations induced by sodium acetate. Biochemistry 2002, 22, 2398-2405. [CrossRef]

290. Wang, A.J.; Quigley, G.J.; Kolpak, F.J.; van der Marel, G.; van Boom, J.H.; Rich, A. Left-handed double helical DNA: Variations in the backbone conformation. Science 1981, 211, 171-176. [CrossRef] [PubMed]

291. Wang, A.H.; Quigley, G.J.; Kolpak, F.J.; Crawford, J.L.; van Boom, J.H.; van der Marel, G.; Rich, A. Molecular structure of a left-handed double helical DNA fragment at atomic resolution. Nature 1979, 282, 680-686. [CrossRef] [PubMed]

292. Behe, M.; Felsenfeld, G. Effects of methylation on a synthetic polynucleotide: The B-Z transition in poly(dG-m5dC).poly(dG-m5dC). Proc. Natl. Acad. Sci. USA 1981, 78, 1619-1623. [CrossRef]

293. Russell, W.C.; Precious, B.; Martin, S.R.; Bayley, P.M. Differential promotion and suppression of $Z$ leads to $B$ transitions in poly $[\mathrm{d}(\mathrm{G}-\mathrm{C})]$ by histone subclasses, polyamino acids and polyamines. EMBO J. 1983, 2, 1647-1653. [CrossRef] [PubMed]

294. Pohl, F.M. Polymorphism of a synthetic DNA in solution. Nature 1976, 260, 365-366. [CrossRef] 
295. Feigon, J.; Wang, A.H.; van der Marel, G.A.; van Boom, J.H.; Rich, A. A one- and two-dimensional NMR study of the B to Z transition of (m5dC-dG)3 in methanolic solution. Nucleic Acids Res. 1984, 12, 1243-1263. [CrossRef]

296. Zimmer, C.; Tymen, S.; Marck, C.; Guschlbauer, W. Conformational transitions of poly(dA-dC). poly(dG-dT) induced by high salt or in ethanolic solution. Nucleic Acids Res. 1982, 10, 1081-1091. [CrossRef]

297. Van de Sande, J.H.; McIntosh, L.P.; Jovin, T.M. $\mathrm{Mn}^{2+}$ and other transition metals at low concentration induce the right-to-left helical transformation of poly[d(G-C)]. EMBO J. 1982, 1, 777-782. [CrossRef]

298. Pohl, F.M.; Jovin, T.M.; Baehr, W.; Holbrook, J.J. Ethidium Bromide as a Cooperative Effector of a DNA Structure. Proc. Natl. Acad. Sci. USA 1972, 69, 3805-3809. [CrossRef] [PubMed]

299. Mirau, P.A.; Kearns, D.R. The effect of Intercalating drugs on the kinetics of the B to $Z$ transition of poly(dG-dC). Nucleic Acids Res. 1983, 11, 1931-1941. [CrossRef] [PubMed]

300. Zacharias, W.; Larson, J.E.; Klysik, J.; Stirdivant, S.M.; Wells, R.D. Conditions which cause the right-handed to left-handed DNA conformational transitions. Evidence for several types of left-handed DNA structures in solution. J. Biol. Chem. 1982, 257, 2775-2782.

301. Wu, Z.; Tian, T.; Yu, J.; Weng, X.; Liu, Y.; Zhou, X. Formation of sequence-independent Z-DNA induced by a ruthenium complex at low salt concentrations. Angew. Chem. Int. Ed. Engl. 2011, 50, 11962-11967. [CrossRef]

302. Johnson, A.; Qu, Y.; Van Houten, B.; Farrell, N. B $\uparrow$ Z DNA conformational changes induced by a family of dinuclear bis(platinum) complexes. Nucleic Acids Res. 1992, 20, 1697-1703. [CrossRef] [PubMed]

303. Nordén, B.; Lincoln, P.; Akerman, B.; Tuite, E. DNA interactions with substitution-inert transition metal ion complexes. Met. Ions. Biol. Syst. 1996, 33, 177-252. [PubMed]

304. Nordén, B.; Tjerneld, F. Binding of inert metal complexes to deoxyribonucleic acid detected by linear dichroism. FEBS Lett. 1976, 67, 368-370. [CrossRef]

305. Barton, J.K. Tris (phenanthroline) metal complexes: Probes for DNA helicity. J. Biomol. Struct. Dyn. 1983, 1, 621-632. [CrossRef]

306. Chow, C.S.; Barton, J.K. Transition metal complexes as probes of nucleic acids. Methods Enzymol. 1992, 212, 219-242.

307. Xu, Y.; Zhang, Y.X.; Sugiyama, H.; Umano, T.; Osuga, H.; Tanaka, K. (P)-helicene displays chiral selection in binding to Z-DNA. J. Am. Chem. Soc. 2004, 126, 6566-6567. [CrossRef]

308. Tsuji, G.; Kawakami, K.; Sasaki, S. Enantioselective binding of chiral 1,14-dimethyl[5]helicene-spermine ligands with B- and Z-DNA. Bioorg. Med. Chem. 2013, 21, 6063-6068. [CrossRef]

309. Qu, X.; Trent, J.O.; Fokt, I.; Priebe, W.; Chaires, J.B. Allosteric, chiral-selective drug binding to DNA. Proc. Natl. Acad. Sci. USA 2000, 97, 12032-12037. [CrossRef]

310. Doi, I.; Tsuji, G.; Kawakami, K.; Nakagawa, O.; Taniguchi, Y.; Sasaki, S. The spermine-bisaryl conjugate as a potent inducer of B- to Z-DNA transition. Chemistry 2010, 16, 11993-11999. [CrossRef]

311. Haque, L.; Pradhan, A.B.; Bhuiya, S.; Das, S. Structural conversion of left handed protonated form of calf thymus DNA to right handed B-DNA by the alkaloid chelerythrine. J. Lumin. 2016, 173, 44-51. [CrossRef]

312. Kim, J.; Ha, C.S.; Lee, H.J.; Song, K. Repetitive exposure to a 60-Hz time-varying magnetic field induces DNA double-strand breaks and apoptosis in human cells. Biochem. Biophys. Res. Commun. 2010, 400, 739-744. [CrossRef]

313. Lopez-Diaz, B.; Mercado-Saenz, S.; Martinez-Morillo, M.; Sendra-Portero, F.; Ruiz-Gomez, M.J. Long-term exposure to a pulsed magnetic field $(1.5 \mathrm{mT}, 25 \mathrm{~Hz})$ increases genomic DNA spontaneous degradation. Electromagn. Biol. Med. 2014, 33, 228-235. [CrossRef]

314. Ruiz-Gomez, M.J.; Martinez-Morillo, M. Enhancement of the cell-killing effect of ultraviolet-C radiation by short-term exposure to a pulsed magnetic field. Int. J. Radiat. Biol. 2005, 81, 483-490. [CrossRef]

315. Ivancsits, S.; Diem, E.; Pilger, A.; Rüdiger, H.W.; Jahn, O. Induction of DNA strand breaks by intermittent exposure to extremely-low-frequency electromagnetic fields in human diploid fibroblasts. Mutat. Res. Genet. Toxicol. Environ. Mutagen. 2002, 519,1-13. [CrossRef]

316. Wolf, F.I.; Torsello, A.; Tedesco, B.; Fasanella, S.; Boninsegna, A.; D’Ascenzo, M.; Grassi, C.; Azzena, G.B.; Cittadini, A. 50-Hz extremely low frequency electromagnetic fields enhance cell proliferation and DNA damage: Possible involvement of a redox mechanism. Biochim. Biophys. Acta. 2005, 1743, 120-129. [CrossRef]

317. Scarfí, M.R.; Sannino, A.; Perrotta, A.; Sarti, M.; Mesirca, P.; Bersani, F. Evaluation of Genotoxic Effects in Human Fibroblasts after Intermittent Exposure to $50 \mathrm{~Hz}$ Electromagnetic Fields: A Confirmatory Study. Radiat. Res. 2005, 164, 270-276. [CrossRef] 
318. Igarashi, A.; Kobayashi, K.; Matsuki, H.; Endo, G.; Haga, A. Evaluation of damage in DNA molecules resulting from very-low-frequency magnetic fields by using bacterial mutation repairing genetic system. IEEE Trans. Magn. 2005, 41, 4368-4370. [CrossRef]

319. Lai, H.; Singh, N.P. Magnetic-field-induced DNA strand breaks in brain cells of the rat. Environ. Health Perspect. 2004, 112, 687-694. [CrossRef]

320. Zheng, Y.; Sanche, L. Influence of organic ions on DNA damage induced by $1 \mathrm{eV}$ to $60 \mathrm{keV}$ electrons. J. Chem. Phys. 2010, 133, 155102. [CrossRef]

321. Zmyslony, M.; Palus, J.; Dziubaltowska, E.; Politanski, P.; Mamrot, P.; Rajkowska, E.; Kamedula, M. Effects of in vitro exposure to power frequency magnetic fields on UV-induced DNA damage of rat lymphocytes. Bioelectromagnetics 2004, 25, 560-562. [CrossRef]

322. Williams, P.A.; Ingebretsen, R.J.; Dawson, R.J. $14.6 \mathrm{mT}$ ELF magnetic field exposure yields no DNA breaks in model system Salmonella, but provides evidence of heat stress protection. Bioelectromagnetics 2006, 27, 445-450. [CrossRef]

323. McNamee, J.P.; Bellier, P.V.; Chauhan, V.; Gajda, G.B.; Lemay, E.; Thansandote, A. Evaluating DNA Damage in Rodent Brain after Acute 60 Hz Magnetic-Field Exposure. Radiat. Res. 2005, 164, 791-797. [CrossRef]

324. Li, S.H.; Chow, K.C. Magnetic field exposure induces DNA degradation. Biochem. Biophys. Res. Commun. 2001, 280, 1385-1388. [CrossRef]

325. Ruiz-Gómez, M.J.; Martínez-Morillo, M. Electromagnetic fields and the induction of DNA strand breaks. Electromagn. Biol. Med. 2009, 28, 201-214. [CrossRef]

326. Aydin, M.; Taspinar, M.S.; Cakmak, Z.E.; Dumlupinar, R.; Agar, G. Static magnetic field induced epigenetic changes in wheat callus. Bioelectromagnetics 2016, 37, 504-511. [CrossRef]

327. Potenza, L.; Cucchiarini, L.; Piatti, E.; Angelini, U.; Dacha, M. Effects of high static magnetic field exposure on different DNAs. Bioelectromagnetics 2004, 25, 352-355. [CrossRef]

328. Zhang, Q.M.; Tokiwa, M.; Doi, T.; Nakahara, T.; Chang, P.W.; Nakamura, N.; Hori, M.; Miyakoshi, J.; Yonei, S. Strong static magnetic field and the induction of mutations through elevated production of reactive oxygen species in Escherichia coli soxR. Int. J. Radiat. Biol. 2003, 79, 281-286. [CrossRef]

329. Boulikas, T. Evolutionary consequences of nonrandom damage and repair of chromatin domains. J. Mol. Evol. 1992, 35, 156-180. [CrossRef]

330. Villarini, M.; Moretti, M.; Scassellati-Sforzolini, G.; Boccioli, B.; Pasquini, R. Effects of co-exposure to extremely low frequency $(50 \mathrm{~Hz})$ magnetic fields and xenobiotics determined in vitro by the alkaline comet assay. Sci. Total Environ. 2006, 361, 208-219. [CrossRef] 